\title{
Myocardial Substrate Metabolism in the Normal and Failing Heart
}

\author{
WILLIAM C. STANLEY, FABIO A. RECCHIA, AND GARY D. LOPASCHUK \\ Department of Physiology and Biophysics, School of Medicine, Case Western Reserve University, \\ Cleveland, Ohio; Scuola Superiore Sant'Anna, Pisa, Italy; Department of Physiology, New York Medical College, \\ Valhalla, New York; and Department of Pediatrics, University of Alberta, Edmonton, Canada
}

I. Introduction

1093

II. Overview of Myocardial Substrate Metabolism

A. Regulation of metabolic pathways in the heart

1095

B. Carbohydrate metabolism

1096

C. Fatty acid metabolism

1099

D. Ketone body metabolism

1101

E. Interregulation of fatty acid and carbohydrate oxidation

F. Effects of substrate selection on contractile function and efficiency

1102

G. Role of nitric oxide in regulation of myocardial energy substrate metabolism 1103

III. Regulation of Myocardial Metabolic Phenotype

A. Control of the expression of metabolic enzymes in the heart 1104

B. Cardiac lipotoxicity

C. Regulation of phenotype switch from fetal to adult state: implications for heart failure 1106

D. Effects of aging on substrate metabolism 1106

IV. Metabolic Phenotype in Heart Failure

A. Considerations regarding the etiology of heart failure

B. Electron transport chain and oxidative phosphorylation defects in heart failure

C. Substrate metabolism in heart failure

D. Alterations in expression and function of metabolic proteins in heart failure 1111

V. Therapeutic Potential for Manipulation of Substrate Metabolism

A. Short-term metabolic therapy to optimize cardiac function 1112

B. Long-term metabolic therapy to slow heart failure progression and improve function 1113

VI. Conclusions

Stanley, William C., Fabio A. Recchia, and Gary D. Lopaschuk. Myocardial Substrate Metabolism in the Normal and Failing Heart. Physiol Rev 85: 1093-1129, 2005; doi:10.1152/physrev.00006.2004.-The alterations in myocardial energy substrate metabolism that occur in heart failure, and the causes and consequences of these abnormalities, are poorly understood. There is evidence to suggest that impaired substrate metabolism contributes to contractile dysfunction and to the progressive left ventricular remodeling that are characteristic of the heart failure state. The general concept that has recently emerged is that myocardial substrate selection is relatively normal during the early stages of heart failure; however, in the advanced stages there is a downregulation in fatty acid oxidation, increased glycolysis and glucose oxidation, reduced respiratory chain activity, and an impaired reserve for mitochondrial oxidative flux. This review discusses 1) the metabolic changes that occur in chronic heart failure, with emphasis on the mechanisms that regulate the changes in the expression of metabolic genes and the function of metabolic pathways; 2) the consequences of these metabolic changes on cardiac function; 3) the role of changes in myocardial substrate metabolism on ventricular remodeling and disease progression; and 4) the therapeutic potential of acute and long-term manipulation of cardiac substrate metabolism in heart failure.

\section{INTRODUCTION}

Cardiovascular disease is the leading cause of death and disability in the industrialized world, and although there has been a reduction in mortality from acute myocardial infarction over the last 30 years (215), there has been a concomitant rise in mortality attributable to heart failure (HF). The syndrome of HF was described by Hippocrates over two millennia ago and presented as shortness of breath and peripheral edema $(214,215)$. Autopsies performed in the 17th and 18th centuries revealed an enlarged ventricular chamber and increased heart mass in 
HF patients (215). In the last century a myriad of structural and biochemical cardiac abnormalities were shown to be associated with $\mathrm{HF}$, from defects in mitochondria to abnormal adrenergic signal transduction. At the end stages of HF, the myocardium has low ATP content due to a decreased ability to generate ATP by oxidative metabolism, and thus is unable to effectively transfer the chemical energy from the metabolism of carbon fuels to contractile work $(12,98,213,341)$. The consequences of metabolic dysfunction in HF are poorly understood, but there is growing evidence to support the concept that the alterations in substrate metabolism seen in HF contribute to contractile dysfunction and to the progression of left ventricular (LV) remodeling that are characteristic of the HF state.

Today HF is clinically defined as "a complex clinical syndrome that can result from any structural or functional cardiac disorder that impairs the ability of the ventricle to fill with or eject blood" (179). Heart failure severely reduces exercise capacity and may or may not cause fluid retention and pulmonary congestion. Many HF patients have minimal edema or pulmonary congestion, thus the term heart failure is preferred over the older term congestive heart failure (179). Approximately two-thirds of all HF patients have a history of ischemic heart disease, and the remainder do not (215). HF presents as both systolic and diastolic LV dysfunction, with diastolic dysfunction being more common in a patient with a history of hypertension and/or diabetes in the absence of myocardial ischemia $(6,14,117)$. Current medical therapies for $\mathrm{HF}$ are aimed at suppressing neurohormonal activation (e.g., angiotensin converting enzyme inhibitors, angiotensin II receptor antagonists, $\beta$-adrenergic receptor antagonists, and aldosterone receptor antagonists), and treating fluid volume overload and hemodynamic symptoms (diuretics, digoxin, inotropic agents). These pharmacotherapies for HF can improve clinical symptoms and slow the progression of contractile dysfunction and expansion of LV chamber volume; nevertheless, there is still progression, and the prognosis for even the optimally treated patient remains poor $(39,63,67)$. Moreover, there is recent evidence that intense suppression of the neurohormonal systems does not provide further benefit compared with more modest therapy $(64,385,444)$. Thus there is a need for novel therapies for HF, independent of the neurohormonal axis, that can improve cardiac performance and prevent or reverse the progression of LV dysfunction and remodeling $(38,116,381,452)$.

Agents that act through optimization of cardiac substrate metabolism are particularly attractive because they could work additively with current therapies, while not exerting negative hemodynamic effects $(38,116,381$, 431). Emerging evidence suggests that disturbances in myocardial substrate utilization have adverse effects in the failing myocardium $(212,213)$ and that shifting the substrate preference of the heart away from fatty acids towards carbohydrate oxidation can improve pump function and slow the progression of $\operatorname{HF}(23,27,28,38,53,116$, 428 ). Almost a century ago the observation was made that acute ingestion of cane sugar relieved symptoms in patients with cardiac dysfunction, presumably of ischemia origin $(45,140)$. The optimization of cardiac substrate metabolism to improve cardiac function and slow progression in $\mathrm{HF}$, without causing any direct negative hemodynamic or inotropic effects, remains a conceptually attractive therapeutic approach (38). To date, the role of myocardial substrate metabolism in the natural history of HF has not been thoroughly evaluated. Human, canine, and rodent studies show that in late-stage failure there is downregulation of myocardial fatty acid oxidation and accelerated glucose oxidation (79, 332, 359, 362, 389). However, the time course and the molecular mechanisms for this switch in substrate oxidation are not well understood $(251,388,428)$.

It is important to keep in mind that HF is not a specific disease, but rather an extremely complex syndrome that is dependent on etiology, duration, underlying coronary artery disease and ischemia, endothelial dysfunction, and the co-occurrence of complicating disorders such as diabetes, hypertension, and obesity. In Europe and North America, $\sim 20-30 \%$ of HF patients are diabetic, which in itself greatly alters myocardial substrate use $(434,449,510)$ and affects the development of HF and LV remodeling after myocardial infarction (424). There is tremendous heterogeneity among the published data from patients and animals models of HF that may be attributed to the etiology, severity, and duration of HF and, in the case of animal models, the species studied. Moreover, studies in animal models demonstrate that the changes in myocardial metabolism and cardiac function often occur late in the development of HF. Thus one must use caution in drawing generalities from a single time point or from a single animal model. In addition, within a given failing heart there is likely gross and micro heterogeneity in the metabolic changes within the LV.

Despite these caveats and limitations, it remains of fundamental importance to identify the abnormalities in myocardial substrate metabolism that occur over the course of the development and progression of $\mathrm{HF}$, and to understand the impact they have on left ventricular function and remodeling. This review discusses 1) the metabolic changes that occur in chronic HF, with emphasis on the mechanisms that regulate the changes in the expression of metabolic genes and the function of metabolic pathways; 2) the consequences of these changes on cardiac function; 3) the role of changes in myocardial substrate metabolism in ventricular remodeling and disease progression; and 4) the therapeutic potential of acute and long-term manipulation of cardiac energy metabolism in HF. 
It is important to note that this review focuses on myocardial substrate metabolism in $\mathrm{HF}$, and not on the well-documented HF-induced abnormalities in the transfer of energy from mitochondrial ATP to systolic and diastolic work. The reader is referred to recent reviews on this topic $(98,190,477)$.

\section{OVERVIEW OF MYOCARDIAL SUBSTRATE METABOLISM}

To understand myocardial metabolism in HF, it is important to first have a solid understanding of myocardial metabolism in the normal heart and to understand the complex pathophysiology of HF. The reader is referred to textbooks and reviews on myocardial metabolism (270, $331,433,448,473)$ and the pathophysiology of HF (215).

\section{A. Regulation of Metabolic Pathways in the Heart}

Under nonischemic conditions almost all (>95\%) of ATP formation in the heart comes from oxidative phosphorylation in the mitochondria (Fig. 1), with the remainder derived from glycolysis and GTP formation in the citric acid cycle. The heart has a relatively low ATP content ( $5 \mu \mathrm{mol} / \mathrm{g}$ wet wt) and high rate of ATP hydrolysis $\left(\sim 0.5 \mu \mathrm{mol} \cdot \mathrm{g}\right.$ wet $\mathrm{wt}^{-1} \cdot \mathrm{s}^{-1}$ at rest $)$, thus there is complete turnover of the myocardial ATP pool approximately every $10 \mathrm{~s}$ under normal conditions $(188,331)$. Approximately $60-70 \%$ of ATP hydrolysis fuels contractile shortening, and the remaining $30-40 \%$ is primarily used for the sarcoplasmic reticulum $\mathrm{Ca}^{2+}$-ATPase and other ion pumps $(128,440)$. In the healthy heart the rate of oxidative phosphorylation is exquisitely linked to the rate of ATP hydrolysis so that ATP content remains constant even with large increases in cardiac power $(17,18,153)$, such as occur during intense exercise or acute catecholamine stress. Mitochondrial oxidative phosphorylation is fueled with energy from electrons that are transferred from carbon fuels by dehydrogenation reactions that generate $\mathrm{NADH}$ and $\mathrm{FADH}_{2}$ produced primarily in the fatty acid $\beta$-oxidation pathway, the citric acid cycle, and to a lesser extent from the pyruvate dehydrogenase reaction and glycolysis (Figs. 1 and 2). There is a stoichiometric link between the rate of oxidation of carbon fuels, NADH and $\mathrm{FADH}_{2}$ reduction, flux through the electron transport chain, oxygen consumption, oxidative phosphorylation, ATP hydrolysis, actin-myosin interaction, and external contractile power produced by the heart (Figs. 1 and 2). Thus an increase in contractile power results in a concomitant increase in all of the components in the system.

The regulation of myocardial metabolism is linked to arterial carbon substrate concentration, hormone concentrations, coronary flow, inotropic state, and the nutritional status of the tissue $(331,433,448)$. The citric acid cycle is fueled by acetyl-CoA formed from decarboxylation of pyruvate and from $\beta$-oxidation of fatty acids (Fig. $2)$. The reducing equivalents $\left(\mathrm{NADH}\right.$ and $\left.\mathrm{FADH}_{2}\right)$ that are generated by either the dehydrogenases of glycolysis, the oxidation of lactate and pyruvate and fatty acid $\beta$-oxidation, or the citric acid cycle deliver electrons to the electron transport chain, resulting in ATP formation by oxidative phosphorylation. In the healthy heart the rates of flux through the metabolic pathways linked to ATP generation are set by the requirement for external power generated by the myocardium and the rate of ATP hydrolysis.

The rates of flux through the various metabolic pathways are controlled by both the degree of expression of key metabolic proteins (enzymes and transporters) and complex pathway regulation that is exerted by both allosteric regulation of enzymes and substrate/product relationships. The metabolic machinery in the heart is designed to generate large amounts of ATP to support high rates of external cardiac power. At maximal cardiac work loads in vivo this metabolic machinery consumes oxygen at $80-90 \%$ of the mitochondrial capacity for electron transport chain flux and oxygen consumption (315). At rest, however, the heart operates at $\sim 15-25 \%$ of its maximal oxidative capacity, thus the expression or maximal activity of a key metabolic enzyme can be greatly reduced or increased without necessarily affecting ATP production or flux through the relevant pathway under resting conditions $(106,107)$. This is because flux through metabolic pathways can be rapidly turned on or off by allosteric modification of regulatory enzymes, changes in the

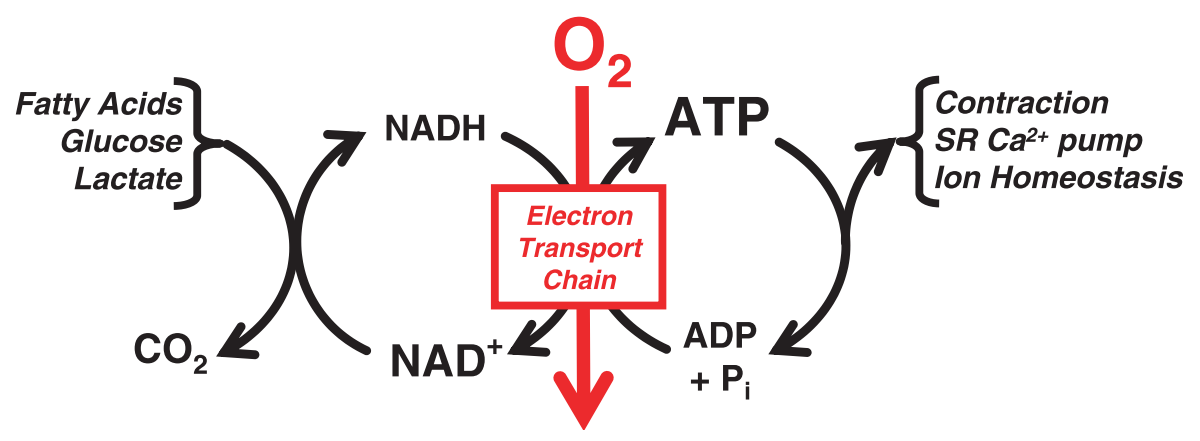

FIG. 1. Linkages between cardiac power, ATP hydrolysis, oxidative phosphorylation, and $\mathrm{NADH}$ generation by dehydrogenases in metabolism. SR, sarcoplasmic reticulum. 


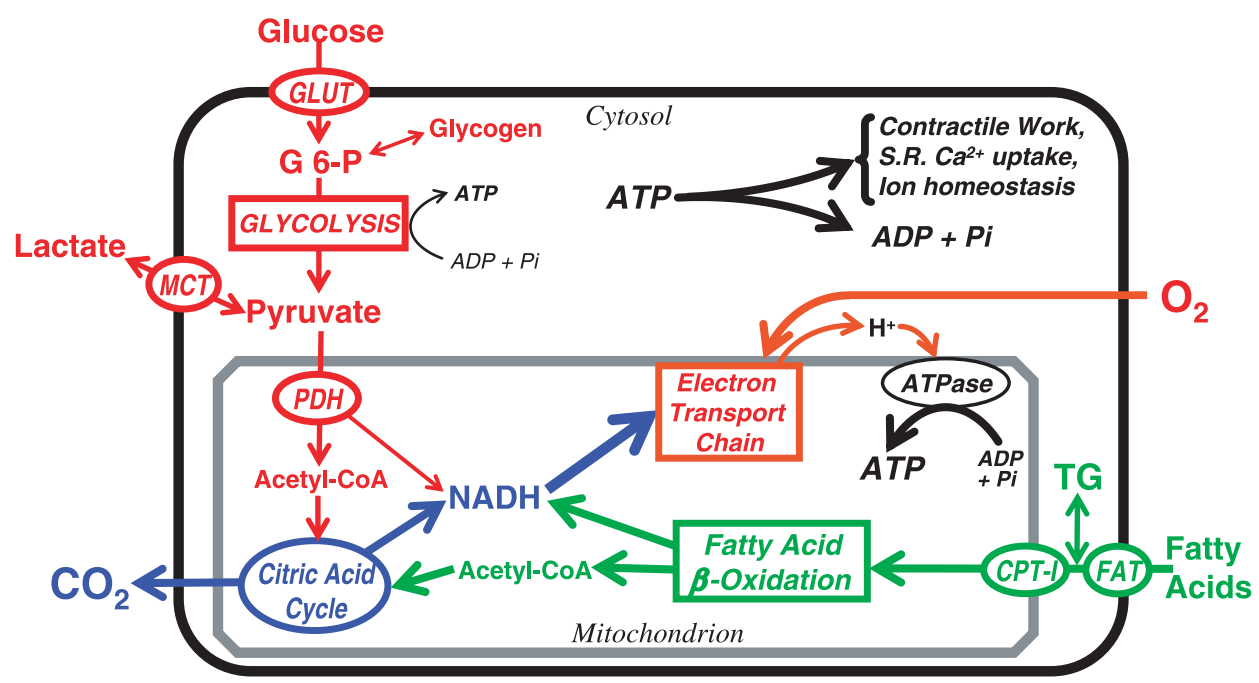

FIG. 2. The pathways and regulatory points of myocardial substrate metabolism. CPT-I, carnitine palmitoyltransferase-I; FAT, fatty acid transporter/CD36; G 6-P, glucose 6-phosphate; GLUT, glucose transporters; MCT, monocarboxylic acid transporters; PDH, pyruvate dehydrogenase. concentration of inhibitory or stimulatory metabolites, or translocation of metabolic proteins to their site of function. These mechanisms allow for the rapid adaptation to acute stresses such as exercise, ischemia, or fasting.

\section{B. Carbohydrate Metabolism}

In the well-perfused heart, $\sim 60-90 \%$ of the acetylCoA comes from $\beta$-oxidation of fatty acids, and $10-40 \%$ comes from the oxidation of pyruvate $(126,433,492$, $493,495)$ that is derived in approximately equal amounts from glycolysis and lactate oxidation (126, 433, 492, 493, 495). The glycolytic pathway converts glucose 6-phosphate and $\mathrm{NAD}^{+}$to pyruvate and NADH and generates two ATP for each molecule of glucose. The NADH and pyruvate formed in glycolysis are either shuttled into the mitochondrial matrix to generate $\mathrm{CO}_{2}$ and $\mathrm{NAD}^{+}$and complete the process of aerobic oxidative glycolysis or converted to lactate and $\mathrm{NAD}^{+}$in the cytosol (nonoxidative glycolysis).

The healthy nonischemic heart is a net consumer of lactate even under conditions of near-maximal cardiac power $(204,292,426)$. The myocardium becomes a net lactate producer only when there is accelerated glycolysis in the face of impaired oxidation of pyruvate, such as occurs with ischemia $(85,331,433)$ or poorly controlled diabetes $(15,145,434)$. There is a high rate of bidirectional lactate transmembrane flux and conversion to pyruvate $(125,141,204,293,492,493)$. Lactate transport across the cardiac sarcolemma is facilitated by the monocarboxylic acid transporter-1 (MCT-1) (Fig. 2; Refs. 118, 203).

Glycolytic substrate is derived from exogenous glucose and glycogen stores. Glucose transport into cardiomyocytes is regulated by the transmembrane glucose gradient and the content of glucose transporters in the sarcolemma (mainly GLUT-4, and to a lesser extent GLUT-1)
(Fig. 2). There is a translocation of glucose transporters from intracellular vesicles to the sarcolemmal membrane in response to insulin stimulation, increased work demand, or ischemia $(433,506,507)$, which increases the membrane capacitance for glucose transport and the rate of glucose uptake. Translocation of GLUT- 4 into the sarcolemma is also stimulated by activation of AMP-activated protein kinase (AMPK) $(379,506)$, which occurs during exercise stress in the rat heart (71). Mice with cardiac-specific overexpression of a dominant negative mutant of AMPK have depressed rates of glucose uptake (499), suggesting a critical role for AMPK in regulating basal glucose uptake in the heart. Russell et al. (380) recently demonstrated that transgenic mice expressing inactive AMPK have normal GLUT4 expression as well as baseline and insulin-stimulated cardiac glucose uptake, but fail to increase glucose uptake and glycolysis during ischemia (380), illustrating a key role for AMPK in mediating insulin-independent ischemia-induced glucose uptake.

An additional source of glucose 6-phosphate for the heart is intracellular glycogen stores. The glycogen pool in the heart is relatively small $(\sim 30 \mu \mathrm{mol} / \mathrm{g}$ wet wt compared with $\sim 150 \mu \mathrm{mol} / \mathrm{g}$ wet wt in skeletal muscle) (35, $331,429)$ and has a relatively rapid turnover despite stable tissue concentrations (155). Glycogen concentrations are increased by an elevated supply of exogenous substrate and/or hyperinsulinemia (235, 246, 433), and glycogenolysis is activated by adrenergic stimulation (e.g., increases in cAMP and $\mathrm{Ca}^{2+}$ ), a fall in the tissue content of ATP, and a rise in inorganic phosphate such as occur with ischemia or intense exercise $(133,176,433)$. Recently, there has been considerable interest focused on the role of AMPK in regulating glycogen content in the heart $(9,71,499)$. Constitutively active AMPK due to a mutation in a regulatory subunit of the enzyme was recently shown to be associ- 
ated with glycogen accumulation and hypertrophic cardiomyopathy $(8,9,134)$. In contrast, acute activation of AMPK has been shown to activate glycogenolysis (267, 346). Clinically, patients with a mutation in the gamma-2 regulatory subunit of AMPK have Wolff-Parkinson-White syndrome and conduction system disease in the absence of cardiac hypertrophy $(134,135,330)$, although the cellular mechanisms linking abnormal AMPK activity and the electrophysiological abnormalities are unclear.

Phosphofructokinase-1 (PFK-1) is a key regulatory enzyme in the glycolytic pathway and catalyzes the first irreversible step (Fig. 3). PFK-1 utilizes ATP to produce fructose 1,6-bisphosphate and is activated by ADP, AMP, and $\mathrm{P}_{\mathrm{i}}$ and inhibited by ATP, thus accelerating flux through glycolysis when the phosphorylation potential falls. PFK-1 can also be inhibited by fructose 1,6-bisphosphate and by a fall in $\mathrm{pH}$. The extent of $\left[\mathrm{H}^{+}\right]$inhibition of PFK-1 depends on ATP levels, with the inhibition being greatest when ATP levels are high (see Ref. 209 for review). As AMP accumulates, the sensitivity of PFK-1 to $\left[\mathrm{H}^{+}\right]$decreases. PFK-1 can also be stimulated by fructose 2,6-bisphosphate (F2,6BP), which is a feedforward activator of the enzyme (177). Citrate is a negative allosteric regulator of PFK-1 and links changes in mitochondrial oxidative metabolism to glycolysis. Accumulation of citrate was first proposed by Philip Randle to contribute to the decrease in glycolysis that occurs in various tissues when fatty acid oxidation increases (119, 325, 351, 352).

$\mathrm{F} 2,6 \mathrm{BP}$ is a potent stimulator of PFK-1 and is formed from fructose 6-phosphate by the bifunctional enzyme phosphofructo-2-kinase/fructose-2,6-bisphosphatase (PFK-2) (Fig. 3) $(176,177)$. Synthesis of F2,6BP by PFK-2 results in an activation of PFK-1. F2,6BP increases PFK-1 by increasing the affinity of the enzyme for fructose 6-phos-

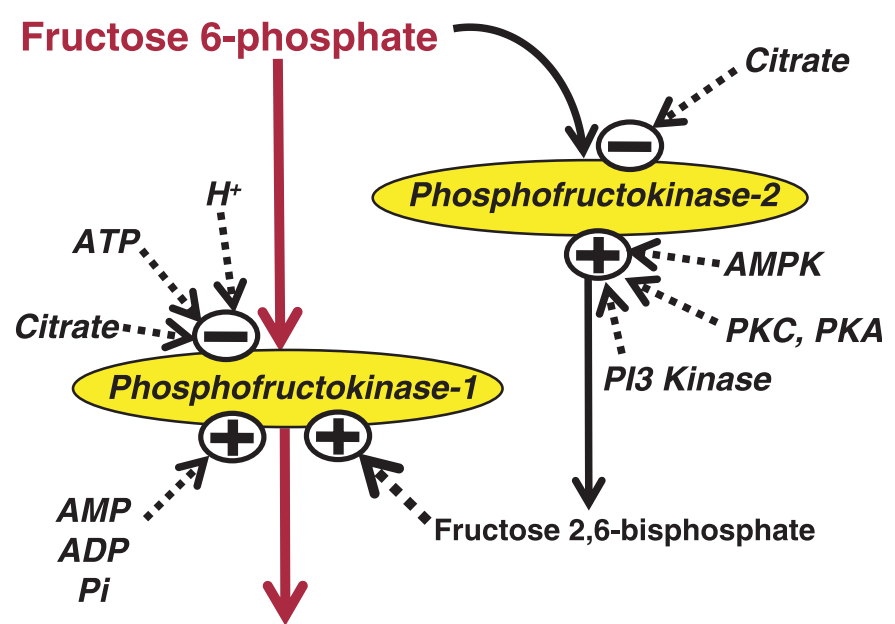

Fructose 1,6-bisphosphate

FIG. 3. Regulation of phosphofructokinase-1 (PFK-1) by PFK-2 and fructose 2,6-bisphosphate. PKA, protein kinase A; PKC, protein kinase C; PI3K, phosphatidylinositol 3-kinase. phate and by decreasing the inhibitory effects of ATP on PFK-1. The production of F2,6BP itself is highly regulated (Fig. 3), with PFK-2 activity controlled by three main mechanisms: 1) by allosteric modulation of PFK-2 activity, 2) by phosphorylation control of PFK-2 activity, and 3) by transcriptional control of enzyme activity (249, 368). PFK-2 is allosterically inhibited by citrate, which by decreasing F2,6BP levels is a second mechanism by which citrate can inhibit PFK-1 activity. A number of hormones that activate glycolysis, including insulin, glucagon, epinephrine, norepinephrine, and thyroid hormone, exert phosphorylation control on PFK-2 (209). In addition, AMPK can also phosphorylate PFK-2 $(175,288)$. Phosphorylation and activation of PFK-2 by AMPK is an attractive mechanism to explain AMP-induced acceleration of glycolysis.

Glyceraldehyde-3-phosphate dehydrogenase (GAPDH) catalyzes the conversion of glyceraldehyde 3-phosphate to 1,3-diphosphoglycerate and produces the NADH molecules that originate from glycolysis. GAPDH is a major regulatory step in the glycolytic pathway, since the accumulation of NADH within the cytoplasm of cells inhibits the GAPDH reaction rate. In contrast, an increase in $\mathrm{NAD}^{+}$activates GAPDH activity. High concentrations of lactate inhibit the regeneration of $\mathrm{NAD}^{+}$from $\mathrm{NADH}$ and thus reduce the flux through GAPDH, as do high concentrations of the product of the reaction, 1,3-diphosphoglycerate. During myocardial ischemia, an accumulation of lactate and $\mathrm{NADH}$ can result in GAPDH becoming the main rate-controlling reaction in glycolysis. For instance, severe ischemia in heart muscle will result in the cessation of oxidative metabolism, and the subsequent accumulation of NADH in the cytosol, and accumulation of lactate within the cell.

Cell fraction studies demonstrate that glycolytic enzymes are clustered near the sarcoplasmic reticulum and sarcolemma (103, 344, 486, 500), suggesting that glycolytic reactions are not distributed throughout the cytosol, but rather occur in a subdomain outside around the perimeter of the cardiomyocyte. Further support for this concept comes from in silico studies of the transition from normal to ischemic conditions, which shows that compartmentation of glycolysis to $\sim 10 \%$ of the cytosolic space is required to simulate the burst of glycolysis that occurs with the onset of ischemia in vivo (519). Studies assessing the effect of inhibition of glycolysis suggest that glycolytically generated ATP is perferentially used by the sarcoplasmic reticulum to fuel $\mathrm{Ca}^{2+}$ uptake (103) and by the sarcolemma to maintain ion homeostatis $(487,488)$. Furthermore, inhibition of glycolysis impairs relaxation in ischemic and postischemic reperfused myocardium, suggesting that glycolytic ATP may be essential for optimal diastolic relaxation $(197,240,486)$.

The pyruvate formed from glycolysis has three main fates: conversion to lactate, decarboxylation to acetylCoA, or carboxylation to oxaloacetate or malate. Pyru- 
vate decarboxylation is the key irreversible step in carbohydrate oxidation and is catalyzed by pyruvate dehydrogenase (PDH) (Fig. 4) (350), a multienzyme complex located in the mitochondrial matrix. PDH is inactivated by phosphorylation on the $\mathrm{E}_{1}$ subunit of the enzyme complex by a specific PDH kinase (PDK) and is activated by dephosphorylation by a specific PDH phosphatase (219, 350, 355, 491) (Fig. 4). PDK is inhibited by pyruvate and by decreases in the acetyl-CoA/free $\mathrm{CoA}$ and $\mathrm{NADH} / \mathrm{NAD}^{+}$ ratios $(219,355,490)$ (Fig. 4). There are four isoforms of PDK; PDK4 is the predominant form in heart, and its expression is rapidly induced by starvation, diabetes, and peroxisome proliferater activated receptor- $\alpha$ (PPAR $\alpha)$ ligands $(36,150,496)$, suggesting that its expression is controlled by the activity of the PPAR $\alpha$ promoter system (see sect. III $A$ ). High circulating lipid and intracellular accumulation of long-chain fatty acid moieties, such as occur with fasting or diabetes, enhance PPAR $\alpha$-mediated expression of PDK4, resulting in greater phosphorylation inhibition of PDH and less oxidation of pyruvate derived from glycolysis and lactate oxidation $(172,496)$. The PDH complex also contains a PDH phosphatase that dephosphorylates and activates PDH. The activity of PDH phosphatase is increased by $\mathrm{Ca}^{2+}$ and $\mathrm{Mg}^{2+}$ (295). Adrenergic stimulation of the heart increases the cytosolic $\mathrm{Ca}^{2+}$ transient, and mitochondrial $\mathrm{Ca}^{2+}$ concentration results in activation of $\mathrm{PDH}(294,296)$, thus explaining the activation of $\mathrm{PDH}$ and greater pyruvate oxidation in response to a $\beta$-adrenergic-induced increase in cardiac power (66, $126,139,294)$, despite no changes in any of the activators of PDK4 activity (416).

The oxidation of glucose and pyruvate and the activity of PDH in the heart are decreased by elevated rates of fatty acid oxidation, such as occur if plasma levels of free fatty acids (FFA) are elevated. In addition, pyruvate oxidation is enhanced by suppression of fatty acid oxidation, as observed with a decreased plasma FFA levels, or by a direct inhibition of fatty acid oxidation $(61,164,165,235$, $270,410,433)$. As discussed above, high rates of fatty acid oxidation also inhibit PFK-1 and PFK-2 (and thus glycolysis) via an increase in cytosolic citrate concentration (Fig. 4) This "glucose-fatty acid cycle" was first described by Philip Randle and colleagues in the 1960s (119, 353, 354 ), and thus is generally referred to as the "Randle cycle." The maximal rate of pyruvate oxidation at any given time is set by the degree of phosphorylation of PDH; however, the actual flux is determined by the concentrations of substrates and products in the mitochondrial matrix as these control the rate of flux through the active dephosphorylated complex (148).

In addition to lactate formation and oxidation by $\mathrm{PDH}$, pyruvate enters the citric acid cycle (CAC) via carboxylation to either malate or oxaloacetate (442). This reaction is "anaplerotic" $(127,231)$ and acts to maintain the pool size of CAC intermediates and CAC function in the face of the small but constant loss of CAC intermediates through efflux of citrate and, to a lesser extent, succinate and fumarate from the heart $(55,69,102,244$, 456, 458, 479). Pyruvate carboxylation accounts for $\sim 2-6 \%$ of the CAC flux under normal flow aerobic conditions $(69,336)$, and it is reduced relative to CAC flux when $\mathrm{MVO}_{2}$ is reduced in acutely hibernating swine myocardium (335). Another source of anaplerotic flux into the CAC is via transamination of glutamate to $\alpha$-ketoglutarate, as demonstrated by the low but persistent uptake of glutamate in the human heart $(318,457-459)$. Studies using ${ }^{13} \mathrm{C}$-labeled glutamate in perfused rat hearts suggest that conversion to $\alpha$-ketoglutarate may be critical for the

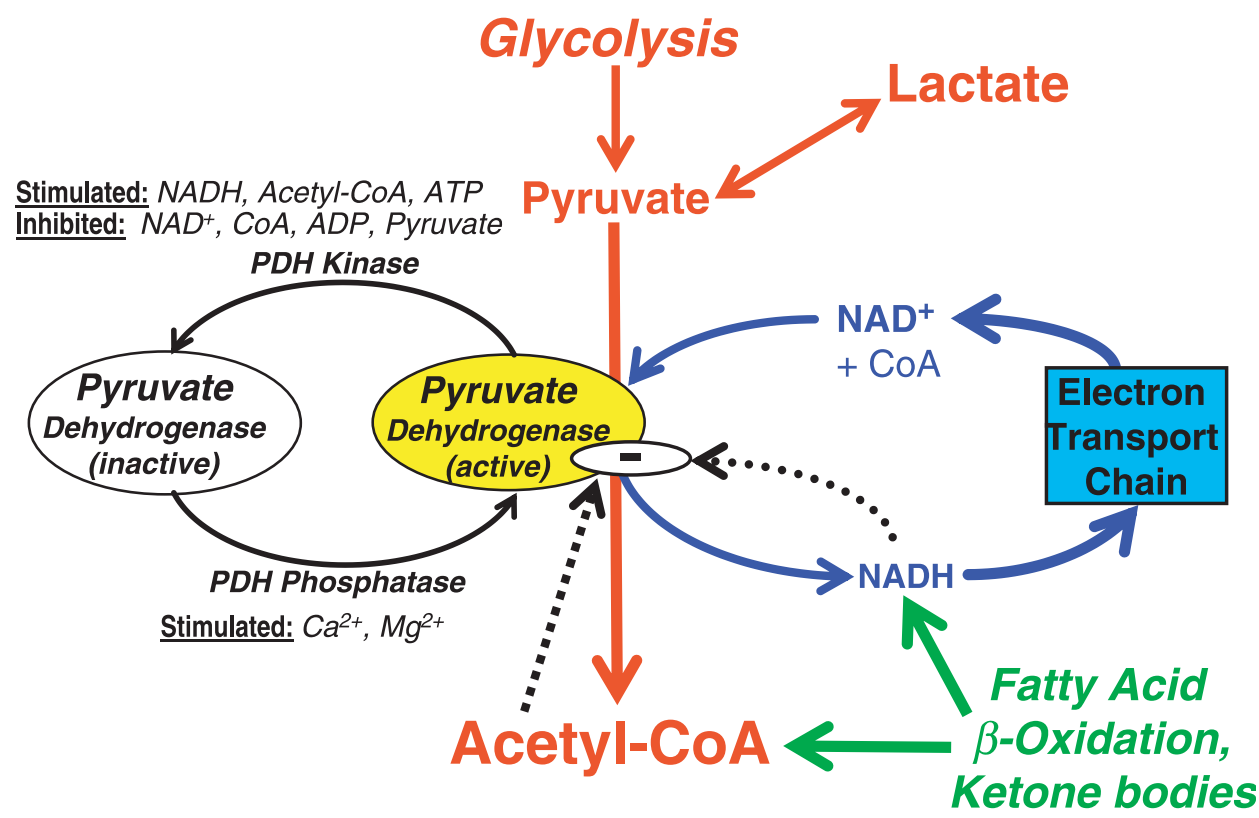

FIG. 4. Regulation of the oxidation of glucose and lactate by pyruvate dehydrogenase (PDH). The activity of PDH is inhibited by product inhibition from acetyl$\mathrm{CoA}$ and $\mathrm{NADH}$ (dashed arrows), and by phosphorylation by PDH kinase and dephosphorylation by PDH phosphatase. 


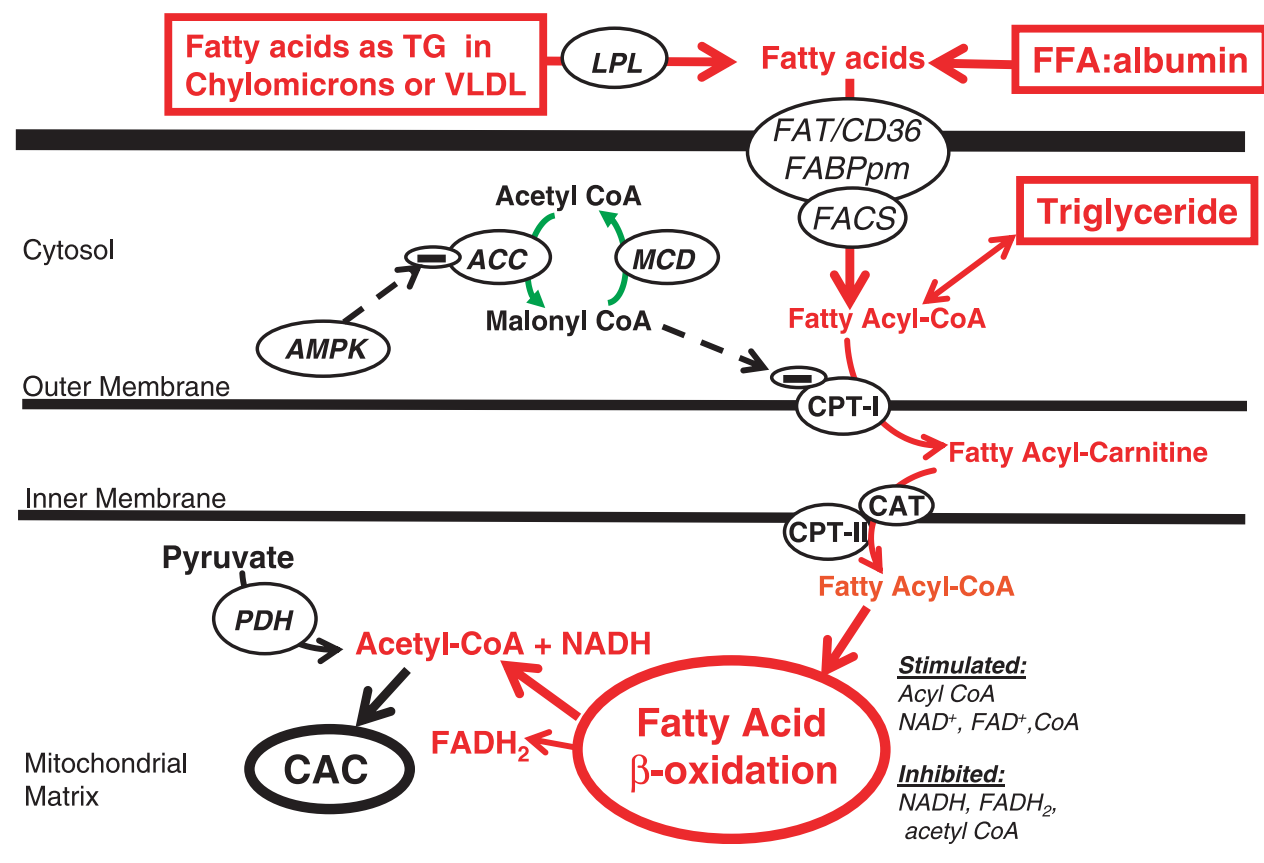

FIG. 5. Schematic depiction of myocardial fatty acid metabolism. ACC, acetyl-CoA carboxylase; AMPK, AMP-activated protein kinase; CAT, carnitine acyltranslocase; CPT-I, carnitine palmitoyltransferase-I; CPT-II, carnitine palmitoyltransferase-II; FABP ${ }_{\mathrm{PM}}$, plasma membrane fatty acid binding protein; FAT, fatty acid transporter; FFA, free fatty acids; LPL, lipoprotein lipase; MCD, malonyl-CoA decarboxylase; TG, triglyceride; VLDL, very-low-density lipoproteins. regulation of the initial span of the CAC, particularly during ischemia (68). Another anaplerotic pathway is the formation of succinyl-CoA from propionyl-CoA that is generated from the terminal three carbons of odd chain length fatty acids (127, 258, 284, 290, 367). Plasma levels of propionate and other odd-chain-length fatty acids are low in humans; thus this is not a major pathway under normal conditions. However, a recent small clinical study in patients with deficiencies in long-chain fatty acid oxidation have clinical improvement and reversal of cardiac dysfunction with dietary supplementation with heptanoate, perhaps due to increased anaplerosis (369).

Pyruvate can also contribute to anaplerosis by transamination with glutamate to form alanine and the CAC intermediate $\alpha$-ketoglutarate. The rate of alanine output by the myocardium is relatively low in dogs, pigs, and humans $(15,142,305,412,459,495)$ and is unaffected by acute ischemia (142) or when glycolysis is accelerated with hyperinsulinemia and hyperglycemia (495). Studies in stable coronary artery disease patients showed elevated alanine output compared with healthy people (318).

\section{Fatty Acid Metabolism}

The rate of fatty acid uptake by the heart is primarily determined by the concentration of nonesterified fatty acids in the plasma $(32,270,494)$, which can vary over a fourfold range in healthy humans during the course of the day (from $\sim 0.2$ to $0.8 \mathrm{mM}$ ). Under conditions of metabolic stress, such as ischemia, diabetes, or starvation, plasma FFA concentrations can increase to much higher levels $(>1.0 \mathrm{mM}$ ) (271). Free fatty acids are highly hydrophobic and are never truly free in vivo but rather are associated with proteins or covalently bound to coenzyme A or carnitine. They are transported in the plasma in the nonesterified form attached to albumin, or covalently bound in triglyceride, contained with chylomicrons or very-lowdensity lipoproteins. Plasma fatty acid concentration is regulated by their net release from triglycerides in adipocytes, which reflects the net balance between triglyceride breakdown by hormone-sensitive lipase and synthesis by glycerolphosphate acyltransferase (270). Hormone-sensitive lipase is activated by catecholamines and inhibited by insulin. Thus, with fasting, when insulin is low and catecholamines are high, the plasma FFA concentration is elevated, resulting in a high rate of fatty acid uptake and oxidation by the heart. Fatty acids are also released from triglyceride in chylomicrons and in very-low-density lipoproteins that are hydrolyzed by lipoprotein lipase bound to the outside of capillary endothelial cells and cardiomyocytes (13, 306, 501, 505).

Fatty acids enter the cardiomyocyte by either passive diffusion or by protein-mediated transport across the sarcolemma (Fig. 5) (473) involving either a fatty acid translocase (FAT), or a plasma membrane fatty acid binding protein $\left(\mathrm{FABP}_{\mathrm{pm}}\right)(131,401,473)$. A specific $88-\mathrm{kDa}$ FAT protein called CD36 is abundantly expressed in skeletal and cardiac muscle and appears to be the predominant form of FAT in the heart $(401,473)$. People with mutations in the CD36 gene have lower rates of uptake of the long-chain fatty acid analog ${ }^{123} \mathrm{I}-15$-( $p$-iodophenyl)-3methylpentadecanoic acid compared with normal people (226), suggesting that CD36 partially regulates the rate of myocardial fatty acid uptake in humans. Once transported 
across the sarcolemma, the nonesterified fatty acids bind to FABP and are then activated by esterification to fatty acyl-CoA by fatty acyl-CoA synthase (FACS) (Fig. 5). FABPs are abundant in the cytosol and appear to be the primary intracellular carrier of nonesterified fatty acids. Recent studies show that there are FABP and FACS protein associated with CD36 on the cytosolic side of the sarcolemmal membrane, thus raising the possibility that fatty acids transported across the membrane can also be immediately esterified to fatty acyl-CoA (401). Inhibitable fatty acid transport is greater in electrically stimulated isolated cardiomyocytes compared with unstimulated conditions, suggesting that there is a translocation of FAT/CD36 into the sarcolemma from an intracellular site in response to contraction or increased energy demand (277-279). A similar phenomenon was observed in response to insulin stimulation (279). Translocation of FAT/ CD36 has not been demonstrated in response to increased cardiac energy expenditure or insulin stimulation in the intact heart (277); thus it remains to be seen if translocation of FAT/CD36 regulates myocardial fatty acid transport under physiologically relevant conditions.

The product of FACS, long-chain fatty acyl-CoA, can either be esterified to triglyceride by glycerolphosphate acyltransferase $(65,270,473)$ or converted to long-chain fatty acylcarnitine by carnitine palmitoyltransferase I (CPT-I) (Fig. 5) (270). Studies in normal humans, coronary artery disease patients, and large animals demonstrate that 70-90\% of the $\left[{ }^{14} \mathrm{C}\right]$ - or $\left[{ }^{3} \mathrm{H}\right]$ oleate or palmitate that is taken up by the heart is immediately released into the venous effluent as ${ }^{14} \mathrm{CO}_{2}$ or ${ }^{3} \mathrm{H}_{2} \mathrm{O}(51,54,245,494)$. This suggests that in the healthy normal heart $70-90 \%$ of the fatty acids entering the cell are converted to acylcarnitine and immediately oxidized, and $10-30 \%$ enter the intracardiac triglyceride pool (270, 391, 392). The myocardial triglyceride pool is an important source of fatty acids, with the rate of lipolysis of myocardial triglycerides and its contribution to overall myocardial ATP production being inversely related to the concentration of exogenous fatty acids $(72,75,339,391)$. Triglyceride turnover can be rapidly accelerated by adrenergic stimulation $(73,74,76,138,139,233,443)$ and is increased in uncontrolled diabetes $(339,393)$ and during reperfusion of ischemic hearts (392).

Fatty acid $\beta$-oxidation occurs primarily in the mitochondria and to a small extent in peroxisomes $(238,409)$. The primary products of fatty acid oxidation are NADH, $\mathrm{FADH}_{2}$, and acetyl-CoA (Fig. 5). Before mitochondrial $\beta$-oxidation, the cytoplasmic long-chain acyl-CoA must first be transported into the mitochondrial matrix. Because the inner mitochondrial membrane is not permeable to long-chain acyl-CoA, the long-chain fatty acyl moiety is transferred from the cytosol into the matrix by a carnitine-dependent transport system (220, 270). First, CPT-I catalyzes the formation of long-chain acylcarnitine from long-chain acyl-CoA in the compartment between the inner and outer mitochondrial membranes. Next, carnitine acyltranslocase transports this long-chain acylcarnitine across the inner mitochondrial membrane in exchange for free carnitine. Lastly, carnitine palmitoyltransferase II (CPT-II) regenerates long-chain acyl CoA in the mitochondrial matrix (Fig. 5). Of the three enzymes involved in the transmitochondrial membrane transport, CPT-I serves the key regulatory role in controlling the rate of fatty acid uptake by the mitochondria $(220,270)$.

The activity of CPT-I is strongly inhibited by malonylCoA, which binds to CPT-I on the cytosolic side of the enzyme (Fig. 5) $(220,302,513)$. There are two isoforms of CPT-I: CPT-I $\alpha$ predominates in the liver, and CPT-I $\beta$ is the main isoform in the heart $(300,302)$. CPT-I $\beta$ is 30 -fold more sensitive to malonyl-CoA inhibition than is CPT-I $\alpha(300,302$, 485). Malonyl-CoA is a key physiological regulator of fatty acid oxidation in the heart. A fall in malonyl-CoA increases fatty acid uptake and oxidation (2, 143, 236), and an increase suppresses fatty acid oxidation (390, 430). Malonyl-CoA is formed from the carboxylation of acetyl-CoA by acetyl-CoA carboxylase (ACC) $(137,143,145,236,375,390,454)$ and has a rapid rate of turnover in the heart $(364,366)$. Most of the acetyl-CoA in cardiomyocytes resides in the mitochondria (185); however, CPT-I activity is regulated by malonyl-CoA that is formed from carboxylation of extramitochondrial acetyl-CoA. There is indirect evidence to suggest that extramitochondrial acetyl-CoA is derived from citrate via the ATP-citrate lyase reaction $(345,395)$ and from the export for mitochondrial acetyl-CoA as acetylcarnitine $(281,390)$. More recently, results from studies with ${ }^{13} \mathrm{C}$-labeled substrates and isotopomer analysis of malonyl-CoA provided direct evidence that in the perfused rat heart malonyl-CoA is derived from acetyl-CoA formed in peroxisomal $\beta$-oxidation of long-chain fatty acids (365). Furthermore, the data were consistent with long-chain fatty acids undergoing only a few cycles of $\beta$-oxidation in peroxisomes, followed by the generation of $\mathrm{C}_{12}$ and $\mathrm{C}_{14}$ fatty acyl-CoAs that are subsequently oxidized to acetyl-CoA in the mitochondria (365).

The activity of ACC is inhibited by phosphorylation by AMPK $(236,319,394)$; thus activation of AMPK can result in reduced malonyl-CoA formation and acceleration of fatty acid oxidation $(94,95)$. It was recently shown there is an increase in AMPK activity in rats with LV hypertrophy produced by aortic banding (462), although the metabolic consequences of this activation are unclear. As discussed in section $\mathrm{II} B$, mutations in the gamma-2 regulatory subunit of AMPK result in glycogen accumulation and hypertrophic cardiomyopathy in mice $(8,9)$ and Wolffe-Parkinson-White syndrome in patients $(135,135$, 330). To our knowledge, the effect of HF on AMPK expression and activity are not known. As discussed above, AMPK activation in the heart also stimulates glucose transporter translocation and glucose uptake (71, 379, 499); thus activation of AMPK can effect an increase in both carbohydrate and fatty acid metabolism. Thus, when 
the metabolic rate of the heart is increased, as occurs during exercise, increased AMPK activity would increase acetyl-CoA production from both carbohydrates and lipids, and thus ensure an adequate supply of substrate to the mitochondria (71).

The degradation of malonyl-CoA is regulated by the activity of malonyl-CoA decarboxylase (MCD), which converts malonyl-CoA back to acetyl-CoA and $\mathrm{CO}_{2}$ in the cytosol and mitochondrial (Fig. 5) (93, 146, 221, 225, 394). In general, situations where MCD activity is high results in low myocardial malonyl-CoA content and high rates of fatty acid oxidation $(48,92,93)$. We have recently shown that pharmacological inhibition of MCD activity increases myocardial malonyl-CoA content, and (93) MCD activity regulates fatty acid oxidation. In addition, inhibition of MCD activity reduces malonyl-CoA turnover (366) and increases glucose oxidation under aerobic, ischemic, and postischemic conditions and improves postischemic recovery of contractile function (93), as has been previously observed with CPT-I inhibitors $(163,164,427)$. An increase in cardiac power induced by $\beta$-adrenergic receptor stimulation results in a fall in myocardial malonyl-CoA content and accelerated fatty acid uptake and oxidation; however, this effect is not due to activation of AMPK or reduced ACC activity $(137,143)$ but has been associated with a reduction in the $K_{\mathrm{m}}$ of $\mathrm{MCD}(137)$, although this has not been a consistent finding (366).

Once taken up by the mitochondria, fatty acids undergo $\beta$-oxidation, a process that repeatedly cleaves off two carbon acetyl-CoA units, generating $\mathrm{NADH}$ and $\mathrm{FADH}_{2}$ in the process (Fig. 5). The $\beta$-oxidation process involves four reactions, with specific enzymes for each step, and each reaction has specific enzymes for long-, medium-, and shortchain length fatty intermediates $(30,32)$. The first step is catalyzed by acyl-CoA dehydrogenase, followed by 2-enoylCoA hydratase, and then 3-hydroxyacyl-CoA dehydrogenase. The final step is 3-ketoacyl-CoA thiolase (3-KAT), which regenerates acyl-CoA for another round of $\beta$-oxidation and releases acetyl-CoA for the citric acid cycle. AcylCoA dehydrogenase and 3-hydroxyacyl-CoA dehydrogenase generate $\mathrm{FADH}_{2}$ and $\mathrm{NADH}$, respectively, and the acetyl$\mathrm{CoA}$ formed from $\beta$-oxidation generates more $\mathrm{NADH}$ and $\mathrm{FADH}_{2}$ in the CAC.

\section{Ketone Body Metabolism}

The heart extracts and oxidizes ketone bodies $(\beta$ hydroxybutyrate and acetoacetate) in a concentrationdependent manner $(56,114,152,441)$. Plasma ketone bodies are formed from fatty acids in the liver, and the arterial plasma concentration is normally very low, thus they are normally a minor substrate for the myocardium. During starvation or poorly controlled diabetes, plasma ketone body concentrations are elevated secondary to low insulin and high fatty acids, and they become a major substrate for the myocardium $(15,145)$. As with fatty acids, the uptake and oxidation of glucose and lactate are inhibited by elevated plasma ketone bodies (32, 436, 441, 467), with the inhibitory effect presumably mediated through product inhibition on PDH (see sect. ${ }_{\mathrm{II}} F$ ).

Oxidation of ketone bodies inhibits myocardial fatty acid oxidation (56, 114, 152, 243, 261, 436, 474). Diabetic myocardium has a high rate of $\beta$-hydroxybutyrate uptake and relatively low rates of fatty acid uptake (145), suggesting that in diabetic patients elevated plasma ketone concentrations can act to inhibit fatty acid uptake and oxidation. Clinical studies demonstrate that HF results in an increase in plasma ketone body concentration that appears to be secondary to elevated fatty acid levels (264-266); however, data on myocardial ketone body metabolism have not been reported from animals or patients with HF. The biochemical mechanisms responsible for inhibition of fatty acid $\beta$-oxidation by ketone bodies are not well understood, but do not appear to be related to changes in malonyl-CoA or the acetyl-CoA-to-free CoA ratio (436). Elevated rates of $\beta$-hydroxybutyrate and acetoacetate oxidation could inhibit fatty acid $\beta$-oxidation by increasing the intramitochondrial ratio of $\mathrm{NADH}$ to $\mathrm{NAD}^{+}$, which would inhibit the ketoacyl-CoA dehydrogenase step of the fatty acid $\beta$-oxidation spiral $(219,238)$. Hasselbaink et al. (152) recently showed that palmitate oxidation was significantly enhanced in isolated cardiomyocytes from streptozotocin diabetic rats in the absence of acetoacetate; however, when measurements were made with the addition of ketone bodies, the rate of palmitate oxidation was not affected by diabetes. They also noted greater fatty acid uptake in the myocytes from diabetic rats and suggested that ketoneinduced impairment of fatty acid oxidation might be responsible for the greater triglyceride storage in the heart with diabetes (82).

\section{E. Interregulation of Fatty Acid and Carbohydrate Oxidation}

The primary physiological regulator of flux through $\mathrm{PDH}$ and the rate of glucose oxidation in the heart is the rate of fatty acid oxidation (Fig. 4). High rates of fatty acid oxidation inhibit PDH activity via an increase in mitochondrial acetyl-CoA/free $\mathrm{CoA}$ and $\mathrm{NADH} / \mathrm{NAD}^{+}$, which activates PDH kinase causing phosphorylation and inhibition of PDH (Fig. 4). In addition, in isolated heart mitochondria elevated rates of fatty acid oxidation inhibit flux through PDH at a given PDH phosphorylation state (148). Conversely, inhibition of fatty acid oxidation increases glucose and lactate uptake and oxidation by 1) decreasing citrate levels and inhibition of PFK and 2) lowering acetyl$\mathrm{CoA}$ and/or NADH levels in the mitochondrial matrix, 
thereby relieving the inhibition of PDH (165) (Figs. 4 and 5). This effect has been demonstrated with 1) lowering plasma free fatty acid concentration by administering an inhibitor of lipolysis in adipocytes (229, 230, 245, 438), 2) inhibition of CPT-I $(51,164,165), 3)$ inhibition of malonylCoA decarboxylase (which elevates malonyl-CoA content and inhibits CPT-I activity)(93, 366), and 4) direct inhibitors of fatty acid $\beta$-oxidation $(207,297)$. It is important to note that partial inhibitors of myocardial fatty acid oxidation have been shown to lessen ischemic dysfunction and tissue damage in animal models of ischemia and reperfusion and have clear benefits in clinical trials in patients with chronic stable angina $(26,50,78,195,340$, 406, 445); this effect has been attributed to increased pyruvate oxidation and less lactate accumulation and efflux, and decreased proton accumulation (29, 164, 165, 427, 433).

\section{F. Effects of Substrate Selection on Contractile Function and Efficiency}

Several lines of evidence suggest that the contractile performance of the heart at a given $\mathrm{MV}_{2}$ is greater when the heart is oxidizing more glucose and lactate, and less fatty acids $(47,183,227,232,243,309,310,421)$. Studies in isolated rat hearts demonstrate that the mechanical power of the LV is less at a given rate of oxygen consumption when fatty acids rather than glucose are the sole exogenous substrate (47). Classic studies by Ole Mjøs in closed-chest dogs demonstrated that increasing the rate of fatty acid uptake by the heart with an infusion of heparin and triglyceride emulsion resulted in a $26 \%$ increase in myocardial oxygen consumption without changing the mechanical power of the $\operatorname{LV}(309,310)$. A similar decrease in cardiac mechanical efficiency with elevated plasma FFA concentration was observed in healthy humans (421) and pigs (232), as well as during ischemia of moderate severity in dogs $(227,311)$. Furthermore, inhibition of fatty acid $\beta$-oxidation by 4 -bromocrotonic acid decreased $\mathrm{MV}_{2}$ and improved mechanical efficiency of the LV of the working rat heart (183); a similar response was observed following acute administration of the fatty acid oxidation inhibitor ranolazine in dogs with HF (53). Korvald et al. (232) compared the relationship between $\mathrm{MVO}_{2}$ and the LV pressure-volume loop over a wide range of work loads in anesthetized pigs. Treatment with insulin and glucose resulted in a 39\% reduction in noncontractile basal $\mathrm{MVO}_{2}$ [estimated from the intercept of the $\mathrm{MV}_{2_{2}}$ pressure-volume loop relationship (232)] compared with pigs subjected to high plasma fatty acids. Importantly, they did not observe a difference in the slope of this relationship, suggesting that under these conditions fatty acids did not affect excitation-contraction coupling or the ATP requirement for contractile power.
The mechanisms for impaired mechanical efficiency with high fatty acid oxidation are unclear. On a theoretical basis, fatty acid oxidation requires a greater rate of oxygen consumption for a given rate of ATP synthesis than do carbohydrates (428). The theoretical ATP-to-oxygen ratio for glucose or lactate are 3.17 and 3.00, respectively, while for palmitate and oleate the values are 2.80 and 2.86 , respectively $(209,428)$. The actual values in vivo may be much lower due to constitutive leakage of protons across the inner mitochondrial membrane (37, 370, 371, 439). Fatty acid concentrations uncouple oxidative phosphorylation (decrease the $\mathrm{P} / \mathrm{O}$ ) and cause wasting of $\mathrm{O}_{2}$ by mitochondria $(34,348)$. This would require a greater $\mathrm{MV}_{2}$ for a given rate of ATP formation by oxidative phosphorylation when fatty acids are the substrate (34, 348). These effects would alter the $\mathrm{MVO}_{2}$ requirement for ATP production for both basal metabolism and for generating contractile power and relaxation (i.e., ATP hydrolysis to support $\mathrm{Ca}^{2+}$ uptake into the sarcoplasmic reticulum). In addition, high concentrations of long-chain fatty acids can also activate sarcolemmal $\mathrm{Ca}^{2+}$ channels, which would increase the entry of extracellular $\mathrm{Ca}^{2+}$ into the cytosol and increase the rate of ATP hydrolysis required to maintain normal cytosolic $\mathrm{Ca}^{2+}$ cycling (173).

It has been proposed that fatty acids waste ATP (and hence $\mathrm{O}_{2}$ ) through the extrusion of long-chain fatty acids out of the mitochondria via uncoupling protein 3 (UCP3) $(166,408)$. In this scheme high rates of intramitochondrial fatty acyl-CoA production would result in formation of FFA by mitochondrial thioesterase-1, which would be transported out of the mitochondria by UCP3 and reesterified by FACS to long-chain fatty acyl-CoA in the cytosol (a reaction that consumes two ATP) $(166,178)$. Garlid and co-workers (120-123, 193, 198-201) observed that UCP3 can translocate the $\mathrm{FA}^{-}$out of the mitochondrial matrix; once in the intramembranous space, the $\mathrm{FA}^{-}$ can associate with a proton. The resulting neutral FA species is able to "flip-flop" back into the mitochondrial matrix, where it relinquishes the proton. The net effect is a leak of protons, as with classic uncoupling, but with no net flux of fatty acids (120-123, 193, 198-201). While this clearly occurs, it may not play a major role in the energywasting effects of fatty acid observed in vivo, as many studies show no effect of UCP3 content on the P/O in isolated mitochondria $(60,62,222,408,478)$. Studies in isolated skeletal muscle mitochondria show that lipid substrate (palmitoylcarnitine or palmitoyl-CoA) causes a UCP3-dependent decrease in state 4 respiration with no change in state III respiration or $\mathrm{P} / \mathrm{O}$, an effect that is not observed with nonlipid substrates (222). In addition, skeletal muscle mitochondria isolated from mice lacking UCP3 show a decreased in state 4 respiration (478) and mice overexpressing UCP3 show an increase in state 4 respiration (60) with no effect on state 3 respiration $(60$, 478). Thus exposure of the myocardium to high plasma 
concentrations of FFA could waste ATP via this UCP3mediated futile cycle.

\section{G. Role of Nitric Oxide in Regulation of Myocardial Energy Substrate Metabolism}

In 1989, Brune and Lapetina demonstrated that nitric oxide (NO) can enhance ADP-ribosylation of a $37-\mathrm{kDa}$ cytosolic protein (43), later identified as GAPDH (90, 91, $313,475)$, a key enzyme of the glycolytic pathway. Zhang and Snyder documented a similar action of NO in neuronal cells (517). These seminal studies on the direct effects of NO on glucose metabolism were followed by others that described inhibitory actions of NO on phosphofructokinase of pancreatic islets (465) and an indirect stimulatory action of NO on 6-phosphofructo-2-kinase in neurons (4). Although the mechanisms are still poorly defined, convincing evidence has been provided that NO also plays an important role in the regulation of myocardial substrate metabolism. Depre et al. (83) observed a decreased glucose uptake in isolated hearts during 8bromo-cGMP infusion. They concluded that NO, via its second messenger cGMP, probably inhibits glucose transport into cardiomyocytes and that this could explain their previous findings of a cardioprotective action of NO synthase (NOS) inhibition during myocardial ischemia (84, 87 ), when cardiac function is highly dependent on glycolytic flux. In hearts isolated from endothelial cell NOS knockout mice, Tada et al. (447) found that basal cardiac glucose uptake is markedly increased and can be inhibited by 8 -bromo-cGMP. It is possible that all of these findings in vitro were affected by nonphysiological conditions of substrate and oxygen supply. This was not the case, however, since we found that cardiac glucose uptake and oxidation are increased after systemic NOS inhibition in conscious dogs $(360,361)$. Conversely, under the same experimental conditions, fatty acid uptake and oxidation are reduced. On the other hand, we did not observe this shift in substrate oxidation with NOS inhibition in isolated rat hearts (239). An interesting paradox is that NO/cGMP exerts opposite effects on glucose transport and metabolism in skeletal muscle (512). Additional research is needed to elucidate the mechanisms underlying the regulation of myocardial substrate metabolism by NO.

It has been suggested that the activity of cardiac NOS during metabolic stress is regulated by a possible feedback mechanism involving AMPK (57). Chen et al. (57) found that AMPK coimmunoprecipitates with cardiac eNOS and activated it by phosphorylating Ser-1177, but only in the presence of $\mathrm{Ca}^{2+}$-calmodulin, both in tissue homogenates and in ischemic isolated rat hearts. Because $\mathrm{NO}$ is a main regulator of vascular tone and cardiac function, these findings lead to the intriguing hypothesis that the stimulatory effect exerted by AMPK on eNOS may represent a link between metabolic adaptations and cardiovascular function under conditions of stress. Li et al. (255) also observed coprecipitation of AMPK and eNOS and demonstrated that activation of AMPK with 5-amino4-imidazole-1- $\beta$-carboxamide ribofuranoside (AICAR) results in activation of eNOS, GLUT4 translocation and greater glucose uptake in isolated papillary muscles. AICAR treatment also results in increased glucose uptake (255), which is in contrast with previous studies showing decreased glucose uptake with NOS inhibition or 8bromo-cGMP (83, 84, 87, 360, 361). Additional research is needed to elucidate the mechanisms underlying the complex interactions between myocardial substrate metabolism and NO.

\section{REGULATION OF MYOCARDIAL METABOLIC PHENOTYPE}

Myocardial metabolic phenotype can be defined as the substrate preference by the heart at a given metabolic milieu (e.g., arterial concentrations of glucose, lactate, fatty acids, insulin, catecholamines, oxygen), hemodynamic condition (heart rate, preload, afterload, coronary blood flow), and inotropic state. This phenotype is primarily dependent on the content of the proteins (enzymes and transporters) that facilitate flux through the metabolic pathways and the structure and integrity of key cellular organelles, such as mitochondria, that are responsible for energy metabolism. To affect metabolic phenotype, however, it is important that the protein that is modified exerts a key regulatory role in metabolism. Many metabolic enzymes in a pathway are redundant or expressed in great excess and therefore do not regulate flux through the pathway. It is therefore possible to have dramatic changes in expression of some proteins without much effect on substrate flux. In other words, changes in flux cannot simply be inferred from changes in enzyme activity or expression. Therefore, in evaluating the effects of heart failure on myocardial substrate metabolism, it is important to assess several aspects of the metabolic pathway of interest, specifically: 1) the rate of flux through metabolic pathways under physiologically relevant conditions; 2) the expression, activity, and characteristics of key regulatory proteins (e.g., $V_{\max }, K_{\mathrm{m}}$, allosteric modification of an enzyme); and 3) the tissue content of regulatory metabolites.

There have been a variety of investigations into the metabolic phenotype changes that occur in response to chronic cardiac stress like cardiac hypertrophy and HF. These studies have used a variety of methodological approaches but have mainly been aimed at the assessment of flux through the metabolic pathway [either in vivo using invasive $(30,31,338,493,494)$ or noninvasive tech- 
niques, e.g., positron emission tomography (PET)] (79, 81, $237,453,480)$, or in isolated perfused hearts $(24,224,269)$, or they have sampled the myocardium to evaluate mRNA levels using real-time quantitative polymerase chain reaction $(86,356,357,509)$ or gene chip microarrays (307, 451). It is more complex to assess changes in the protein expression, activity, and rate of turnover. Nevertheless, in studying the effects of HF on metabolic phenotype, the goal has been to understand the relative importance of changes in the function of selected proteins on the flux through various metabolic pathways, on cardiac function, and on the progression of HF. At present, much emphasis is placed on understanding the mechanisms that signal changes in the expression of genes encoding proteins that regulate substrate metabolism and, in turn, affect cardiac function and progression in HF. However, as discussed, care should be taken in interpreting these data without parallel measurements of metabolic flux.

\section{A. Control of the Expression of Metabolic Enzymes in the Heart}

Regulation of the expression of the multitude of enzymes and transporters involved in myocardial energy metabolism is complex and not well understood. In HF, recent interest has focused on altered expression of both glycolytic and mitochondrial enzymes. In general, the overall capacity for oxidative metabolism in a cell is dependent on the volume density and composition of mitochondria. However, over the last decade it has become clear that mitochondrial fuel selection can be al- tered by differential expression of enzymes of the fatty acid oxidation pathway relative to enzymes that oxidize pyruvate (PDH and PDK) or acetyl-CoA (e.g., citrate synthase), or those in the electron transport chain. Mitochondria have a circular DNA genome that encodes for the 13 subunits of the respiratory complexes I, III, IV, and V (400). The remaining respiratory subunits and all of the proteins required for carbon substrate metabolism are encoded by nuclear genes. It is becoming clear that both nuclear and mitochondrial transcription alterations are important in the metabolic phenotype changes observed in $\operatorname{HF}(124,477)$.

An important nuclear gene transcription control that regulates the capacity for myocardial mitochondrial fatty acid oxidation is regulated by the ligand-activated transcription factors, named peroxisome proliferator-activated receptors, or PPARs $(25,180)$. These transcription factors control gene expression by first forming heterodimers with retinoid $\mathrm{X}$ receptors and then binding to specific response elements (PPAR response elements, or PPREs) located within promoter regions of many genes encoding metabolic enzymes (Fig. 6). In addition, the PPAR/RXR complex is positively regulated by the cofactor PPAR $\gamma$ coactivator-1 (PGC-1) $(25,180,476)$. Cardiac overexpression of PGC-1 increases the mRNA of numerous mitochondrial genes and triggers mitochondrial biogenesis $(181,250,476)$. Once bound to the PPRE, the PPAR/RXR/PGC-1 complex increases the rate of transcription of fatty acid oxidation genes and PDK-4 (the inhibitory kinase of PDH) (129, 150, 172, 251). In addition, stimulation of gene transcription is inhibited by the bind-

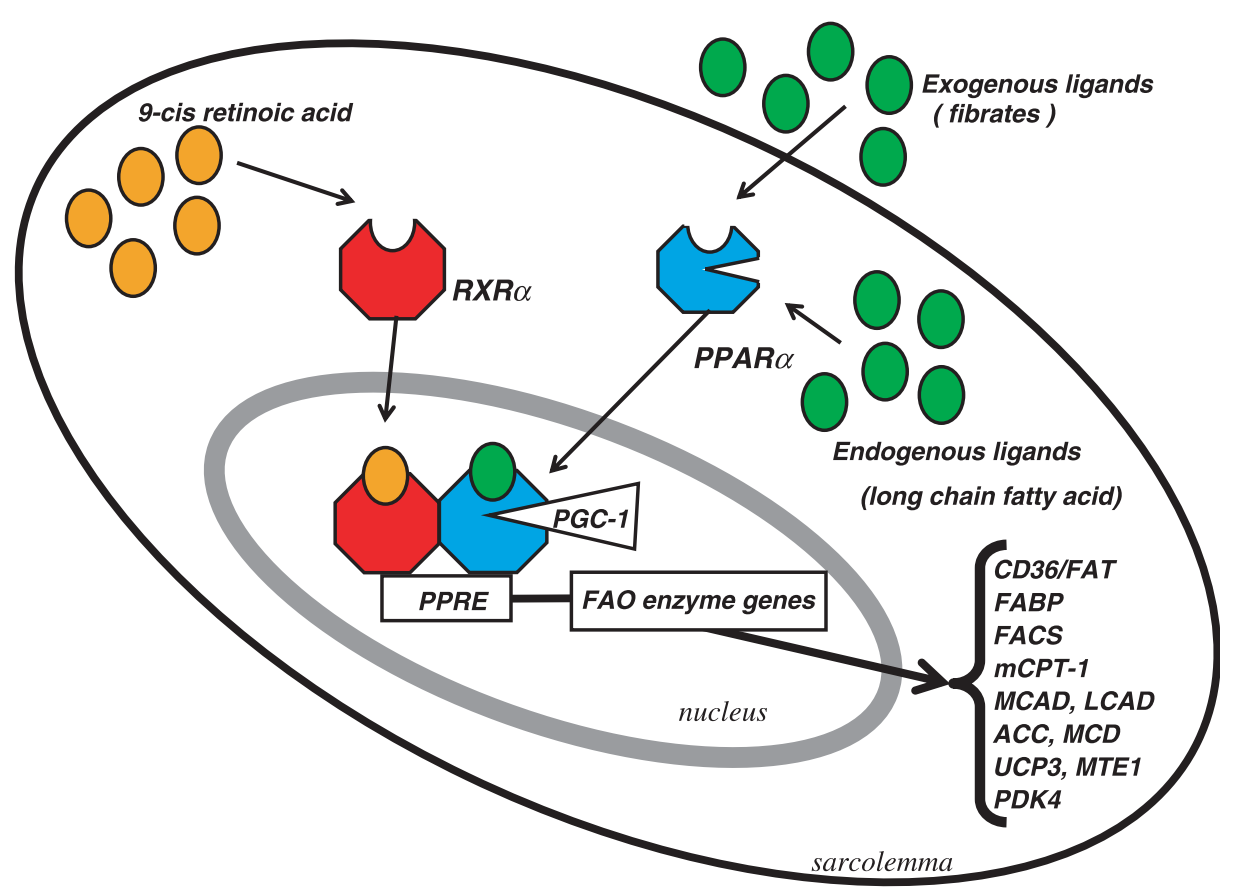

FIG. 6. Regulation of expression of metabolic genes in cardiomyocytes by stimulation of the peroxisome proliferator activated receptor $\alpha(\operatorname{PPAR} \alpha)$. Note that $\operatorname{PPAR} \delta$ has similar, but less well described, effects on gene expression (see text). ACC, acetyl-CoA carboxylase, mCPT-I, muscle isoform of carnitine palmitoyltransferase-I; FABP, fatty acid binding protein; LCAD, long-chain acylCoA dehydrogenase; MCAD, medium-chain acyl-CoA dehydrogenase; MCD, malonylCoA decarboxylase; MTE1, mitochondrial thioesterase 1; PDK4, pyruvate dehydrogenase kinase 4; PPRE, peroxisome proliferator activated receptor response element; $\mathrm{RXR} \alpha$, retinoid X receptor $\alpha$; UCP3, uncoupling protein 3 . 
ing of several cofactors such as COUP and SP1 (251). The activity of PPAR/RXR heterodimers is increased by fatty acids and eicosanoids; thus PPAR/RXR heterodimers act as lipid sensors in the cell, resulting in a greater capacity for fatty acid catabolism in response to a greater cell exposure to lipid (Fig. 6) $(25,180)$.

There are three isoforms of PPARs: PPAR $\alpha$, PPAR $\beta / \delta$, and PPAR $\gamma(25,129,180,251,472) . \operatorname{PPAR} \alpha$ expression is high in tissues that have high rates of fatty acid oxidation (heart, liver, brown fat, kidney) and regulates the expression of key components of fatty acid uptake, esterification, and oxidation by transcriptional activation of genes encoding for key proteins in the pathway (Fig. 6). In the heart, $\operatorname{PPAR} \alpha$ forms a heterodimer with $\operatorname{RXR} \alpha$; the natural activating ligand for $\operatorname{RXR} \alpha$ is 9-cis-retinoic acid (25). Activation of $\operatorname{PPAR} \alpha$ by pharmacological ligands (e.g., fenofibrate, clofibrate, or WY-14,643) increases the expression of fatty acid oxidation enzymes $(129,180,509)$ and the rate of fatty acid oxidation in cardiomyocytes (129). Consistent with these findings is the observation that PPAR $\alpha$ knockout mice have low expression of fatty acid oxidation enzymes and suppressed fatty acid oxidation (48). It was also recently demonstrated that PPAR $\alpha$ regulates the expression of UCP3 (511) and mitochondrial thioesterase 1 (437) in the heart and thus plays a role in regulating the extrusion of fatty acyl-CoA from the mitochondria (166).

$\operatorname{PPAR} \delta$ [also referred to as $\mathrm{PPAR} \beta / \delta$ (129)] is also expressed in cardiomyocytes and stimulates the expression of proteins in the fatty acid oxidation pathway in a manner similar to PPAR $\alpha$ (58, 129). Gilde et al. (129) showed that exposure of isolated neonatal rat cardiomyocytes to PPAR $\delta$ agonists results in upregulation of the mRNA for fatty acid oxidation enzymes and increased fatty acid oxidation. Cheng et al. (58) recently showed that mice with a cardiomyocyte-restricted deletion of PPAR $\delta$ downregulated the expression of the mRNA and protein for fatty acid oxidation enzymes and had reduced myocardial oxidation of fatty acids. The mice had progressive LV dysfunction and hypertrophy, but had myocardial lipid accumulation and increased mortality late in life. These recent findings suggest that PPAR $\delta$ may play a role that is similar to PPAR $\alpha$ in the regulation of cardiac fatty acid metabolism.

PPAR $\gamma$ mRNA is expressed at very low levels in cardiomyocytes, and at higher rates in a broad range of tissues including skeletal muscle, colon, small and large intestines, kidney, pancreas, and spleen. Although PPAR $\gamma$ does not appear to play a direct role regulating fatty acid oxidation in the heart $(129,216)$, it can indirectly regulate fatty acid oxidation by decreasing the fatty acid concentration to which the heart is exposed. The effective insulin-sensitizing agents, the thiazolidinediones, are PPAR $\gamma$ ligands and act to sequester fatty acids in adipocytes, lower circulating fatty acids, and triglycerides and there- fore reduce the exposure of the myocardium to fatty acids (25). Thus the thiazolidinediones ("PPAR $\gamma$ agonists") can decrease myocardial fatty acid oxidation in vivo by decreasing plasma fatty acid levels and thus myocardial fatty acid uptake and oxidation. Furthermore, the action of PPAR $\gamma$ agonists on adipocytes likely reduces ligand stimulation of the PPAR $\alpha /$ RXR complex in cardiomyocytes, and thus reduces the expression of proteins regulating fatty acid uptake and oxidation in the heart.

Recent studies in isolated neonatal cardiomyocytes suggest that the orphan nuclear receptor estrogen-related receptor $\alpha(\mathrm{ERR} \alpha)$ interacts with PGC-1 and binds to the PPRE to increase the expression of $\operatorname{PPAR} \alpha$-regulated genes and increased fatty acid uptake, accumulation, and oxidation $(181,182)$. Overexpression of $\operatorname{ERR} \alpha$ also resulted in an increase in the mRNA for proteins that are not regulated by $\operatorname{PPAR} \alpha$, including contractile proteins and enzymes involved in carbohydrate metabolism and mitochondrial respiration (182). The endogenous ligand(s) for $\mathrm{ERR} \alpha$ have not been identified.

\section{B. Cardiac Lipotoxicity}

Recent evidence from animal studies demonstrates that obesity and elevated plasma fatty acid and triglycerides can result in a cardiac specific "lipotoxicity," characterized by accumulation of neutral lipids (triglycerides) and ceramides, which are associated with increased apoptosis, and contractile dysfunction (109, 301, 402, 468, $469,501,505,520)$. For instance, Zhou et al. (520) showed that mature obese Zucker diabetic rats develop cardiac dilatation and reduced contractility that correspond with elevated myocardial triglycerides, ceramide, and DNA laddering, an index of apoptosis. Suppression of plasma triglyceride with the PPAR $\gamma$ agonist troglitazone lowers myocardial triglyceride and ceramide content, which was associated with complete prevention of DNA laddering and loss of cardiac function. Cardiac overexpression of FACS results in lipid accumulation, cardiac hypertrophy, gradual development of LV dysfunction, and premature death (59). Cardiac overexpression of human lipoprotein lipase with a glycosylphosphatidylinositol anchoring sequence that localizes the enzyme to the surface of cardiomyocytes causes LV chamber enlargement and impaired contractile function compared with wild-type mice (501). The mechanism for lipid-induced cardiac remodeling and dysfunction in this model is unclear but could be due to apoptotic cell loss $(162,260,333,425,520)$ and/or a decrease in cardiac mechanical efficiency with very high rates of fatty acid oxidation and impaired carbohydrate oxidation $(227,232,309,310,421)$.

The toxic effects of lipid accumulation in the heart can be demonstrated in small animal models; however, the clinical significance of these findings is not yet clear in 
type 2 diabetes, obesity, and HF. Epidemiological studies show that obese people have a decrease in life expectancy and greater mortality from cardiovascular disease (113, 174) and a greater risk for developing HF (218). However, once a patient is diagnosed with HF, there is a paradoxical reduction in the rate of mortality in obese compared with lean patients $(80,171,247,248)$. These observations are complicated by the fact that cachexia is a positive predictor of mortality in $\mathrm{HF}$, and weight loss is strongly associated with poor outcome $(7,80)$. The clinical complexities of the HF and obesity, and the paucity of data, make it impossible to draw conclusions at this point regarding mechanistic interactions between the two syndromes.

\section{Regulation of Phenotype Switch from Fetal to Adult State: Implications for Heart Failure}

One of the hallmarks of $\mathrm{HF}$ is a reexpression of fetal forms of genes expressing contractile proteins, specifically myosin (411). A similar reexpression of some fetal metabolic genes has been noted in HF; however, there is not a clear recapitulation of the fetal metabolic phenotype (see discussion below) (356, 362, 374, 388, 389). Nonetheless, much can be learned about the regulation of metabolic phenotype by studying the rapid transformation in enzyme pathways and substrate use that occurs during the transition from the fetal to neonatal state. During the fetal stages of the developing mammalian heart, glucose is the primary energy substrate for energy transduction, while rates of fatty acid oxidation are very low (130). In the fetal and immediate newborn period, the heart is very reliant on glycolysis as a source of energy $(110,272)$ due both to higher activities of the enzymes in the glycolytic pathway $(110,169,282,372)$ and altered pathway regulation $(272,460)$ in fetal hearts. Direct measurements of glycolysis in perfused rabbit hearts demonstrate that in the immediate newborn period, $44 \%$ of the ATP production is derived from glycolysis (274); however, within days of birth glycolysis decreases and provides only $7 \%$ of ATP production, values similar to those seen in the adult rabbit heart $(273,274)$. Even though glycolysis is high in the fetal and newborn heart, these hearts still have a considerable mitochondrial oxidative capacity (273, 274, $482,483)$. Fetal hearts readily extract $(110-112)$ and oxidize lactate (489), and because circulating lactate levels are very high in the fetus (130), lactate oxidation accounts for the majority of myocardial oxygen consumption (110, 111). While glycolytic rates are high in the immediate newborn period, glucose oxidation is very low and is not a major source of ATP production $(274,275)$. The capacity to oxidize glucose increases as the heart matures (192, 272, 273).

In the fetal and newborn heart, fatty acid oxidation rates are low and provide only a small proportion of overall ATP production $(130,132,273,274)$. In the imme- diate newborn period, $<20 \%$ of the heart's ATP requirements are met by the oxidation of fatty acids (274). However, after birth, there is a dramatic 10-fold increase in fatty acid oxidation, which is accompanied by a parallel decrease in glycolytic rates $(192,274)$. This is opposite to the switch towards reduced fatty acid oxidation and increased glucose oxidation observed in some forms of severe HF. Interestingly, if the newborn heart is subjected to a volume overload hypertrophy, the expression and activity of key enzymes controlling fatty acid oxidation remain in the "fetal state" (208).

A number of key enzymes involved in fatty acid oxidation are altered in the transitions from fetal to adult metabolism. In the fetal heart there is a greater proportion of CPT-I $\alpha$ relative to CPT-I $\beta$, a phenomenon similar to what is observed in cardiac hypertrophy (41, 304, 461, 497). However, one of the most dramatic differences in fatty acid oxidation control in the newborn period is the levels of malonyl-CoA, and the control of malonyl-CoA levels $(275,282)$. In the immediate newborn period, malonyl-CoA content in the heart is very high, but then rapidly decreases within days of birth $(92,275,282)$. This dramatic drop in malonyl-CoA is an important contributor to the maturation of fatty acid oxidation following birth (275) and is due to both decreased synthesis by ACC and increased degradation by MCD $(92,275)$. The decrease in ACC activity with maturation is due to an increase in AMPK activity following birth (92), which phosphorylates and inhibits ACC activity (275). An increase in AMPK activity has also been observed with cardiac hypertrophy in the rat, illustrating that there is not a simple switch to fetal metabolic regulation in response to chronic cardiac stress (462). The increase in MCD activity in the newborn period is primarily due to an increase in MCD expression (92), which may be due to activation of $\operatorname{PPAR} \alpha$, a known transcriptional regulator of $\mathrm{MCD}(48,508)$. The role of PPAR $\alpha$ in HF is discussed below.

\section{Effects of Aging on Substrate Metabolism}

It is important to consider that the incidence of $\mathrm{HF}$ is directly related to age (33) and that the progression from adulthood to senescence affects cardiac contractile properties and LV chamber size (241, 242, 422), myocardial flow reserve (471) and cardiac mitochondria function (104, 147, 253, 276), and affects myocardial substrate metabolism independent of HF. Recent studies using PET show that with aging ( $\sim 69$ vs. 29 years of age), humans have a decrease in myocardial fatty acid uptake and oxidation, with no change in glucose uptake under resting conditions (211). However, when $\mathrm{MVO}_{2}$ is increased by an infusion of dobutamine, there is a similar increase in myocardial fatty acid uptake in both young and old subjects, and an increase in glucose uptake in the young 
subject but not in the old subjects. This is in contrast to studies in perfused rat hearts, where there was no difference between 6 and 24 mo in palmitate oxidation for a given $\mathrm{MVO}_{2}$ at either low or high work loads (3). Old rats have a decrease in myocardial GLUT4 mRNA and protein content that is not affected by exercise training by treadmill running (144). McMillin et al. (303) observed a decrease palmitoylcarnitine oxidation, CPT-I activity, and carnitine exchange in isolated mitochondria from old rats compared with adult animals. In addition, old animals did not exhibit fatty acid suppression of glucose oxidation that was evident in the adult rat heart, consistent with the concept of an aging defect in long-chain fatty acid oxidation (303). Iemitsu et al. (186) found a decrease in mRNA and protein expression for PPAR $\alpha$ in 23- compared with 4-mo-old rats and that this decrease was prevented by swim training from 21 to 23 mo. Aging resulted in a decrease in the activity of cytochrome oxidase, citrate synthase, and 3-hydroxylacyl-CoA dehydrogenase, which was also prevented by 2 mo of swim training (186). Most animal studies investigating the pathophysiology of HF are performed in juvenile or young adult animals, and thus the effects of age are not present, suggesting that one should be cautious in interpreting such data.

\section{METABOLIC PHENOTYPE IN HEART FAILURE}

\section{A. Considerations Regarding the Etiology of Heart Failure}

The etiology of HF can be divided into two broad categories: those patients with a history of myocardial ischemia/coronary artery disease (approximately twothirds of all patients) and those without a history of coronary disease ("idiopathic cardiomyopathy") (215). The early stages of HF are often clinically asymptomatic due to physiological compensatory mechanisms (e.g., activation of the renin-angiotensin system, greater sympathetic nervous system activity, and development of cardiomyocyte hypertrophy); however, these same mechanisms also contribute to the progression of $\mathrm{HF}$ by precipitating ventricular remodeling (increased LV chamber volume, wall thinning, and myocardial fibrosis). It is important to note that inborn errors in mitochondrial metabolism and the electron transport chain can result in cardiomyopathy and present as clinical HF (49, 156, 217, 285); however, this area is outside the scope of the present review.

Due to the difficulties in obtaining myocardial tissue samples and assessing substrate flux in humans, little is known about myocardial substrate metabolism in HF patients. Furthermore, analysis of data from patients is complicated by the diverse etiology of the HF syndrome, the numerous pharmacotherapies used to treat these pa- tients, the presence of complicating disorders (diabetes, insulin resistance, obesity), and the clinical stage. At present, there are few measurements of myocardial substrate metabolism in HF patients. Several studies have assessed levels of mRNA and protein expression in myocardium from hearts explanted from HF patients undergoing transplantation. However, these studies are compromised by the lack of a proper "normal" control group (the HF samples are rapidly obtained, while the control tissue is generally obtained from donor hearts that were unacceptable for transplantation and thus are usually on ice from several hours before processing). Despite these limitations, there is clear agreement between animal and human studies on many of the effects of HF on changes in the expression of key metabolic enzymes (see below).

The greatest impediment to understanding myocardial metabolism in $\mathrm{HF}$ is the limitations of existing animal models of HF (10, 317, 347, 386). Human HF of ischemic origin usually develops slowly following a myocardial infarction, affecting areas of the ventricle remote from the infarcted regions that have normal myocardial blood flow. While transient $\mathrm{HF}$ can occur during the acute phase of a myocardial infarction or with unstable angina, chronic HF slowly develops after establishment of the infarct, with evolution of LV remodeling and adverse changes in both the infarcted and the noninfarcted regions. Several animal models have been developed to mimic this condition, specifically the rat infarct model $(263,342,343)$, the canine direct-current shock model (299), and the pig infarct model (262). Like in humans, in these models infarction does not always result in true HF (i.e., decreased LV systolic function, chamber dilation, or elevated LV enddiastolic pressure), although a predictable number of animals progress to a state similar to human HF. A particularly robust and well-characterized canine model of $\mathrm{HF}$ has been developed by Sabbah et al. (386), where HF is produced by repeated bouts of ischemic injury induced by microembolizations caused by intracoronary injections of 90- $\mu \mathrm{m}$-diameter microspheres $\sim 4-7$ times 1 wk apart, which generates diffuse infarcts and progressive LV dysfunction, chamber dilation, and $\operatorname{HF}(384,418)$.

Clinically, HF can develop in the absence of coronary artery disease in patients with a history of LV hypertrophy due to hypertension or aortic stenosis, though unlike HF in patients with a history of ischemic heart disease, LV chamber dilation develops relatively late in hypertensive patients who progress to HF (215). Animal models of LV hypertrophy have been developed using chronic aortic constrictions in rats, dogs, and pigs $(504,516)$. There are numerous studies on the effects of LV hypertrophy in rodents on myocardial substrate metabolism in the absence of $\operatorname{HF}(16,251,291,396,516,518)$; however, there are few studies where the animals actually progressed from concentric LV hypertrophy to overt HF (e.g., decreased cardiac output, LV ejection fraction, and increase 
LV end-diastolic pressure). In dogs and pigs subjected to aortic constriction, HF develops after $6-12$ mo in $\sim 40 \%$ of the animals, whereas the remaining animals hypertrophy but do not progress to failure $(167,504)$.

Another widely used model that does not involve myocardial ischemic injury is the rapid pacing-induced model in dogs, where the heart rate is increased to $>220$ beats/min, resulting in decompensated end-stage failure after 4-6 wk of pacing. This model is highly reproducible and has also been produced in pigs, sheep, and rabbits $(10,317,347)$. The mechanisms that precipitate HF in the model are related to neurohormonal activation secondary to poor cardiac function, presumably due to poor diastolic filling and increased metabolic stress and decreased phosphorylation potential $(314,420)$.

\section{B. Electron Transport Chain and Oxidative Phosphorylation Defects in Heart Failure}

The focus of this review is on the metabolism of carbon substrates in HF. However, the ultimate fate of the reducing equivalents generated from intermediary metabolism is the electron transport chain (ETC) and oxidative phosphorylation, making it important to briefly address this topic (Fig. 7) [the reader is referred to several recent reviews that more specifically address mitochondrial and ETC defects in HF $(49,98,253,287,477)]$. In addition, HF generates defects in the transfer of the energy from mitochondrial ATP to the site of ATP hydrolysis and the function of the creatine phosphate system (97-99, 190, $257,322-324,463,477)$; however, this topic is outside the scope of this review.

Studies in patients and animal models show that there is a decrease in tissue ATP content, a rise in ADP, and a fall in the phosphorylation potential $(21,22,189$, $257,298,314,322-324,420,463,470$ ), thus impairing the kinetics for ATP utilization for cell contraction (myosin ATPase) and relaxation (sarcoplasmic reticulum $\mathrm{Ca}^{2+}$ ATPase). In addition, HF impairs the capacity for the creatine kinase system to transfer mitochondrial ATP to the myofibril $(88,97,98,257,463,477,504)$. An impaired ETC could also affect the mitochondrial and cytosolic redox state $\left(\mathrm{NADH} / \mathrm{NAD}^{+}\right)$and the concentrations of ATP, ADP, and $\mathrm{P}_{\mathrm{i}}$, which could influence the rate of flux through key metabolic enzymes such as PDH or phosphofructokinase.

Mitochondria in the failing heart are characterized by a greater occurrence of membrane disruption and matrix depletion $(383,403,417,419)$, a lower capacity for respiration with a variety of substrates $(136,170,334,383$, 397-399, 419), defects in complexes of the ETC (44, 49, $196,286,287,298,349,404)$, and a decreased capacity for oxidative phosphorylation $(49,253,262,286,349)$. In rats with infarct-induced HF, there is a decrease in myocardial ATP and creatine phosphate and in ADP stimulated respiration in isolated permeabilized myocyte bundles with glutamate and malate as substrates at 12 wk after coronary ligation (397-399). Myocardial homogenates from cardiomyopathic Syrian hamster have a decreased ability to oxidize fatty acids $(19,205)$, which was subsequently shown by Hoppel et al. (170) to reflect a generalized defect in oxidative metabolism that is not specific for fatty acids. This defect in oxidative phosphorylation was found in interfibrillar mitochondria, and not in subsarcolemmal mitochondria (170). To our knowledge, this is the only study to investigate the effects of HF on select populations of cardiac mitochondria (253).

Studies in patients and animals with HF show a reduced activity of several ETC complexes. Jarreta and co-workers $(49,196)$ measured the activity of complexes I-IV in myocardial biopsies from HF patients. They observed that the activity of complex III was reduced by $35 \%$ with no changes in the other complexes in patients with either idiopathic dilated cardiomyopathy or a history of ischemic heart disease compared with donor hearts with normal cardiac function. The only genetic defects they found were neutral polymorphisms in the cytochrome $b$ gene, strongly suggesting that the decreased activity in the respiratory chain complex III activity was not due to expression of an abnormal gene (196). This observation is
Outer Mitochondrial Membrane

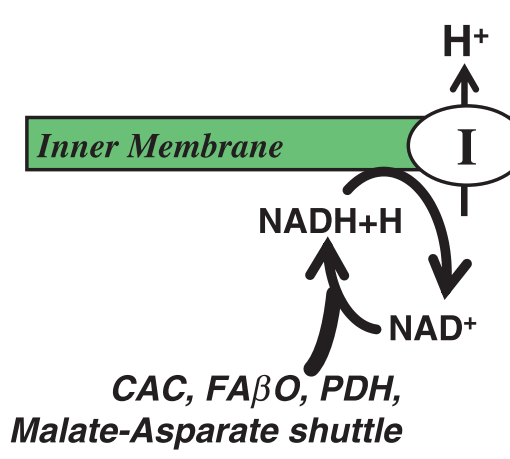

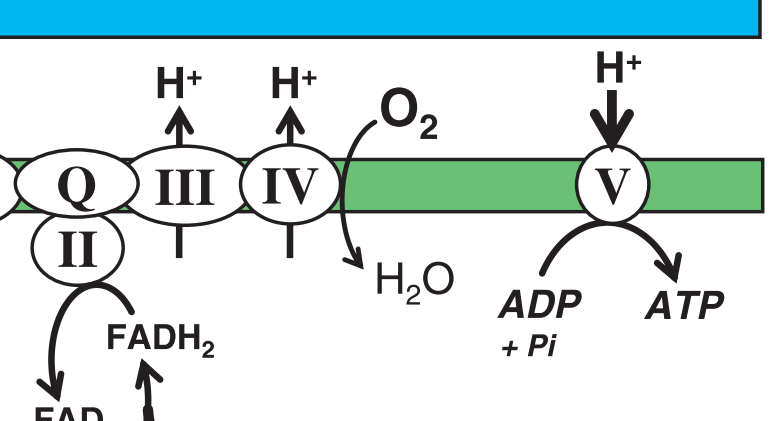

FIG. 7. The electron transport chain. Studies in heart failure (HF) patients show conflicting results, with reduced activity of either complex I (404), complex III $(49,196)$, or complexes III and IV (44). Conflicting results are also reported in the canine rapid pacing model of HF, with defects observed in either complex I activity (184) or in complexes III and V (286). CAC, citric acid cycle; $\mathrm{FA} \beta \mathrm{O}$, fatty acid $\beta$-oxidation; PDH, pyruvate dehydrogense. 
further supported by the fact that patients with a congenital complex III defect do not present with cardiomyopathy (316). Depressed complex III activity could not be attributed to mitochondrial DNA damage or depressed mitochondrial gene expression (196). Buchwald et al. (44) measured the activity of the ETC complexes in isolated mitochondrial particles from transplant recipients with dilated cardiomyopathy (DCM) and from unused donor hearts. Cytochrome $c$ content and the activity of complexes III and IV were decreased by 21, 24, and 28\% compared with donor hearts, with no differences in the activities of complexes II and V. On the other hand, similar measurements of respiratory complex activities in HF patients by Scheubel et al. (404) showed a $28 \%$ decrease in complex I activity compared with donor hearts, but no changes in complexes II-IV or of the CAC enzyme citrate synthase.

Defects in the ETC have also been identified in the canine rapid pacing model of HF. Marin-Garcia et al. (286) showed that in severe end-stage decompensated pacinginduced HF (LV end-diastolic pressure of $38 \mathrm{mmHg}$ ), there was no decrease in the activities of complexes I, II, or IV, but a highly significant decrease in the activities of complexes III (81\% reduction) and V (70\% reduction), with no change in the activity of citrate synthase. They also observed a similar reduction in the activities of these enzymes, although to a lesser extent, in skeletal muscle. The defects in ETC complexes were correlated to plasma concentration of tumor necrosis factor- $\alpha$ (286), and treatment of dogs with etanercept, a soluble tumor necrosis factor receptor fusion protein, partially prevents the defect, suggesting the possibility that tumor necrosis factor- $\alpha$ somehow regulates ETC complexes III and IV (312). In contrast, using the same pacing-induced canine model of $\mathrm{HF}$, Ide et al. (184) reported a 50\% decrease in complex I activity in cardiac submitochondrial particles, which was associated with greater production of reactive oxygen species.

Regardless of such differences among studies, these findings are consistent with the concept that in HF there is a major lesion in oxidative metabolism at the level of the ETC. On the other hand, there is a large disparity among the clinical and experimental studies regarding the sites of the lesions in the respiratory chain. It is also unclear if 1) these effects are isolated to a subpopulation of cardiomyocytes, or if they occur uniformly throughout all cells, or 2) they are localized to either subsarcolemmal or intrafibrillar populations of mitochondria. In addition, the consequences of these lesions on cardiac metabolism, oxidative damage, and contractile function are not clear. One possibility is that impairment in the ETC reduces the in vivo capacity for myocardial ATP generation and thus limits cardiac contractile function during high work states, such as exercise or acute adrenergic stress. Nikolaidis et al. (328) recently observed a reduced $\mathrm{MV}_{\mathrm{O}_{2}}$ re- sponse to increased cardiac power in dogs with pacinginduced HF that was due to a limitation in oxygen extraction, but not in myocardial blood flow. These finding are consistent with the concept of impaired mitochondrial respiratory capacity in $\mathrm{HF}$, resulting in reduced ability to generate ATP in response to increased demand for cardiac power.

Recent studies demonstrate that downregulation of fatty acid oxidation enzymes can be triggered by a defect in the ETC in the mouse heart (149). Hansson et al. (149) knocked out mitochondrial transcription factor A and observed a progressive decline in ETC activities and mitochondrial ATP production. The downregulation of enzymes of fatty acid oxidation occurred early in the development of mitochondrial dysfunction and was accompanied by an upregulation of hexokinase with no change in other glycolytic enzymes. The mechanisms that link impaired respiratory chain function to changes in the expression of metabolic genes are unclear. Nevertheless, these findings suggest the possibility that the metabolic switch in HF could be secondary to impaired ETC function.

\section{Substrate Metabolism in Heart Failure}

\section{Results from HF patients}

While numerous studies in patients and animal models show that HF reduces the capacity to transduce the energy from foodstuffs into ATP, less is known about the effects of HF on myocardial substrate metabolism and fuel selection. There are few measurements of myocardial substrate oxidation in HF patients, and the results are somewhat conflicting. In general, the data support the concept that in the early stages of HF there is a normal (or slightly elevated) rate of fatty acid oxidation, and in advanced or end-stage HF there is downregulation of fatty acid oxidation. Paolisso et al. (338) found increased extraction and uptake of plasma FFA and decreased glucose uptake in congestive HF patients $[n=10$; New York Heart Association (NYHA) classes II and III] compared with age-matched healthy individuals. In addition, the rate of myocardial lipid oxidation, as estimated from the transmyocardial respiratory quotient, increased by $50 \%$ in HF patients. In these patients there was a corresponding $60 \%$ decrease in cardiac carbohydrate oxidation compared with healthy controls. It should be noted that these indirect measurements of substrate oxidation do not differentiate between lactate, glucose, or glycogen oxidation. HF patients had increased plasma norepinephrine $(5.2 \pm 0.2 \mathrm{vs} .1 .4 \pm 0.3 \mathrm{pmol} / \mathrm{ml})$ which corresponded to increased plasma FFA concentrations $(1.0 \pm 0.1$ vs. $0.66 \pm$ $0.08 \mathrm{mM}$, presumably due to greater $\beta$-adrenergic stimulation). However, the HF patients also had significantly higher plasma insulin levels, which would likely stimulate glucose uptake and oxidation by the heart. The alterna- 
tions in plasma substrate and norepinephrine concentrations make if difficult to separate HF-induced changes in myocardial metabolic pathways from changes in the metabolic milieu.

Using PET, Taylor et al. (453) found greater myocardial uptake of a radiolabeled fatty acid analog and less radiolabeled deoxyglucose uptake in class III HF patients compared with healthy subjects. On the other hand, patients with idiopathic dilated cardiomyopathy appear to have greater myocardial glucose uptake and less fatty acid uptake compared with normal people. Yazaki et al. (503) found a reduced retention of the radiolabeled fatty acid analog ${ }^{123}$ I-beta-methyl-iodophenylpentadecanoic acid (BMIPP) in circumscribed cardiac regions of patients with severe idiopathic dilated cardiomyopathy, consistent with impaired fatty acid utilization; however, the kinetics of BMIPP are complex and not validated in failing myocardium $(228,234,363)$. A recent PET study by DávilaRomán et al. (79) showed decreased fatty acid utilization and increased myocardial glucose metabolism in patients with idiopathic dilated cardiomyopathy. It is important to note that with PET one can estimate glucose uptake from the accumulation of ${ }^{18} \mathrm{~F}$-deoxyglucose 6 -phosphate in the tissue during infusion of ${ }^{18} \mathrm{~F}$-deoxyglucose tracer, or from estimations derived from the decay in tissue ${ }^{11} \mathrm{C}$ content following injection of $\left[{ }^{11} \mathrm{C}\right]$ glucose; however, it is not possible to directly measure the rate of glucose oxidation, as done with invasive studies using $\left[{ }^{14} \mathrm{C}\right]$ glucose and myocardial production of ${ }^{14} \mathrm{CO}_{2}(492,493)$. The discrepancy among these clinical investigations may be attributable to the severity of HF, supporting the idea that in the early stages of HF there is a normal (or slightly elevated) rate of fatty acid oxidation, with a dramatic downregulation of fatty acid oxidation in advanced or end-stage HF.

\section{Results from animal models of $H F$}

Studies in the canine rapid pacing model of heart failure by Recchia et al. (359) support the concept that there is relatively normal myocardial substrate metabolism in the early and middle stages of the development of HF, but a sharp switch away from fatty acid towards carbohydrate oxidation in end-stage HF (e.g., LV enddiastolic pressure $\geq 25 \mathrm{mmHg}$ ). The substrate switch was evidenced by a sharp rise in glucose uptake and a fall in fatty acid uptake that coincided with a steep elevation in LV end-diastolic pressure and cardiac decompensation, all occurring during the last week of pacing. Further support for this late switch comes from the transmyocardial respiratory quotient (an estimate of substrate oxidation from $\mathrm{CO}_{2}$ production and $\mathrm{MV}_{2}$, with 0.7 reflecting $100 \%$ fat oxidation, and $1.0100 \%$ carbohydrate oxidation), which did not change significantly from the prepacing value $(0.73 \pm 0.06)$ at $3 \mathrm{wk}$ of pacing $(0.80 \pm 0.04)$, but increased sharply with the onset of decompensation
$(0.87 \pm 0.09,0.96 \pm 0.08$, and $1.02 \pm 0.06$ at 24,27 , and 29 days of pacing). Nikolaidis et al. (329) observed a similar fall in fatty acid uptake in end-stage HF in this model despite a rise in plasma fatty acid concentration, but also found decreases in glucose and lactate uptake despite no change in $\mathrm{MV}_{2}$. Studies using isotopic tracers to directly measure substrate oxidation showed a significant increase in glucose oxidation and decrease in fatty acid oxidation in end-stage pacing-induced failure compared with normal dogs $(252,332)$.

Interestingly, the metabolic changes in canine pacinginduced $\mathrm{HF}$ are paralleled by a fall in cardiac production of NO metabolites. Whether reduced NO synthesis and a switch in substrate metabolism, in the failing heart, are linked by a cause-effect relationship is presently unknown. Convincing evidence indicates that $\mathrm{NO}$ exerts a direct action on cardiac substrate utilization (83, 84, 358, 360, 361, 447), but only one of those studies (447) determined the effects of permanent reduction in NO synthesis in hearts isolated from endothelial cell NOS knock-out mice, while the others tested short-term effects (see sect. II $G$ ). Molecular alterations in the failing heart, including downregulation of metabolic enzymes (see sect. Iv) and of NOS (423), occur over long periods of time. Ideally, the relationship between lack of cardiac NO and substrate selection should be tested by reestablishing a normal NO production selectively in the heart and during the progression of $\mathrm{HF}$, a difficult task to perform with the pharmacological tools presently available. A further element of complexity is that the lack of NO in the failing heart might 1) lead to excessive mitochondrial $\mathrm{O}_{2}$ consumption (498) and 2) contribute to coronary microcirculatory dysfunction (464), therefore causing subliminal myocardial ischemia in the absence of coronary macrovascular disease, resulting in metabolic adaptations. In fact, as mentioned in section $\mathrm{IV} D$, pacing-induced $\mathrm{HF}$, similar to human dilated cardiomyopathy, is characterized by regional myocardial perfusion abnormalities, detectable only with careful assessment of regional flow distribution $(154,321)$.

Studies in early-stage HF in the canine microembolization model suggest that the changes in substrate use are a late-stage phenomenon. Chandler et al. (52) measured myocardial substrate oxidation in dogs with well-compensated microembolization-induced HF using isotopic tracers and found no differences in myocardial glucose, lactate, or fatty acid metabolism compared with normal dogs. These results support the concept that there is not a decrease in fatty acid oxidation early in $\mathrm{HF}$ and that the dramatic downregulation of fatty acid oxidation enzymes and the switch to carbohydrate metabolism occurs only in more severe or decompensated HF.

Studies in rats 8 wk after myocardial infarction showed an elevated LV end-diastolic pressure (12 vs. 3 $\mathrm{mmHg}$ ) and decreased developed pressure (69 vs. 78 mmHg compared with sham rats in vivo) (362). When hearts were isolated and perfused with erythrocyte con- 
taining buffer, there was no difference in $\mathrm{MV}_{\mathrm{O}_{2}}$ between groups; however, there was an $84 \%$ increase in glucose oxidation with no significant change in palmitate oxidation (362). These results suggest that early in the development of HF in this model there is activation of glucose metabolism but not a reduction in exogenous fatty acid oxidation.

\section{Alterations in Expression and Function of Metabolic Proteins in Heart Failure}

Studies describing the expression of metabolic enzymes in HF have primarily focused on advanced endstage failure and have provided consistent evidence for a downregulation of myocardial fatty acid oxidation enzymes, which is consistent with the switch in substrate metabolism away from fatty acid oxidation toward greater glucose oxidation. Sack et al. (389) showed that explanted hearts from transplant recipients had a dramatic downregulation of the enzymes of the fatty acid oxidation pathway compared with unused donor hearts. The failed hearts had significantly reduced mRNA for the fatty acid oxidation enzymes long-chain acyl-CoA dehydrogenase (LCAD) and medium-chain acyl-CoA dehydrogenase (MCAD), as well as protein levels of MCAD, with no downregulation of the mRNA for the glycolytic enzyme GAPDH. Karbowska et al. (210) found a 54\% reduction in $\operatorname{PPAR} \alpha$ protein level in ventricular biopsies from five patients with compensated end-stage HF compared with control donor hearts. This suggests that the downregulation of the mRNA, protein expression, and activity of $\operatorname{PPAR} \alpha$ regulated genes in end-stage $\mathrm{HF}$ is due to less $\operatorname{PPAR} \alpha / \operatorname{RXR} \alpha$ heterodimer activity. The expression of $\mathrm{RXR} \alpha$ has not been reported in HF patients.

Studies in dogs with end-stage pacing-induced HF found a similar downregulation of enzymes involved in fatty acid oxidation; there was a $40 \%$ reduction in the activity and expression of MCAD and in the activity of CPT-I, which correlated with a $40 \%$ decrease in the rate of fatty acid oxidation and a $155 \%$ increase in the rate of glucose oxidation measured in vivo $(252,332)$. Surprisingly, MCAD downregulation was not paralleled by reduced expression of PPAR $\alpha$, the nuclear receptor that controls the expression of many key enzymes of the fatty acid oxidative pathway (Fig. 6) (332). On the other hand, consistent with impaired fatty acid oxidation, we found a reduced availability of $\mathrm{RXR} \alpha$, the obligate cofactor of $\operatorname{PPAR} \alpha$, which significantly correlated with MCAD expression and activity. Based on previous findings in vitro (96), we hypothesized that RXR $\alpha$ downregulation was due to sustained hypoxia in the paced ventricle consequent to supply/demand mismatch, even if we could not detect significant changes in mean coronary blood flow and in the rate of nonoxidative glycolysis. This hypothesis is supported by the finding that pacing-induced HF is characterized by a reduced subendocardial blood flow, especially in the LV free wall, when the pacemaker is activated (154). Similar regional myocardial perfusion abnormalities have been observed with PET in patients with idiopathic dilated cardiomyopathy $(320,321)$.

Measurements of the mRNA expression in myocardium from dogs with end-stage pacing-induced HF suggest that not only the mRNA levels of key enzymes of the fatty acid oxidation pathway are downregulated, but also GLUT-1, GLUT-4, GAPDH, PDH ( $\mathrm{E}_{2}$ subunit), and PDK-4 were reduced in failing hearts compared with normal myocardium $(252,356)$. This suggests that the failing heart represses the expression of all metabolic enzymes, rather than selectively suppressing fatty acid oxidation enzyme and potentiating the carbohydrate pathway.

Studies in less advanced HF suggest that the change in the expression of metabolic genes is a late-stage phenomenon. Chandler et al. (52) analyzed the myocardium from dogs with well-compensated microembolization-induced HF. Mitochondria were isolated for the measurement of CPT-I activity and the ability of malonyl-CoA to inhibit CPT-I activity. As discussed above, the heart expresses two isoforms of CPT-I: liver (CPT-I $\alpha$ ) and heart (CPT-I $\beta$ ), with CPT-I $\alpha$ not as sensitive to malonyl-CoA inhibition as CPT-I $\beta(223,300,302)$. This has potential significance in HF since Depre et al. (86) showed that in human end-stage HF and in cardiac hypertrophy in the rat heart there is a significant reduction in the mRNA for CPT-I $\beta$, but no change in the mRNA for CPT-I $\alpha$. This could translate into predominance of the liver isoform in the failing heart and loss of malonyl-CoA sensitivity (357). However, we did not observe any difference in the maximal activity of CPT-I between groups, or in the sensitivity of CPT-I to malonyl-CoA inhibition in isolated mitochondria $(52,337)$, which suggests there was not a relative switch from the muscle form of CPT-I to the malony-CoA insensitive liver form. We did, however, observe a $22 \%$ decrease in the myocardial content of malonyl-CoA in HF, suggesting less in vivo inhibition of CPT-I activity (52). In addition, the total activity and the activation state of PDH, the key enzyme regulating myocardial pyruvate oxidation (and hence glucose and lactate oxidation), was not affected by HF. These data further support the concept that in the early stages of HF the myocardium primarily relies on fatty acid as an oxidative substrate, and that there is not yet a switch to greater glucose oxidation and less fatty acid oxidation.

Similar to our observations in dogs with HF, Martin et al. (289) found that the activity of CPT-I was not different between myocardial biopsies obtained from HF patients undergoing transplantation compared with nonfailing donor hearts. However, they did find that the activity of CPT-II was significantly reduced. Consistent with this observation, the myocardial content of long-chain 
acylcarnitine was increased over fourfold, and the free carnitine content was reduced by one-half in the HF patients. This study did not measure mitochondrial volume density or the activity of marker enzymes (e.g., citrate synthase), so it is unclear if the HF patients had a general reduction in mitochondrial density.

Studies in the rat infarct model of $\mathrm{HF}$ found that 20 wk after coronary artery ligation there is a decrease in the mRNA expression of selected fatty acid oxidation enzymes (fatty acid binding protein, MCAD, and very-longchain acyl-CoA dehydrogenase) with no change in CPT-I or long-chain acyl-CoA dehydrogenase $(362,374)$. HF develops in this model (e.g., increase in LV end-diastolic volume and decrease in LVEF) at $\sim 12 \mathrm{wk}$ after infarction $(263,342,343,362,374)$. There was also decreased protein expression for MCAD (362, 374), suggesting a response similar to patients in end-stage HF $(20,388,389)$ or dogs with decompensated pacing-induced $\mathrm{HF}(332,359)$. Iemitsu et al. (186) found approximately an $80 \%$ reduction in the mRNA expression of PPAR $\alpha$ and of the fatty acid oxidation enzymes hydroxyacyl-CoA dehydrogense and CPT-1 6 mo after infarction in the rat; however, protein expression or enzyme activities were not reported.

Recent studies by Miyamoto et al. (308) in a rabbit model of volume overload hypertrophic HF induced by a carotid-jugular shunt found that after 6 wk there was no downregulation of $\operatorname{PPAR} \alpha$ protein expression, or in the expression of enzymes fatty acids $\beta$-oxidation (308). Volume overload resulted in eccentric hypertrophy, as documented by an increase in LV end-diastolic dimension without an increase in anterior or posterior wall thickness. The myocardial uptake of the fatty acid analog ${ }^{125}$ I-iodophenyl 9-methylpentadecanoic acid was increased in the volume-loaded animals, suggestive of a greater fatty acid uptake and oxidation. Thus, in the early stages of cardiac failure in this model, there is no downregulation of the fatty acid oxidation pathway, but rather evidence for enhanced fatty acid oxidation without upregulation of the pathway (308).

There is little evidence for upregulation of the proteins involved in the carbohydrate utilization pathway (glucose transporters, glycolytic enzymes, or the PDH complex) in HF. Paradoxically, there is a decrease in glycolytic enzyme activity and expression despite increased glycolysis in severe rapid pacing HF in dogs (97, 252) and in patients with either hypertrophic or dilated cardiomyopathy (206). Studies in the rat infarct model of HF found an increased protein expression of GLUT-1 and downregulation of GLUT-4 compared with sham hearts (374). We recently observed that at end-stage pacinginduced HF in dogs, there is downregulation of mRNA for GLUT-1, GLUT-4, and GAPDH, with no change in the GLUT-1 and GLUT-4 protein content in the sarcolemmal membrane, but a decrease in the protein expression and activity of GAPDH (252). Paradoxically, there was an increase in glucose uptake and oxidation despite downregulation of the pathway $(252,332)$. Studies in Syrian hamsters found reduced activity of PDH in two cardiomyopathic strains (reduction of $68-84 \%$ compared with normal hearts) (89). When the hearts were perfused with $5 \mathrm{mM}$ dichloroacetate (DCA) to inhibit PDK and convert the enzyme to the dephosphorylated active form, there was an increase in PDH activity and a significant increase in systolic function of the heart, but the maximal activity of PDH was still significantly less in cardiomyopathic animals (32 and 38\% reduction from values obtained from normal hamsters). These results suggest that in this model of HF there is less total PDH enzyme present and greater phosphorylation inhibition that contributes to contractile dysfunction. We recently observed greater protein expression of PDK4 and less PDH E2 subunit, and no change in PDH activity in dogs with end stage pacinginduced HF compared with normal dogs, yet the rate of glucose oxidation was elevated by 2.5-fold (252). Taken together, these results suggest that any increase in glycolytic flux and glucose oxidation with $\mathrm{HF}$ is due to alterations in pathway regulation that are secondary to suppression of fatty acid oxidation, and are not due to upregulation of proteins involved in glucose uptake, glycolysis, or pyruvate oxidation.

Little is known about the effect of HF on myocardial lactate metabolism. Recent studies in the rat infarct model of HF demonstrated upregulation of the lactate transporter MCT-1 that corresponded to an increase in the $V_{\max }$ for lactate uptake in isolated cardiomyocytes (202). A similar increase in MCT-1 expression and myocardial lactate transport was observed in rats with $\mathrm{HF}$ caused by chronic volume overload induced by an arterial-venous fistula (11). The effects of HF on MCT-1 expression have not been reported in large animal HF models or patients, nor have the effects of HF on myocardial lactate uptake been assessed under conditions of cardiac stress or elevated arterial lactate concentrations.

\section{THERAPEUTIC POTENTIAL FOR MANIPULATION OF SUBSTRATE METABOLISM}

\section{A. Short-Term Metabolic Therapy to Optimize Cardiac Function}

On the basis of our previous discussion, increasing the flux through PDH may improve myocardial contractile function in HF. While this effect might not be effective in advanced end-stage HF, where the metabolic substrate preference has already switched to reduced fatty acid oxidation and accelerated glucose oxidation $(252,332$, $359,389,428$ ), it could be effective in the earlier stages of $\mathrm{HF}$, when substrate oxidation is relatively normal (52, 
338). In support of this, Bersin and co-workers (27, 28) observed improved contractile function in ten HF patients (NYHA classes III and IV) treated with intravenous DCA to inhibit PDH kinase, activate $\mathrm{PDH}$, and increase pyruvate oxidation. DCA was infused at $1.67 \mathrm{mg} \cdot \mathrm{kg}^{-1} \cdot \mathrm{min}^{-1}$ for $30 \mathrm{~min}$, and cardiovascular measurements made during the treatment period were compared with values obtained immediately before infusion. Myocardial lactate uptake increased during DCA infusion despite a significant fall in arterial lactate concentration. Consistent with a stimulation of PDH, during treatment with DCA there was a significant increase in stroke volume and stroke work, and an increase in LV mechanical efficiency from 15.2 to $20.6 \%$. Although rates of glucose or FFA uptake and oxidation were not measured, these results suggest that DCA increases pyruvate oxidation and mechanical efficiency by switching the heart towards the more efficient fuel. However, one should use caution in interpreting these results because of the lack of a vehicle-treated control group. To establish the mechanism of action of DCA in improving ventricular function in HF patients, it is important to show that DCA increases the rates of glucose and lactate oxidation and decreases fatty acid oxidation. We observed a similar increase in LV pump function without an increase in LV energy expenditure in response to acute treatment with the fatty acid oxidation inhibitor ranolazine in dogs with microembolization-induced $\mathrm{HF}$ (53, 382).

In vitro studies demonstrate that high concentrations of pyruvate increase contractile function and potentiate the contractile effects of $\beta$-adrenergic stimulation in normal myocardium $(46,160,283)$ and in isolated samples of failing human myocardium $(151,157,161)$. Hermann et al. (159) evaluated the effects of an acute intracoronary infusion of sodium pyruvate on LV function in NYHA class III HF patients with dilated cardiomyopathy (ejection fraction $<25 \%$ ). The estimated pyruvate concentration in the coronary artery was between 3 and $6 \mathrm{mM}$ (well above the normal levels of $\sim 0.1 \mathrm{mM}$ ). Pyruvate infusion resulted in a rapid increase in $\mathrm{LV}$ peak $\mathrm{dP} / \mathrm{d} t$, ejection fraction, and cardiac output that immediately reversed upon cessation of the infusion $(158,159)$. The mechanism for this response is unclear but could be due to greater pyruvate oxidation, increased cytosolic phosphorylation potential, or effects on the $\mathrm{Ca}^{2+}$ transient $(151,157,161,283)$. From a practical standpoint, it is not feasible to intravenously infuse sodium pyruvate to attain high arterial pyruvate concentrations due to the high sodium load that accompanies infusion of the sodium salt. It is possible to avoid this problem by infusing glycerol esters of pyruvate, which was recently shown to elevate arterial pyruvate concentrations and reduce myocardial infarct size during reperfusion in pigs (432); however, this approach has not been evaluated in HF.
Another means to rapidly enhance glucose oxidation and inhibit fatty acid oxidation in humans is to raise plasma insulin concentration. The effects of insulin on the heart are complex in that insulin directly stimulates myocardial glucose uptake $(42,194)$, but also dramatically suppresses lipolysis in adipocytes and thus indirectly stimulates myocardial glucose uptake and oxidation via the Randle cycle $(42,108,495)$. Cottin et al. (70) observed an improved wall motion score and LV ejection fraction in patients with ischemic heart disease and LV dysfunction when they were treated with an infusion of insulin under normoglycemic conditions (LV ejection fraction increased from $38.1 \pm 6.4$ to $53.3 \pm 11.6$ after $1 \mathrm{~h}$ ); however, the study was not blinded, and there was no control group. Nikolaidis et al. (326) recently demonstrated that a continuous infusion of the insulinomimetic glucagon-like peptide-1 (GLP-1) over a 2-day period improved LV function and increased myocardial glucose uptake in conscious dogs with advanced pacing-induced HF (326). Moreover, treatment with GLP-1 increased myocardial glucose uptake and increased LV mechanical efficiency (327).

Taken together, there is evidence from small clinical and animal studies to support the concept that acutely stimulating myocardial carbohydrate oxidation and inhibiting myocardial fatty acid oxidation can rapidly improve LV function and mechanical efficiency. The cellular mechanisms responsible for this effect are unclear but are likely due to the various effects described in section ${ }_{\mathrm{II}} F$. While the clinical data are intriguing, they are not definitive, and large-scale controlled clinical trials are needed before conclusions regarding clinical benefit can be drawn.

\section{B. Long-Term Metabolic Therapy to Slow Heart Failure Progression and Improve Function}

Chronic inhibition of myocardial FFA oxidation has been investigated with the fatty acid oxidation inhibitor trimetazidine (105) in HF patients $(23,115,373)$ and rodent models (88a, 446). Trimetazidine is an effective generic antianginal drug used extensively outside of North America $(78,254,427,435,445)$ and is a potent and selective inhibitor of long-chain 3-ketoacyl thiolase (207, 268). In addition, studies in rats and isolated myocytes show that trimetazidine alters myocardial phospholipid metabolism, stimulating the turnover and accumulation of long-chain fatty acids into phospholipid $(413,414)$, decreasing the fraction of phospholipids containing linoleic acid, and increasing the content of phospholipids comprised of oleic and stearic acids (415). Studies in cardiomyopathic Syrian hamsters (a HF model with severely decreased PDH activity; Ref. 89) found that chronic treatment with trimetazidine extended the average survival 
time on treatment from 364 to 560 days (88a). At the time this study was performed, trimetazidine was not known to be an inhibitor of fatty acid oxidation; therefore, the relationship between metabolic alterations and HF progression was not investigated.

A small clinical trial showed that 2 mo of treatment with trimetazidine resulted in significant improvement in LV ejection fraction at rest and enhanced LV wall motion during a dobutamine stress test compared with placebo in NYHA classes II and III HF patients (23). In two recent small clinical studies trimetazidine was shown to improve systolic LV function in patients with diabetes and ischemic cardiomyopathy compared with placebo $(115,373)$. Interestingly, 6 mo of trimetazidine improved diastolic function, as assessed by an increase in the peak E/A ratio on mitral flow (from $0.68 \pm 0.1$ to $0.89 \pm 0.3$ ), while there was no change in the patients treated with placebo (373). Trimetazidine has not been evaluated in patients with $\mathrm{HF}$ from other than an ischemic origin, nor have large-scale clinical trials been conducted.

Another approach to suppression of myocardial fatty acid oxidation is inhibition of CPT-I. Studies by Rupp and co-workers $(376-378,466,515)$ demonstrated that chronic treatment with etomoxir to rats with LV hypertrophy secondary to aortic banding results in improved LV function and sarcoplasmic $\mathrm{Ca}^{2+}$ handling, increased expression of SERCA2, and attenuated the transition from compensated to failing cardiac hypertrophy. We recently tested the hypothesis that pharmacological inhibition of CPT-I with oxfenicine can prevent ventricular remodeling and slow the progression of pacing-induced HF in dogs (259). Treatment with oxfenicine significantly attenuated $\mathrm{LV}$ dilation and hemodynamic dysfunction at 28 days of pacing (Fig. 8) and significantly extended the duration of pacing needed to reach terminal failure (LV end-diastolic pressure $=25 \mathrm{mmHg}$ ). In addition, oxfenicine completely prevented LV wall thinning and the activation of matrix metalloproteinases. Interestingly, inhibition of CPT-I resulted in increased expression of PPAR- $\alpha$ regulated genes and prevented the HF-induced fall in the mRNA for metabolic enzymes. As recently noted by Rupp and co-workers $(378,514)$, inhibition of CPT-I results in not only a reduction in the rate of myocardial fatty acid oxidation, but may also simultaneous stimulate the $\operatorname{PPAR} \alpha / \operatorname{RXR} \alpha$ complex through the build up of long-chain fatty acyl-CoA in the cytosol. This could result in a paradoxical stimulation of the expression of the enzymes of fatty acid oxidation but decrease flux through the pathway. Rupp and co-workers $(377,378)$ noted that inhibition of CPT-I in rats with aortic banding partially prevented both the contractile dysfunction and the downregulation of SERCA2, which they speculated could be due to $\operatorname{PPAR} \alpha / \operatorname{RXR} \alpha$ regulation of SERCA2 expression, noting similarities between the SERCA2 regulatory region and the PPAR $\alpha$ response element (PPRE). Thus chronic inhibition of myo-
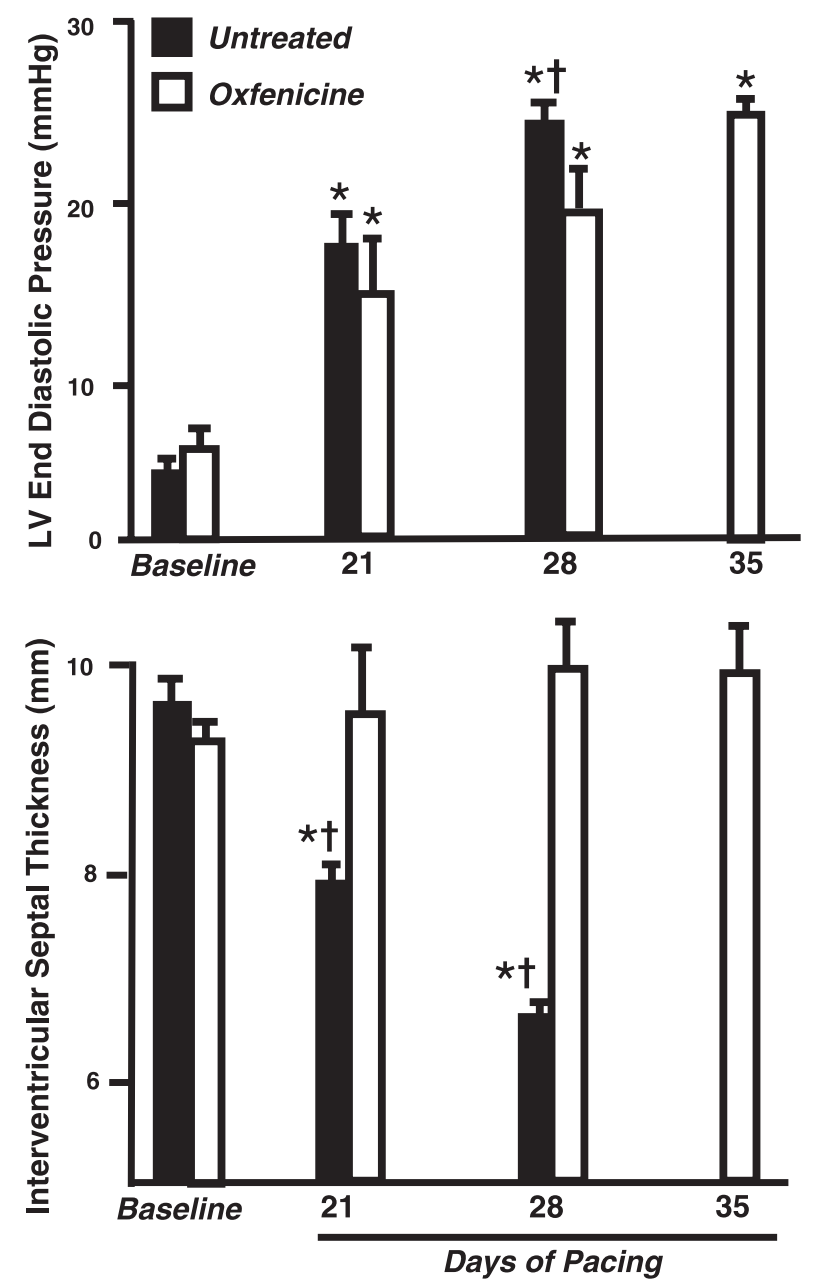

FIG. 8. Effects of the CPT-I inhibitor oxfenicine $(60 \mathrm{mg} / \mathrm{kg}$ po once daily) on left ventricular (LV) end-diastolic pressure (top) and enddiastolic interventricular septal thickness (bottom) in dogs subjected to rapid pacing-induced heart failure. Treatment was initiated on the first day of pacing. $* P<0.05$ compared with baseline. $\dagger P<0.05$ compared with oxfenicine-treated group at the same time point. [Drawn from data presented in Lionetti et al. (259).]

cardial fatty acid oxidation at the level of CPT-I in HF could have very different results than a similar suppression of fatty acid oxidation with trimetazidine (which acts directly on mitochondrial fatty acid $\beta$-oxidation at the level of long-chain 3-keto-acylthiolase). The effects of CPT-I inhibition with etomoxir were assessed in an open label pilot study in class II-III HF patients, showing improved LV function and exercise performance following 3 mo of treatment $(38,405)$. The results of controlled trials with CPT-I inhibitors have not been reported.

Conceptually, another means to switch substrate metabolism would be to directly stimulate glucose uptake or pyruvate oxidation; however, pharmacological agents are not currently available for the chronic inhibition of PDK, or activation of glucose transport or glycolysis. Studies in transgenic mice provide insight for the potential for this approach. Cardiac specific overexpression of GLUT-1 pre- 
vented $L V$ dysfunction in response to ascending aortic constriction and reduced mortality and depletion of high energy phosphates (256), and GLUT-4 ablation in mice results in LV hypertrophy (1). These results suggest that pharmacological activation of carbohydrate oxidation has potential as a drug target for the treatment of HF.

Dietary supplementation with either coenzyme Q or carnitine has been proposed for the treatment of HF. Acute and chronic administration of carnitine can increase glucose oxidation in the isolated perfused rat heart by increasing the acetylcarnitine concentration and decreasing the acetyl-CoA concentration, and thus relieving acetyl-CoA inhibition on PDH (see Fig. 3) (40, 407). A randomized double-blind trial in 472 myocardial infarction patients showed that oral carnitine therapy ( $6 \mathrm{~g} /$ day) initiated within $24 \mathrm{~h}$ after the onset of chest pain failed to effect clinical outcome or LV injection fraction over the course of 1 yr of treatment; however, it did significantly reduce the rate of increase in the $L V$ end-diastolic volume (187). Controlled trials in HF patients have not been reported. The rationale for supplementation with coenzyme $\mathrm{Q}$ is that this will overcome possible lesions in the $\mathrm{ETC}$, as discussed in section $\mathrm{IV} B$. While improved LV function was suggested in small uncontrolled trials in $\mathrm{HF}$ patients $(191,387)$, a double-blind crossover trial of oral coenzyme $\mathrm{Q}$ versus placebo in $32 \mathrm{HF}$ patients (LV ejection fraction of $26 \%$ ) showed that 3 mo with oral coenzyme Q did not affect resting LV systolic function or the patient's quality of life despite more than a doubling of the plasma levels of coenzyme $Q$ (484).

Long-term $\beta$-adrenergic receptor antagonists reduce mortality and improve LV function in HF patients (39, 168), and in clinical studies this improvement is associated with a switch in myocardial metabolism away from fatty acid uptake and oxidation towards more glucose uptake and carbohydrate oxidation (100, 101, 480), and greater lactate uptake (5). The mechanisms for these effects are not known, nor have they been demonstrated in large-scale clinical trials. We observed that 3 mo of metoprolol treatment in dogs with coronary microembolization-induced heart failure improved LV function and a significant $28 \%$ decrease in CPT-I activity (337), suggesting that the shift in substrate metabolism observed in the clinical studies could be due to downregulation of this enzyme.

Despite the clear beneficial effects of angiotensin converting enzyme inhibitors and angiotensin receptor antagonists in slowing the progression of $\mathrm{HF}$, there are little data on the metabolic consequences of suppression of the effects of angiotensin in HF. Indirect measurement of myocardial fatty acid metabolism using noninvasive imaging of the fatty acid analog BMIPP shows that HF patients have less cardiac accumulation of BMIPP and a faster washout rate from the myocardium than in healthy controls and that 6 mo of treatment with either enalipril or candesartan improved cardiac function and increases the accumulation and slows the rate of BMIPP washout $(450,502)$, suggestive of greater fatty acid uptake and clearance after treatment. The interpretation of these findings is complicated by difficulties in quantitatively relating BMIPP kinetics to myocardial fatty acid uptake and oxidation $(228,234,363)$. Nevertheless, these findings are consistent with the idea that improvement in cardiac function following chronic suppression of the renin-angiotensin system also alters myocardial fatty acid metabolism; however, it is not possible to draw a conclusion on the nature of these alterations.

Studies in infarct-induced HF in the rat show a decrease in myocardial ATP and creatine phosphate and in $\mathrm{ADP}$ stimulated respiration and that treatment with either an angiotensin converting enzyme inhibitor or angiotensin receptor antagonist partially prevents this defect (397399). Lygate et al. (280) recently used this model to compare the effects of chronic treatment with the PPAR $\gamma$ activator rosiglitazone, captopril, and rosiglitazone plus captopril for $8 \mathrm{wk}$ after infarction (280). LV ejection fraction was moderately but significantly increased by rosiglitazone treatment, and the increase in LV end-diastolic pressures and reduced $+\mathrm{dP} / \mathrm{d} t(\max )$ was partially prevented by rosiglitazone treatment either alone or in combination with captopril. On the other hand, captopril prevented LV dilatation when given alone or in combination with rosiglitazone, while rosiglitozone alone did not. Importantly, mortality at 8 wk was 26 and 19\% for the rosiglitazone and rosiglitazone plus captopril groups, respectively. Clinically, PPAR $\gamma$ agonists are associated with edema in HF patients and are generally contraindicated $(455,481)$. Further study is required before the effects of pharmacological stimulation of the various PPARs on cardiac function, remodeling, and progression in HF are understood.

\section{CONCLUSIONS}

The alterations in myocardial substrate metabolism that occur in $\mathrm{HF}$, and the causes and consequences of these abnormalities, are poorly understood. There is evidence to suggest that impaired substrate metabolism contributes to contractile dysfunction and to the progressive $\mathrm{LV}$ remodeling that are characteristic of the HF state. The general concept that has recently emerged is that myocardial substrate selection is relatively normal during the early stages of HF; however, in the advanced stages there is a downregulation in fatty acid oxidation, increased glycolysis and glucose oxidation, reduced respiratory chain activity, and an impaired reserve for mitochondrial oxidative flux. While recent work has described many of the molecular mechanisms responsible for the changes in myocardial metabolic phenotype that occur during nor- 
mal physiology (e.g., maturation or fasting), we continue to have a poor understanding of the regulatory mechanisms that affect changes in the expression of metabolic proteins over the course of HF. Initial pharmacological studies suggest that manipulation of myocardial substrate metabolism has therapeutic potential for the treatment of HF. Taken together, we are just beginning to understand the complex role of energy substrate metabolism in HF, and there is a clear need for extensive work in this clinically important area.

\section{ACKNOWLEDGEMENTS}

We thank Dr. Margaret Chandler for critical review of the manuscript and Margaret Chwascinska-Sharel for assistance with the illustrations.

Address for reprint requests and other correspondence: W. C. Stanley, Dept. of Physiology and Biophysics, School of Medicine, Case Western Reserve University, 10900 Euclid Ave., Cleveland, OH 44106-4970 (E-mail: wcs4@case.edu).

\section{GRANTS}

W. C. Stanley and F. A. Recchia were supported by National Heart, Lung, and Blood Institute Grant PO1-HL-74237. G. D. Lopaschuk is a Medical Scientist of the Alberta Heritage Foundation for Medical Research and was supported by the Canadian Institutes of Health.

\section{DISCLOSURES}

W. C. Stanley: CV Therapeutics, consultant and recipient of research funding related to ranolazine; Servier, paid speaker and consultant on trimetazidine. G. D. Lopaschuk: Metabolic Modulators Research Ltd., president and major stock holder; Servier, paid speaker and consultant on trimetazidine.

\section{REFERENCES}

1. Abel ED, Kaulbach HC, Tian R, Hopkins JC, Duffy J, Doetschman T, Minnemann T, Boers ME, Hadro E, ObersteBerghaus C, Quist W, Lowell BB, Ingwall JS, and Kahn BB. Cardiac hypertrophy with preserved contractile function after selective deletion of GLUT4 from the heart. J Clin Invest 104: 1703$1714,1999$.

2. Abu-Elheiga L, Matzuk MM, Abo-Hashema KA, and Wakil SJ. Continuous fatty acid oxidation and reduced fat storage in mice lacking acetyl-CoA carboxylase 2. Science 291: 2613-2616, 2001.

3. Abu-Erreish GM, Neely JR, Whitmer JT, Whitman V, and Sanadi DR. Fatty acid oxidation by isolated perfused working hearts of aged rats. Am J Physiol Endocrinol Metab Gastrointest Physiol 232: E258-E262, 1977.

4. Almeida A, Moncada S, and Bolanos JP. Nitric oxide switches on glycolysis through the AMP protein kinase and 6-phosphofructo2-kinase pathway. Nat Cell Biol 6: 45-51, 2004.

5. Andersson B, Blomstrom-Lundqvist C, Hedner T, and Waagstein F. Exercise hemodynamics and myocardial metabolism during long-term beta-adrenergic blockade in severe heart failure. J Am Coll Cardiol 18: 1059-1066, 1991.

6. Angeja BG and Grossman W. Evaluation and management of diastolic heart failure. Circulation 107: 659-663, 2003.

7. Anker SD, Negassa A, Coats AJ, Afzal R, Poole-Wilson PA, Cohn JN, and Yusuf S. Prognostic importance of weight loss in chronic heart failure and the effect of treatment with angiotensin- converting-enzyme inhibitors: an observational study. Lancet 361 : 1077-1083, 2003.

8. Arad M, Benson DW, Perez-Atayde AR, McKenna WJ, Sparks EA, Kanter RJ, McGarry K, Seidman JG, and Seidman CE. Constitutively active AMP kinase mutations cause glycogen storage disease mimicking hypertrophic cardiomyopathy. J Clin Invest 109: 357-362, 2002.

9. Arad M, Moskowitz IP, Patel VV, Ahmad F, Perez-Atayde AR, Sawyer DB, Walter M, Li GH, Burgon PG, Maguire CT, Stapleton D, Schmitt JP, Guo XX, Pizard A, Kupershmidt S, Roden DM, Berul CI, Seidman CE, and Seidman JG. Transgenic mice overexpressing mutant PRKAG2 define the cause of Wolff-Parkinson-White syndrome in glycogen storage cardiomyopathy. Circulation 107: 2850-2856, 2003.

10. Arnolda LF, Llewellyn-Smith IJ, and Minson JB. Animal models of heart failure. Aust $N Z$ J Med 29: 403-409, 1999.

11. Aschenbach WG, Brower GL, Talmadge RJ, Dobson JL, and Gladden LB. Effect of a myocardial volume overload on lactate transport in skeletal muscle sarcolemmal vesicles. Am J Physiol Regul Integr Comp Physiol 281: R176-R186, 2001.

12. Ashrafian H. Cardiac energetics in congestive heart failure. Circulation 105: e44-e45, 2002.

13. Augustus AS, Kako Y, Yagyu H, and Goldberg IJ. Routes of FA delivery to cardiac muscle: modulation of lipoprotein lipolysis alters uptake of TG-derived FA. Am J Physiol Endocrinol Metab 284: E331-E339, 2003.

14. Aurigemma GP and Gaasch WH. Clinical practice. Diastolic heart failure. N Engl J Med 351: 1097-1105, 2004.

15. Avogaro A, Nosadini R, Doria A, Fioretto P, Velussi M, Vigorito C, Sacca L, Toffolo G, Cobelli $\mathbf{C}$, and Trevisan $\mathbf{R}$. Myocardial metabolism in insulin-deficient diabetic humans without coronary artery disease. Am J Physiol Endocrinol Metab 258: E606-E618, 1990.

16. Bache RJ, Zhang J, Path G, Merkle H, Hendrich K, From AH, and Ugurbil K. High-energy phosphate responses to tachycardia and inotropic stimulation in left ventricular hypertrophy. Am J Physiol Heart Circ Physiol 266: H1959-H1970, 1994.

17. Balaban RS. Regulation of oxidative phosphorylation in the mammalian cell. Am J Physiol Cell Physiol 258: C377-C389, 1990.

18. Balaban RS, Kantor HL, Katz LA, and Briggs RW. Relation between work and phosphate metabolite in the in vivo paced mammalian heart. Science 232: 1121-1123, 1986.

19. Barakat H, Brown W, and Henry SD. Studies of fatty acid oxidation in homogenates of the cardiomyopathic hamster. Life Sci 23: 1835-1840, 1978.

20. Barger PM and Kelly DP. Fatty acid utilization in the hypertrophied and failing heart: molecular regulatory mechanisms. Am J Med Sci 318: 36-42, 1999.

21. Bashore TM, Magorien DJ, Letterio J, Shaffer P, and Unverferth DV. Histologic and biochemical correlates of left ventricular chamber dynamics in man. J Am Coll Cardiol 9: 734-742, 1987.

22. Beer M, Seyfarth T, Sandstede J, Landschutz W, Lipke C, Kostler H, von Kienlin M, Harre K, Hahn D, and Neubauer S. Absolute concentrations of high-energy phosphate metabolites in normal, hypertrophied, and failing human myocardium measured noninvasively with (31)P-SLOOP magnetic resonance spectroscopy. J Am Coll Cardiol 40: 1267-1274, 2002.

23. Belardinelli $\mathbf{R}$ and Purcaro A. Effects of trimetazidine on the contractile response of chronically dysfunctional myocardium to low-dose dobutamine in ischaemic cardiomyopathy. Eur Heart $J$ 22: 2164-2170, 2001.

24. Belke DD, Larsen TS, Lopaschuk GD, and Severson DL. Glucose and fatty acid metabolism in the isolated working mouse heart. Am J Physiol Regul Integr Comp Physiol 277: R1210-R1217, 1999.

25. Berger $\mathbf{J}$ and Moller DE. The mechanisms of action of PPARs. Annu Rev Med 53: 409-435, 2002.

26. Bergman G, Atkinson L, Metcalfe J, Jackson N, and Jewitt DE. Beneficial effect of enhanced myocardial carbohydrate utilisation after oxfenicine (L-hydroxyphenylglycine) in angina pectoris. Eur Heart J 1: 247-253, 1980. 
27. Bersin RM and Stacpoole PW. Dichloroacetate as metabolic therapy for myocardial ischemia and failure. Am Heart $J$ 134: 841-855, 1997.

28. Bersin RM, Wolfe C, Kwasman M, Lau D, Klinski C, Tanaka K, Khorrami P, Henderson GN, de Marco T, and Chatterjee K. Improved hemodynamic function and mechanical efficiency in congestive heart failure with sodium dichloroacetate. J Am Coll Cardiol 23: 1617-1624, 1994.

29. Bielefeld DR, Vary TC, and Neely JR. Inhibition of carnitine palmitoyl-CoA transferase activity and fatty acid oxidation by lactate and oxfenicine in cardiac muscle. J Mol Cell Cardiol 17: 619-625, 1985.

30. Bing RJ. The metabolism of the heart. Harvey Lect 50: 27-70, 1955.

31. Bing RJ, Siegel A, Vitale A, Taeschler M, Balboni FSE, Klappe M, and Edwards S. Metabolic studies on the human heart in vivo. I. Studies on carbohydrate metabolism of the human heart. Am J Med 15: 284-296, 1953.

32. Bing RJ, Siegel A, Ungar I, and Gilbert M. Metabolism of the human heart. II. Studies on fat, ketone and amino acid metabolism. Am J Med 16: 504-515, 1954

33. Bleumink GS, Knetsch AM, Sturkenboom MC, Straus SM, Hofman A, Deckers JW, Witteman JC, and Stricker BH. Quantifying the heart failure epidemic: prevalence, incidence rate, lifetime risk and prognosis of heart failure The Rotterdam Study. Eur Heart J 25: 1614-1619, 2004.

34. Borst PLJA, Christ EJ, and Slater EC. Uncoupling activity of long-chain fatty acids. Biochim Biophys Acta 62: 509-518, 1964.

35. Botker HE, Helligso P, Kimose HH, Thomassen AR, and Nielsen TT. Determination of high energy phosphates and glycogen in cardiac and skeletal muscle biopsies, with special reference to influence of biopsy technique and delayed freezing. Cardiovasc Res 28: 524-527, 1994.

36. Bowker-Kinley MM, Davis WI, Wu P, Harris RA, and Popov KM. Evidence for existence of tissue-specific regulation of the mammalian pyruvate dehydrogenase complex. Biochem $J$ 329: 191-196, 1998.

37. Brand MD, Brindle KM, Buckingham JA, Harper JA, Rolfe DF, and Stuart JA. The significance and mechanism of mitochondrial proton conductance. Int J Obes Relat Metab Disord 23 Suppl 6: S4-S11, 1999.

38. Bristow M. Etomoxir: a new approach to treatment of chronic heart failure. Lancet 356: 1621-1622, 2000.

39. Bristow MR, Gilbert EM, Abraham WT, Adams KF, Fowler MB, Hershberger RE, Kubo SH, Narahara KA, Ingersoll H, Krueger S, Young S, and Shusterman N. Carvedilol produces dose-related improvements in left ventricular function and survival in subjects with chronic heart failure. MOCHA Invest Circ 94: 2807-2816, 1996.

40. Broderick TL, Quinney HA, and Lopaschuk GD. Carnitine stimulation of glucose oxidation in the fatty acid perfused isolated working rat heart. J Biol Chem 267: 3758-3763, 1992.

41. Brown NF, Weis BC, Husti JE, Foster DW, and McGarry JD. Mitochondrial carnitine palmitoyltransferase I isoform switching in the developing rat heart. J Biol Chem 270: 8952-8957, 1995.

42. Brownsey RW, Boone AN, and Allard MF. Actions of insulin on the mammalian heart: metabolism, pathology and biochemical mechanisms. Cardiovasc Res 34: 3-24, 1997.

43. Brune B and Lapetina EG. Activation of a cytosolic ADP-ribosyltransferase by nitric oxide-generating agents. $J$ Biol Chem 264: 8455-8458, 1989.

44. Buchwald A, Till H, Unterberg C, Oberschmidt R, Figulla HR, and Wiegand V. Alterations of the mitochondrial respiratory chain in human dilated cardiomyopathy. Eur Heart $J$ 11: 509-516, 1990.

45. Budingen T. Uber die Moglichkeit einer Ernahrungsbehandlung des Herzmuskels durch Einbringen von Traubenzuckerlosunger in den grober Kreislauf. Dt Arch Klin Med 114: 534-579, 1914.

46. Bunger R, Mallet RT, and Hartman DA. Pyruvate-enhanced phosphorylation potential and inotropism in normoxic and postischemic isolated working heart. Near-complete prevention of reperfusion contractile failure. Eur J Biochem 180: 221-233, 1989.

47. Burkhoff D, Weiss RG, Schulman SP, Kalil-Filho R, Wannenburg $\mathbf{T}$, and Gerstenblith $\mathbf{G}$. Influence of metabolic substrate on rat heart function and metabolism at different coronary flows. Am J Physiol Heart Circ Physiol 261: H741-H750, 1991.

48. Campbell FM, Kozak R, Wagner A, Altarejos JY, Dyck JR, Belke DD, Severson DL, Kelly DP, and Lopaschuk GD. A role for peroxisome proliferator-activated receptor alpha (PPARalpha) in the control of cardiac malonyl-CoA levels: reduced fatty acid oxidation rates and increased glucose oxidation rates in the hearts of mice lacking PPARalpha are associated with higher concentrations of malonyl-CoA and reduced expression of malonyl-CoA decarboxylase. J Biol Chem 277: 4098-4103, 2002.

49. Casademont $\mathbf{J}$ and Miro $\mathbf{O}$. Electron transport chain defects in heart failure. Heart Failure Rev 7: 131-139, 2002.

50. Chaitman BR, Pepine CJ, Parker JO, Skopal J, Chumakova G, Kuch J, Wang W, Skettino SL, and Wolff AA. Effects of ranolazine with atenolol, amlodipine, or diltiazem on exercise tolerance and angina frequency in patients with severe chronic angina: a randomized controlled trial. JAMA 291: 309-316, 2004.

51. Chandler MP, Chavez PN, McElfresh TA, Huang H, Harmon CS, and Stanley WC. Partial inhibition of fatty acid oxidation increases regional contractile power and efficiency during demandinduced ischemia. Cardiovasc Res 59: 143-151, 2003.

52. Chandler MP, Kerner J, Huang H, Vazquez E, Reszko A, Martini WZ, Hoppel CL, Imai M, Rastogi S, Sabbah HN, and Stanley WC. Moderate severity heart failure does not involve a downregulation of myocardial fatty acid oxidation. Am J Physiol Heart Circ Physiol 287: H1538-H1543, 2004.

53. Chandler MP, Stanley WC, Morita H, Suzuki G, Roth BA, Blackburn B, Wolff A, and Sabbah HN. Short-term treatment with ranolazine improves mechanical efficiency in dogs with chronic heart failure. Circ Res 91: 278-280, 2002.

54. Chavez PN, Stanley WC, McElfresh TA, Huang H, Sterk JP, and Chandler MP. Effects of hyperglycemia and fatty acid oxidation inhibition during aerobic conditions and demand-induced ischemia. Am J Physiol Heart Circ Physiol H1521-H1527, 2003.

55. Cheema-Dhadli S, Robinson BH, and Halperin ML. Properties of the citrate transporter in rat heart: implications for regulation of glycolysis by cytosolic citrate. Can J Biochem 54: 561-565, 1976.

56. Chen V, Wagner G, and Spitzer JJ. Regulation of substrate oxidation in isolated myocardial cells by beta-hydroxybutyrate. Horm Metab Res 16: 243-247, 1984.

57. Chen ZP, Mitchelhill KI, Michell BJ, Stapleton D, RodriguezCrespo I, Witters LA, Power DA, Ortiz de Montellano PR, and Kemp BE. AMP-activated protein kinase phosphorylation of endothelial NO synthase. FEBS Lett 443: 285-289, 1999.

58. Cheng L, Ding G, Qin Q, Huang Y, Lewis W, He N, Evans RM, Schneider MD, Brako FA, Xiao Y, Chen YE, and Yang Q. Cardiomyocyte-restricted peroxisome proliferator-activated receptor-delta deletion perturbs myocardial fatty acid oxidation and leads to cardiomyopathy. Nat Med 10: 1245-1250, 2004.

59. Chiu HC, Kovacs A, Ford DA, Hsu FF, Garcia R, Herrero P, Saffitz JE, and Schaffer JE. A novel mouse model of lipotoxic cardiomyopathy. J Clin Invest 107: 813-822, 2001.

60. Clapham JC, Arch JR, Chapman H, Haynes A, Lister C, Moore GB, Piercy V, Carter SA, Lehner I, Smith SA, Beeley LJ, Godden RJ, Herrity N, Skehel M, Changani KK, Hockings PD, Reid DG, Squires SM, Hatcher J, Trail B, Latcham J, Rastan S, Harper AJ, Cadenas S, Buckingham JA, Brand MD, and Abuin A. Mice overexpressing human uncoupling protein-3 in skeletal muscle are hyperphagic and lean. Nature 406: 415-418, 2000.

61. Clarke B, Wyatt KM, and McCormack JG. Ranolazine increases active pyruvate dehydrogenase in perfused normoxic rat hearts: evidence for an indirect mechanism. J Mol Cell Cardiol 28: 341-350, 1996.

62. Cline GW, Vidal-Puig AJ, Dufour S, Cadman KS, Lowell BB, and Shulman GI. In vivo effects of uncoupling protein-3 gene disruption on mitochondrial energy metabolism. J Biol Chem 276: 20240-20244, 2001.

63. Coats AJ. Angiotensin type-1 receptor blockers in heart failure. Prog Cardiovasc Dis 44: 231-242, 2002.

64. Cohn JN, Pfeffer MA, Rouleau J, Sharpe N, Swedberg K, Straub M, Wiltse C, and Wright TJ. Adverse mortality effect of central sympathetic inhibition with sustained-release moxonidine 
in patients with heart failure (MOXCON). Eur $J$ Heart Failure 5: 659-667, 2003.

65. Coleman RA, Lewin TM, and Muoio DM. Physiological and nutritional regulation of enzymes of triacylglycerol synthesis. Annu Rev Nutr 20: 77-103, 2000.

66. Collins-Nakai RL, Noseworthy D, and Lopaschuk GD. Epinephrine increases ATP production in hearts by preferentially increasing glucose metabolism. Am J Physiol Heart Circ Physiol 267: H1862-H1871, 1994.

67. Colucci WS, Packer M, Bristow MR, Gilbert EM, Cohn JN, Fowler MB, Krueger SK, Hershberger R, Uretsky BF, Bowers JA, Sackner-Bernstein JD, Young ST, Holcslaw TL, and Lukas MA. Carvedilol inhibits clinical progression in patients with mild symptoms of heart failure. US Carvedilol Heart Failure Study Group. Circulation 94: 2800-2806, 1996.

68. Comte B, Vincent G, Bouchard B, Benderdour M, and des Rosiers C. Reverse flux through cardiac NADP $(+)$-isocitrate dehydrogenase under normoxia and ischemia. Am J Physiol Heart Circ Physiol 283: H1505-H1514, 2002.

69. Comte B, Vincent G, Bouchard B, and des Rosiers C. Probing the origin of acetyl-CoA and oxaloacetate entering the citric acid cycle from the ${ }^{13} \mathrm{C}$ labeling of citrate released by perfused rat hearts. J Biol Chem 272: 26117-26124, 1997.

70. Cottin Y, Lhuillier I, Gilson L, Zeller M, Bonnet C, Toulouse C, Louis P, Rochette L, Girard C, and Wolf JE. Glucose insulin potassium infusion improves systolic function in patients with chronic ischemic cardiomyopathy. Eur J Heart Failure 4: 181-184, 2002.

71. Coven DL, Hu X, Cong L, Bergeron R, Shulman GI, Hardie DG, and Young LH. Physiological role of AMP-activated protein kinase in the heart: graded activation during exercise. Am J Physiol Endocrinol Metab 285: E629-E636, 2003.

72. Crass MF III. Exogenous substrate effects on endogenous lipid metabolism in the working rat heart. Biochim Biophys Acta 280: 71-81, 1972.

73. Crass MF III. Heart triglyceride and glycogen metabolism: effects of catecholamines, dibutyryl cyclic AMP, theophylline, and fatty acids. Rec Adv Stud Cardiac Struct Metab 3: 275-290, 1973.

74. Crass MF III. Regulation of triglyceride metabolism in the isotopically prelabeled perfused heart. Federation Proc 36: 1995-1999, 1977.

75. Crass MF III and Shipp JC. Metabolism of exogenous and endogenous fatty acids in heart muscle. Rec Adv Stud Cardiac Struct Metab 1: 115-126, 1972.

76. Crass MF III, Shipp JC, and Pieper GM. Effects of catecholamines on myocardial endogenous substrates and contractility. Am J Physiol 228: 618-627, 1975.

78. Dalla-Volta S, Maraglino G, Della-Valentina P, Viena $\mathbf{P}$, and Desideri A. Comparison of trimetazidine with nifedipine in effort angina: a double-blind, crossover study. Cardiovasc Drugs Ther 4 Suppl 4: 853-859, 1990.

79. Davila-Roman VG, Vedala G, Herrero P, de las FL, Rogers JG, Kelly DP, and Gropler RJ. Altered myocardial fatty acid and glucose metabolism in idiopathic dilated cardiomyopathy. $\mathrm{J} \mathrm{Am}$ Coll Cardiol 40: 271-277, 2002.

80. Davos CH, Doehner W, Rauchhaus M, Cicoira M, Francis DP, Coats AJ, Clark AL, and Anker SD. Body mass and survival in patients with chronic heart failure without cachexia: the importance of obesity. J Cardiac Failure 9: 29-35, 2003.

81. De las FL, Herrero P, Peterson LR, Kelly DP, Gropler RJ, and Davila-Roman VG. Myocardial fatty acid metabolism: independent predictor of left ventricular mass in hypertensive heart disease. Hypertension 41: 83-87, 2003.

82. Denton RM and Randle PJ. Concentrations of glycerides and phospholipids in rat heart and gastrocnemius muscles. Effects of alloxan-diabetes and perfusion. Biochem J 104: 416-422, 1967.

83. Depre C, Gaussin V, Ponchaut S, Fischer Y, Vanoverschelde JL, and Hue L. Inhibition of myocardial glucose uptake by cGMP. Am J Physiol Heart Circ Physiol 274: H1443-H1449, 1998.

84. Depre $\mathbf{C}$ and Hue L. Cyclic GMP in the perfused rat heart. Effect of ischaemia, anoxia and nitric oxide synthase inhibitor. FEBS Lett 345: 241-245, 1994.
85. Depre C, Rider MH, and Hue L. Mechanisms of control of heart glycolysis. Eur J Biochem 258: 277-290, 1998.

86. Depre C, Shipley GL, Chen W, Han Q, Doenst T, Moore ML, Stepkowski S, Davies PJ, and Taegtmeyer H. Unloaded heart in vivo replicates fetal gene expression of cardiac hypertrophy. Nat Med 4: 1269-1275, 1998.

87. Depre C, Vanoverschelde JL, Goudemant JF, Mottet I, and Hue L. Protection against ischemic injury by nonvasoactive concentrations of nitric oxide synthase inhibitors in the perfused rabbit heart. Circulation 92: 1911-1918, 1995.

88. De Sousa E, Veksler V, Minajeva A, Kaasik A, Mateo P, Mayoux E, Hoerter $J$, Bigard $X$, Serrurier $B$, and VenturaClapier R. Subcellular creatine kinase alterations. Implications in heart failure. Circ Res 85: 68-76, 1999.

88a.D'Hahan N, Taouil K, Dassouli A, and Morel JE. Long-term therapy with trimetazidine in cardiomyopathic Syrian hamster BIO 14:6. Eur J Pharmacol 328: 163-174, 1997.

89. Di Lisa F, Fan CZ, Gambassi G, Hogue BA, Kudryashova I, and Hansford RG. Altered pyruvate dehydrogenase control and mitochondrial free $\mathrm{Ca}^{2+}$ in hearts of cardiomyopathic hamsters. $\mathrm{Am} J$ Physiol Heart Circ Physiol 264: H2188-H2197, 1993.

90. Dimmeler S and Brune B. Characterization of a nitric-oxidecatalysed ADP-ribosylation of glyceraldehyde-3-phosphate dehydrogenase. Eur J Biochem 210: 305-310, 1992.

91. Dimmeler S, Lottspeich F, and Brune B. Nitric oxide causes ADP-ribosylation and inhibition of glyceraldehyde-3-phosphate dehydrogenase. J Biol Chem 267: 16771-16774, 1992.

92. Dyck JR, Barr AJ, Barr RL, Kolattukudy PE, and Lopaschuk GD. Characterization of cardiac malonyl-CoA decarboxylase and its putative role in regulating fatty acid oxidation. Am J Physiol Heart Circ Physiol 275: H2122-H2129, 1998.

93. Dyck JR, Cheng JF, Stanley WC, Barr R, Chandler MP, Brown S, Wallace D, Arrhenius T, Harmon C, Yang G, Nadzan AM, and Lopaschuk GD. Malonyl coenzyme a decarboxylase inhibition protects the ischemic heart by inhibiting fatty acid oxidation and stimulating glucose oxidation. Circ Res 94: e78-e84, 2004.

94. Dyck JR, Kudo N, Barr AJ, Davies SP, Hardie DG, and Lopaschuk GD. Phosphorylation control of cardiac acetyl-CoA carboxylase by cAMP-dependent protein kinase and 5'-AMP activated protein kinase. Eur J Biochem 262: 184-190, 1999.

95. Dyck JR and Lopaschuk GD. Malonyl CoA control of fatty acid oxidation in the ischemic heart. J Mol Cell Cardiol 34: 1099-1109, 2002.

96. Dyson E, Sucov HM, Kubalak SW, Schmid-Schonbein GW, DeLano FA, Evans RM, Ross J Jr, and Chien KR. Atrial-like phenotype is associated with embryonic ventricular failure in retinoid X receptor alpha -/- mice. Proc Natl Acad Sci USA 92: 7386-7390, 1995.

97. Dzeja PP, Pucar D, Redfield MM, Burnett JC, and Terzic A. Reduced activity of enzymes coupling ATP-generating with ATPconsuming processes in the failing myocardium. Mol Cell Biochem 201: 33-40, 1999.

98. Dzeja PP, Redfield MM, Burnett JC, and Terzic A. Failing energetics in failing hearts. Curr Cardiol Rep 2: 212-217, 2000.

99. Dzeja PP, Vitkevicius KT, Redfield MM, Burnett JC, and Terzic A. Adenylate kinase-catalyzed phosphotransfer in the myocardium: increased contribution in heart failure. Circ Res 84: 11371143, 1999.

100. Eichhorn EJ, Bedotto JB, Malloy CR, Hatfield BA, Deitchman D, Brown M, Willard JE, and Grayburn PA. Effect of betaadrenergic blockade on myocardial function and energetics in congestive heart failure. Improvements in hemodynamic, contractile, and diastolic performance with bucindolol. Circulation 82: 473483, 1990.

101. Eichhorn EJ, Heesch CM, Barnett JH, Alvarez LG, Fass SM, Grayburn PA, Hatfield BA, Marcoux LG, and Malloy CR. Effect of metoprolol on myocardial function and energetics in patients with nonischemic dilated cardiomyopathy: a randomized, double-blind, placebo-controlled study. J Am Coll Cardiol 24: 1310-1320, 1994.

102. England PJ and Robinson BH. The permeability of rat heart mitochondria to citrate. Biochem J 112: 8P, 1969. 
103. Entman ML, Bornet EP, van Winkle WB, Goldstein MA, and Schwartz A. Association of glycogenolysis with cardiac sarcoplasmic reticulum. II. Effect of glycogen depletion, deoxycholate solubilization and cardiac ischemia: evidence for a phorphorylase kinase membrane complex. J Mol Cell Cardiol 9: 515-528, 1977.

104. Fannin SW, Lesnefsky EJ, Slabe TJ, Hassan MO, and Hoppel CL. Aging selectively decreases oxidative capacity in rat heart interfibrillar mitochondria. Arch Biochem Biophys 372: 399-407, 1999.

105. Fantini E, Demaison L, Sentex E, Grynberg A, and Athias P. Some biochemical aspects of the protective effect of trimetazidine on rat cardiomyocytes during hypoxia and reoxygenation. $J \mathrm{Mol}$ Cell Cardiol 26: 949-958, 1994.

106. Fell DA. Increasing the flux in metabolic pathways: a metabolic control analysis perspective. Biotechnol Bioeng 58: 121-124, 1998.

107. Fell DA and Sauro HM. Metabolic control analysis. The effects of high enzyme concentrations. Eur J Biochem 192: 183-187, 1990.

108. Ferrannini E, Santoro D, Bonadonna R, Natali A, Parodi O, and Camici PG. Metabolic and hemodynamic effects of insulin on human hearts. Am J Physiol Endocrinol Metab 264: E308-E315, 1993.

109. Finck BN, Han X, Courtois M, Aimond F, Nerbonne JM, Kovacs $A$, Gross RW, and Kelly DP. A critical role for PPARalphamediated lipotoxicity in the pathogenesis of diabetic cardiomyopathy: modulation by dietary fat content. Proc Natl Acad Sci USA 100: 1226-1231, 2003.

110. Fisher DJ, Heymann MA, and Rudolph AM. Myocardial oxygen and carbohydrate consumption in fetal lambs in utero and in adult sheep. Am J Physiol Heart Circ Physiol 238: H399-H405, 1980.

111. Fisher DJ, Heymann MA, and Rudolph AM. Myocardial consumption of oxygen and carbohydrates in newborn sheep. Pediatr Res 15: 843-846, 1981.

112. Fisher DJ, Heymann MA, and Rudolph AM. Regional myocardial blood flow and oxygen delivery in fetal, newborn, and adult sheep. Am J Physiol Heart Circ Physiol 243: H729-H731, 1982.

113. Fontaine KR, Redden DT, Wang C, Westfall AO, and Allison DB. Years of life lost due to obesity. JAMA 289: 187-193, 2003.

114. Forsey RG, Reid K, and Brosnan JT. Competition between fatty acids and carbohydrate or ketone bodies as metabolic fuels for the isolated perfused heart. Can J Physiol Pharmacol 65: 401-406, 1987.

115. Fragasso G, Piatti Md PM, Monti L, Palloshi A, Setola E, Puccetti P, Calori G, Lopaschuk GD, and Margonato A. Shortand long-term beneficial effects of trimetazidine in patients with diabetes and ischemic cardiomyopathy. Am Heart J 146: E18, 2003.

116. From AH. Should manipulation of myocardial substrate utilization patterns be a component of the congestive heart failure therapeutic paradigm? J Card Fail 4: 127-129, 1998.

117. Gaasch WH and Zile MR. Left ventricular diastolic dysfunction and diastolic heart failure. Annu Rev Med 55: 373-394, 2004.

118. Garcia CK, Goldstein JL, Pathak RK, Anderson RG, and Brown MS. Molecular characterization of a membrane transporter for lactate, pyruvate, and other monocarboxylates: implications for the Cori cycle. Cell 76: 865-873, 1994.

119. Garland PB, Randle PJ, and Newsholme EA. Citrate as an intermediary in the inhibition of phosphofructokinase in rat heart muscle by fatty acids, ketone bodies, pyruvate, diabetes, and starvation. Nature 200: 169-170, 1963.

120. Garlid KD, Jaburek M, and Jezek P. The mechanism of proton transport mediated by mitochondrial uncoupling proteins. FEBS Lett 438: 10-14, 1998.

121. Garlid KD, Jaburek M, and Jezek P. Mechanism of uncoupling protein action. Biochem Soc Trans 29: 803-806, 2001.

122. Garlid KD, Jaburek M, Jezek P, and Varecha M. How do uncoupling proteins uncouple? Biochim Biophys Acta 1459: 383389, 2000.

123. Garlid KD, Orosz DE, Modriansky M, Vassanelli S, and Jezek P. On the mechanism of fatty acid-induced proton transport by mitochondrial uncoupling protein. J Biol Chem 271: 2615-2620, 1996.

124. Garnier A, Fortin D, Delomenie C, Momken I, Veksler V, and Ventura-Clapier R. Depressed mitochondrial transcription fac- tors and oxidative capacity in rat failing cardiac and skeletal muscles. J Physiol 551: 491-501, 2003.

125. Gertz EW, Wisneski JA, Neese R, Bristow JD, Searle GL, and Hanlon JT. Myocardial lactate metabolism: evidence of lactate release during net chemical extraction in man. Circulation 63: 1273-1279, 1981.

126. Gertz EW, Wisneski JA, Stanley WC, and Neese RA. Myocardial substrate utilization during exercise in humans. Dual carbonlabeled carbohydrate isotope experiments. J Clin Invest 82: 20172025, 1988

127. Gibala MJ, Young ME, and Taegtmeyer H. Anaplerosis of the citric acid cycle: role in energy metabolism of heart and skeletal muscle. Acta Physiol Scand 168: 657-665, 2000.

128. Gibbs CL. Cardiac energetics. Physiol Rev 58: 174-254, 1978.

129. Gilde AJ, Van Der Lee KA, Willemsen PH, Chinetti G, Van Der Leij FR, van der Vusse GJ, Staels B, and van Bilsen M. Peroxisome proliferator-activated receptor (PPAR) $\alpha$ and $\mathrm{PPAR} \beta / \delta$, but not PPAR $\gamma$, modulate the expression of genes involved in cardiac lipid metabolism. Circ Res 92: 518-524, 2003.

130. Girard J, Ferre P, Pegorier JP, and Duee PH. Adaptations of glucose and fatty acid metabolism during perinatal period and suckling-weaning transition. Physiol Rev 72: 507-562, 1992.

131. Glatz JF, Luiken JJ, and Bonen A. Involvement of membraneassociated proteins in the acute regulation of cellular fatty acid uptake. J Mol Neurosci 16: 123-132, 2001.

132. Glatz JF and Veerkamp JH. Postnatal development of palmitate oxidation and mitochondrial enzyme activities in rat cardiac and skeletal muscle. Biochim Biophys Acta 711: 327-335, 1982.

133. Goldfarb AH, Bruno JF, and Buckenmeyer PJ. Intensity and duration effects of exercise on heart cAMP, phosphorylase, and glycogen. J Appl Physiol 60: 1268-1273, 1986.

134. Gollob MH. Glycogen storage disease as a unifying mechanism of disease in the PRKAG2 cardiac syndrome. Biochem Soc Trans 31: 228-231, 2003.

135. Gollob MH, Seger JJ, Gollob TN, Tapscott T, Gonzales O, Bachinski L, and Roberts R. Novel PRKAG2 mutation responsible for the genetic syndrome of ventricular preexcitation and conduction system disease with childhood onset and absence of cardiac hypertrophy. Circulation 104: 3030-3033, 2001.

136. Gong G, Liu J, Liang P, Guo T, Hu Q, Ochiai K, Hou M, Ye Y, Wu X, Mansoor A, From AH, Ugurbil K, Bache RJ, and Zhang J. Oxidative capacity in failing hearts. Am J Physiol Heart Circ Physiol 285: H541-H548, 2003.

137. Goodwin GW and Taegtmeyer H. Regulation of fatty acid oxidation of the heart by MCD and ACC during contractile stimulation. Am J Physiol Endocrinol Metab 277: E772-E777, 1999.

138. Goodwin GW and Taegtmeyer H. Improved energy homeostasis of the heart in the metabolic state of exercise. Am J Physiol Heart Circ Physiol 279: H1490-H1501, 2000.

139. Goodwin GW, Taylor CS, and Taegtmeyer H. Regulation of energy metabolism of the heart during acute increase in heart work. J Biol Chem 273: 29530-29539, 1998.

140. Goulston A. The beneficial effect of ingestion of cane sugar in certain forms of heart disease. Br J Med i: 615,1911

141. Guth BD, Wisneski JA, Neese RA, White FC, Heusch G, Mazer CD, and Gertz EW. Myocardial lactate release during ischemia in swine. Relation to regional blood flow. Circulation 81: 1948-1958, 1990.

142. Hacker TA, Renstrom B, Paulson D, Liedtke AJ, and Stanley WC. Ischemia produces an increase in ammonia output in swine myocardium. Cardioscience 5: 255-260, 1994.

143. Hall JL, Lopaschuk GD, Barr A, Bringas J, Pizzurro RD, and Stanley WC. Increased cardiac fatty acid uptake with dobutamine infusion in swine is accompanied by a decrease in malonyl CoA levels. Cardiovasc Res 32: 879-885, 1996.

144. Hall JL, Mazzeo RS, Podolin DA, Cartee GD, and Stanley WC. Exercise training does not compensate for age-related decrease in myocardial GLUT-4 content. J Appl Physiol 76: 328-332, 1994.

145. Hall JL, Stanley WC, Lopaschuk GD, Wisneski JA, Pizzurro RD, Hamilton CD, and McCormack JG. Impaired pyruvate oxidation but normal glucose uptake in diabetic pig heart during dobutamine-induced work. Am J Physiol Heart Circ Physiol 271: H2320-H2329, 1996 
146. Hamilton C and Saggerson ED. Malonyl-CoA metabolism in cardiac myocytes. Biochem $J$ 350: 61-67, 2000.

147. Hansford RG and Castro F. Age-linked changes in the activity of enzymes of the tricarboxylate cycle and lipid oxidation, and of carnitine content, in muscles of the rat. Mech Ageing Dev 19: 191-200, 1982.

148. Hansford RG and Cohen L. Relative importance of pyruvate dehydrogenase interconversion and feed-back inhibition in the effect of fatty acids on pyruvate oxidation by rat heart mitochondria. Arch Biochem Biophys 191: 65-81, 1978.

149. Hansson A, Hance N, Dufour E, Rantanen A, Hultenby K, Clayton DA, Wibom R, and Larsson NG. A switch in metabolism precedes increased mitochondrial biogenesis in respiratory chaindeficient mouse hearts. Proc Natl Acad Sci USA 101: 3136-3141, 2004.

150. Harris RA, Huang B, and Wu P. Control of pyruvate dehydrogenase kinase gene expression. Adv Enzyme Regul 41: 269-288, 2001.

151. Hasenfuss G, Maier LS, Hermann HP, Luers C, Hunlich M, Zeitz O, Janssen PM, and Pieske B. Influence of pyruvate on contractile performance and $\mathrm{Ca}(2+)$ cycling in isolated failing human myocardium. Circulation 105: 194-199, 2002.

152. Hasselbaink DM, Glatz JF, Luiken JJ, Roemen TH, and van der Vusse GJ. Ketone bodies disturb fatty acid handling in isolated cardiomyocytes derived from control and diabetic rats. Biochem $J$ 371: 753-760, 2003.

153. Heineman FW and Balaban RS. Control of mitochondrial respiration in the heart in vivo. Annu Rev Physiol 52: 523-542, 1990.

154. Helmer GA, McKirnan MD, Shabetai R, Boss GR, Ross J Jr, and Hammond HK. Regional deficits of myocardial blood flow and function in left ventricular pacing-induced heart failure. Circulation 94: 2260-2267, 1996.

155. Henning SL, Wambolt RB, Schonekess BO, Lopaschuk GD, and Allard MF. Contribution of glycogen to aerobic myocardial glucose utilization. Circulation 93: 1549-1555, 1996.

156. Henry CG, Strauss AW, Keating JP, and Hillman RE. Congestive cardiomyopathy associated with beta-ketothiolase deficiency. J Pediatr 99: 754-757, 1981.

157. Hermann HP. Energetic stimulation of the heart. Cardiovasc Drugs Ther 15: 405-411, 2001.

158. Hermann HP, Arp J, Pieske B, Kogler H, Baron S, Janssen PM, and Hasenfuss G. Improved systolic and diastolic myocardial function with intracoronary pyruvate in patients with congestive heart failure. Eur J Heart Fail 6: 213-218, 2004.

159. Hermann HP, Pieske B, Schwarzmuller E, Keul J, Just H, and Hasenfuss G. Haemodynamic effects of intracoronary pyruvate in patients with congestive heart failure: an open study. Lancet 353: 1321-1323, 1999.

160. Hermann HP, Zeitz O, Keweloh B, Hasenfuss G, and Janssen PM. Pyruvate potentiates inotropic effects of isoproterenol and $\mathrm{Ca}(2+)$ in rabbit cardiac muscle preparations. Am J Physiol Heart Circ Physiol 279: H702-H708, 2000.

161. Hermann HP, Zeitz O, Lehnart SE, Keweloh B, Datz N, Hasenfuss G, and Janssen PM. Potentiation of beta-adrenergic inotropic response by pyruvate in failing human myocardium. Cardiovasc Res 53: 116-123, 2002.

162. Hickson-Bick DL, Buja ML, and McMillin JB. Palmitate-mediated alterations in the fatty acid metabolism of rat neonatal cardiac myocytes. J Mol Cell Cardiol 32: 511-519, 2000.

163. Higgins AJ, Faccini JM, and Greaves P. Coronary hyperemia and cardiac hypertrophy following inhibition of fatty acid oxidation. Evidence of a regulatory role for cytosolic phosphorylation potential. Adv Myocardiol 6: 329-338, 1985.

164. Higgins AJ, Morville M, Burges RA, and Blackburn KJ. Mechanism of action of oxfenicine on muscle metabolism. Biochem Biophys Res Commun 100: 291-296, 1981.

165. Higgins AJ, Morville M, Burges RA, Gardiner DG, Page MG, and Blackburn KJ. Oxfenicine diverts rat muscle metabolism from fatty acid to carbohydrate oxidation and protects the ischaemic rat heart. Life Sci 27: 963-970, 1980.

166. Himms-Hagen J and Harper ME. Physiological role of UCP3 may be export of fatty acids from mitochondria when fatty acid oxidation predominates: an hypothesis. Exp Biol Med 226: 78-84, 2001.
167. Hittinger L, Shannon RP, Bishop SP, Gelpi RJ, and Vatner SF. Subendomyocardial exhaustion of blood flow reserve and increased fibrosis in conscious dogs with heart failure. Circ Res 65: 971-980, 1989.

168. Hjalmarson A, Goldstein S, Fagerberg B, Wedel H, Waagstein F, Kjekshus J, Wikstrand J, El Allaf D, Vitovec J, Aldershvile J, Halinen M, Dietz R, Neuhaus KL, Janosi A, Thorgeirsson G, Dunselman PH, Gullestad L, Kuch J, Herlitz J, Rickenbacher P, Ball S, Gottlieb S, and Deedwania P. Effects of controlledrelease metoprolol on total mortality, hospitalizations, and wellbeing in patients with heart failure: the Metoprolol CR/XL Randomized Intervention Trial in congestive heart failure (MERIT-HF). MERIT-HF Study Group. JAMA 283: 1295-1302, 2000.

169. Hoerter JA and Opie LH. Perinatal changes in glycolytic function in response to hypoxia in the incubated or perfused rat heart. Biol Neonate 33: 144-161, 1978.

170. Hoppel CL, Tandler B, Parland W, Turkaly JS, and Albers LD. Hamster cardiomyopathy. A defect in oxidative phosphorylation in the cardiac interfibrillar mitochondria. J Biol Chem 257: 1540 $1548,1982$.

171. Horwich TB, Fonarow GC, Hamilton MA, MacLellan WR, Woo MA, and Tillisch JH. The relationship between obesity and mortality in patients with heart failure. $J$ Am Coll Cardiol 38: 789-795, 2001.

172. Huang B, Wu P, Bowker-Kinley MM, and Harris RA. Regulation of pyruvate dehydrogenase kinase expression by peroxisome proliferator-activated receptor-alpha ligands, glucocorticoids, and insulin. Diabetes 51: 276-283, 2002.

173. Huang JM, Xian H, and Bacaner M. Long-chain fatty acids activate calcium channels in ventricular myocytes. Proc Natl Acad Sci USA 89: 6452-6456, 1992

174. Hubert HB, Feinleib M, McNamara PM, and Castelli WP. Obesity as an independent risk factor for cardiovascular disease: a 26-year follow-up of participants in the Framingham Heart Study. Circulation 67: 968-977, 1983.

175. Hue L, Beauloye C, Bertrand L, Horman S, Krause U, Marsin AS, Meisse D, Vertommen D, and Rider MH. New targets of AMP-activated protein kinase. Biochem Soc Trans 31: 213-215, 2003.

176. Hue L, Depre C, Lefebvre V, Rider MH, and Veitch K. Regulation of glucose metabolism in cardiac muscle. Biochem Soc Trans 23: 311-314, 1995.

177. Hue L and Rider MH. Role of fructose 2,6-bisphosphate in the control of glycolysis in mammalian tissues. Biochem $J$ 245: 313$324,1987$.

178. Hunt MC and Alexson SE. The role Acyl-CoA thioesterases play in mediating intracellular lipid metabolism. Prog Lipid Res 41: 99-130, 2002

179. Hunt SA, Baker DW, Chin MH, Cinquegrani MP, Feldmanmd AM, Francis GS, Ganiats TG, Goldstein S, Gregoratos G, Jessup ML, Noble RJ, Packer M, Silver MA, Stevenson LW, Gibbons RJ, Antman EM, Alpert JS, Faxon DP, Fuster V, Gregoratos G, Jacobs AK, Hiratzka LF, Russell RO, and Smith SC Jr. ACC/AHA Guidelines for the Evaluation and Management of Chronic Heart Failure in the Adult: Executive Summary A Report of the American College of Cardiology/American Heart Association Task Force on Practice Guidelines (committee to revise the 1995 Guidelines for the Evaluation and Management of Heart Failure): developed in collaboration with the International Society for Heart and Lung Transplantation; endorsed by the Heart Failure Society of America. Circulation 104: 2996-3007, 2001.

180. Huss JM and Kelly DP. Nuclear receptor signaling and cardiac energetics. Circ Res 95: 568-578, 2004.

181. Huss JM, Kopp RP, and Kelly DP. Peroxisome proliferatoractivated receptor coactivator-1alpha (PGC-1alpha) coactivates the cardiac-enriched nuclear receptors estrogen-related receptor-alpha and -gamma. Identification of novel leucine-rich interaction motif within PGC-1alpha. J Biol Chem 277: 40265-40274, 2002.

182. Huss JM, Torra IP, Staels B, Giguere V, and Kelly DP. Estrogen-related receptor alpha directs peroxisome proliferator-activated receptor alpha signaling in the transcriptional control of energy metabolism in cardiac and skeletal muscle. $\mathrm{Mol} \mathrm{Cell} \mathrm{Biol} \mathrm{24:}$ 9079-9091, 2004. 
183. Hutter JF, Schweickhardt C, Piper HM, and Spieckermann PG. Inhibition of fatty acid oxidation and decrease of oxygen consumption of working rat heart by 4 -bromocrotonic acid. $J$ Mol Cell Cardiol 16: 105-108, 1984.

184. Ide T, Tsutsui H, Kinugawa S, Utsumi H, Kang D, Hattori N, Uchida K, Arimura K, Egashira K, and Takeshita A. Mitochondrial electron transport complex I is a potential source of oxygen free radicals in the failing myocardium. Circ Res 85: 357-363, 1999.

185. Idell-Wenger JA, Grotyohann LW, and Neely JR. Coenzyme A and carnitine distribution in normal and ischemic hearts. $J$ Biol Chem 253: 4310-4318, 1978.

186. Iemitsu M, Miyauchi T, Maeda S, Tanabe T, Takanashi M, Irukayama-Tomobe $\mathbf{Y}$, Sakai $S$, Ohmori $H$, Matsuda $M$, and Yamaguchi I. Aging-induced decrease in the PPAR-alpha level in hearts is improved by exercise training. Am J Physiol Heart Circ Physiol 283: H1750-H1760, 2002.

187. Iliceto S, Scrutinio D, Bruzzi P, D'Ambrosio G, Boni L, Di Biase M, Biasco G, Hugenholtz PG, and Rizzon P. Effects of L-carnitine administration on left ventricular remodeling after acute anterior myocardial infarction: the L-Carnitine Ecocardiografia Digitalizzata Infarto Miocardico (CEDIM) Trial. J Am Coll Cardiol 26: 380-387, 1995.

188. Ingwall JS. ATP and the Heart. Boston, MA: Kluwer, 2001.

189. Ingwall JS. Transgenesis and cardiac energetics: new insights into cardiac metabolism. J Mol Cell Cardiol 37: 613-623, 2004.

190. Ingwall JS and Weiss RG. Is the failing heart energy starved? On using chemical energy to support cardiac function. Circ Res 95: 135-145, 2004.

191. Ishiyama T, Morita Y, Toyama S, Yamagami T, and Tsukamoto N. A clinical study of the effect of coenzyme $Q$ on congestive heart failure. Jpn Heart $J$ 17: 32-42, 1976.

192. Itoi T and Lopaschuk GD. The contribution of glycolysis, glucose oxidation, lactate oxidation, and fatty acid oxidation to ATP production in isolated biventricular working hearts from 2-week-old rabbits. Pediatr Res 34: 735-741, 1993.

193. Jaburek M, Varecha M, Jezek P, and Garlid KD. Alkylsulfonates as probes of uncoupling protein transport mechanism. Ion pair transport demonstrates that direct $\mathrm{H}(+)$ translocation by UCP1 is not necessary for uncoupling. J Biol Chem 276: 3189731905,2001

194. Jagasia D, Whiting JM, Concato J, Pfau S, and McNulty PH. Effect of non-insulin-dependent diabetes mellitus on myocardial insulin responsiveness in patients with ischemic heart disease. Circulation 103: 1734-1739, 2001.

195. Jain D, Dasgupta P, Hughes LO, Lahiri A, and Raftery EB. Ranolazine (RS-43285): a preliminary study of a new anti-anginal agent with selective effect on ischaemic myocardium. Eur J Clin Pharmacol 38: 111-114, 1990.

196. Jarreta D, Orus J, Barrientos A, Miro O, Roig E, Heras M, Moraes CT, Cardellach F, and Casademont J. Mitochondrial function in heart muscle from patients with idiopathic dilated cardiomyopathy. Cardiovasc Res 45: 860-865, 2000.

197. Jeremy RW, Koretsune Y, Marban E, and Becker LC. Relation between glycolysis and calcium homeostasis in postischemic myocardium. Circ Res 70: 1180-1190, 1992.

198. Jezek P, Engstova H, Zackova M, Vercesi AE, Costa AD, Arruda P, and Garlid KD. Fatty acid cycling mechanism and mitochondrial uncoupling proteins. Biochim Biophys Acta 1365: 319-327, 1998.

199. Jezek P, Engstova H, Zackova M, Vercesi AE, Costa AD, Arruda P, and Garlid KD. Fatty acid cycling mechanism and mitochondrial uncoupling proteins. Biochim Biophys Acta 1365: 319-327, 1998.

200. Jezek P, Modriansky M, and Garlid KD. A structure-activity study of fatty acid interaction with mitochondrial uncoupling protein. FEBS Lett 408: 166-170, 1997.

201. Jezek P, Modriansky M, and Garlid KD. Inactive fatty acids are unable to flip-flop across the lipid bilayer. FEBS Lett 408: 161-165, 1997.

202. Johannsson E, Lunde PK, Heddle C, Sjaastad I, Thomas MJ, Bergersen L, Halestrap AP, Blackstad TW, Ottersen OP, and Sejersted OM. Upregulation of the cardiac monocarboxylate transporter MCT1 in a rat model of congestive heart failure. Circulation 104: 729-734, 2001.

203. Johannsson E, Nagelhus EA, McCullagh KJ, Sejersted OM, Blackstad TW, Bonen A, and Ottersen OP. Cellular and subcellular expression of the monocarboxylate transporter MCT1 in rat heart. A high-resolution immunogold analysis. Circ Res 80: 400407, 1997.

204. Kaijser L and Berglund B. Myocardial lactate extraction and release at rest and during heavy exercise in healthy men. Acta Physiol Scand 144: 39-45, 1992.

205. Kako KJ, Thornton MJ, and Heggtveit HA. Depressed fatty acid and acetate oxidation and other metabolic defects in homogenates from hearts of hamsters with hereditary cardiomyopathy. Circ Res 34: 570-580, 1974.

206. Kalsi KK, Smolenski RT, Pritchard RD, Khaghani A, Seymour AM, and Yacoub MH. Energetics and function of the failing human heart with dilated or hypertrophic cardiomyopathy. Eur J Clin Invest 29: 469-477, 1999.

207. Kantor PF, Lucien A, Kozak R, and Lopaschuk GD. The antianginal drug trimetazidine shifts cardiac energy metabolism from fatty acid oxidation to glucose oxidation by inhibiting mitochondrial long-chain 3-ketoacyl coenzyme A thiolase. Circ Res 86: 580588,2000

208. Kantor PF, Robertson MA, Coe JY, and Lopaschuk GD. Volume overload hypertrophy of the newborn heart slows the maturation of enzymes involved in the regulation of fatty acid metabolism. J Am Coll Cardiol 33: 1724-1734, 1999.

209. Kantor PFLGDOLH. Myocardial energy metabolism. In: Heart Physiology and Pathophysiology, edited by Opie LH. Orlando, FL: Academic, 2004, p. 543-569.

210. Karbowska J, Kochan Z, and Smolenski RT. Peroxisome proliferator-activated receptor alpha is downregulated in the failing human heart. Cell Mol Biol Lett 8: 49-53, 2003.

211. Kates AM, Herrero P, Dence C, Soto P, Srinivasan M, Delano DG, Ehsani A, and Gropler RJ. Impact of aging on substrate metabolism by the human heart. J Am Coll Cardiol 41: 293-299, 2003.

212. Katz AM. Energetics and the failing heart. Hosp Pract 26: 78-90, 1991.

213. Katz AM. Metabolism of the failing heart. Cardioscience 4: 199203, 1993.

214. Katz AM and Katz PB. Diseases of the heart in the works of Hippocrates. Br Heart $J$ 24: 257-264, 1962.

215. Katz AM. Heart Failure: Pathophysiology, Molecular Biology, and Clinical Management. Philadelphia, PA: Lippincott Williams \& Wilkins, 2000.

216. Kelly DP. PPARs of the heart: three is a crowd. Circ Res 92: 482-484, 2003

217. Kelly DP and Strauss AW. Inherited cardiomyopathies. $N$ Engl J Med 330: 913-919, 1994.

218. Kenchaiah S, Evans JC, Levy D, Wilson PW, Benjamin EJ, Larson MG, Kannel WB, and Vasan RS. Obesity and the risk of heart failure. N Engl J Med 347: 305-313, 2002.

219. Kerbey AL, Randle PJ, Cooper RH, Whitehouse S, Pask HT, and Denton RM. Regulation of pyruvate dehydrogenase in rat heart. Mechanism of regulation of proportions of dephosphorylated and phosphorylated enzyme by oxidation of fatty acids and ketone bodies and of effects of diabetes: role of coenzyme A, acetylcoenzyme A and reduced and oxidized nicotinamide-adenine dinucleotide. Biochem J 154: 327-348, 1976.

220. Kerner J and Hoppel C. Fatty acid import into mitochondria. Biochim Biophys Acta 1486: 1-17, 2000.

221. Kerner J and Hoppel CL. Radiochemical malonyl-CoA decarboxylase assay: activity and subcellular distribution in heart and skeletal muscle. Anal Biochem 306: 283-289, 2002.

222. Kerner J, Turkaly PJ, Minkler PE, and Hoppel CL. Aging skeletal muscle mitochondria in the rat: decreased uncoupling protein-3 content. Am J Physiol Endocrinol Metab 281: E1054E1062, 2001.

223. Kerner J, Zaluzec E, Gage D, and Bieber LL. Characterization of the malonyl-CoA-sensitive carnitine palmitoyltransferase (CPTo) of a rat heart mitochondrial particle. Evidence that the catalytic unit is CPTi. J Biol Chem 269: 8209-8219, 1994. 
224. Khairallah M, Labarthe F, Bouchard B, Danialou G, Petrof BJ, and Des Rosiers C. Profiling substrate fluxes in the isolated working mouse heart using ${ }^{13} \mathrm{C}$-substrates: focusing on the origin and fate of pyruvate and citrate carbons. Am J Physiol Heart Circ Physiol 286: H1461-H1470, 2004.

225. Kim YS and Kolattukudy PE. Purification and properties of malonyl-CoA decarboxylase from rat liver mitochondria and its immunological comparison with the enzymes from rat brain, heart, and mammary gland. Arch Biochem Biophys 190: 234-246, 1978.

226. Kintaka T, Tanaka T, Imai M, Adachi I, Narabayashi I, and Kitaura Y. CD36 genotype and long-chain fatty acid uptake in the heart. Circ J 66: 819-825, 2002.

227. Kjekshus JK and Mjos OD. Effect of free fatty acids on myocardial function and metabolism in the ischemic dog heart. J Clin Invest 51: 1767-1776, 1972.

228. Knapp FF Jr and Kropp J. BMIPP-design and development. Int J Card Imaging 15: 1-9, 1999.

229. Knuuti MJ, Maki M, Yki-Jarvinen H, Voipio-Pulkki LM, Harkonen R, Haaparanta M, and Nuutila P. The effect of insulin and FFA on myocardial glucose uptake. J Mol Cell Cardiol 27: 1359-1367, 1995.

230. Knuuti MJ, Yki-Jarvinen H, Voipio-Pulkki LM, Maki M, Ruotsalainen U, Harkonen R, Teras M, Haaparanta M, Bergman J, AND Hartiala J. Enhancement of myocardial [fluorine-18]fluorodeoxyglucose uptake by a nicotinic acid derivative. J Nucl Med 35: 989-998, 1994.

231. Kornberg HL. Anaplerotic sequences and their role in metabolism. In: Essays in Biochemistry, edited by Campbell PN and Marshall RD. London: Academic, 1966, p. 1-31.

232. Korvald C, Elvenes OP, and Myrmel T. Myocardial substrate metabolism influences left ventricular energetics in vivo. $A m J$ Physiol Heart Circ Physiol 278: H1345-H1351, 2000.

233. Kreisberg RA. Effect of epinephrine on myocardial triglyceride and free fatty acid utilization. Am J Physiol 210: 385-389, 1966.

234. Kropp J, Eisenhut M, Ambrose KR, Knapp FF Jr, and Franke WG. Pharmacokinetics and metabolism of the methyl-branched fatty acid (BMIPP) in animals and humans. J Nucl Med 40: 1484$1491,1999$.

235. Kruszynska YT, McCormack JG, and McIntyre N. Effects of glycogen stores and non-esterified fatty acid availability on insulinstimulated glucose metabolism and tissue pyruvate dehydrogenase activity in the rat. Diabetologia 34: 205-211, 1991.

236. Kudo N, Barr AJ, Barr RL, Desai S, and Lopaschuk GD. High rates of fatty acid oxidation during reperfusion of ischemic hearts are associated with a decrease in malonyl-CoA levels due to an increase in 5'-AMP-activated protein kinase inhibition of acetylCoA carboxylase. J Biol Chem 270: 17513-17520, 1995.

237. Kudo T, Fukuchi K, Annala AJ, Chatziioannou AF, Allada V, Dahlbom M, Tai YC, Inubushi M, Huang SC, Cherry SR, Phelps ME, and Schelbert HR. Noninvasive measurement of myocardial activity concentrations and perfusion defect sizes in rats with a new small-animal positron emission tomograph. Circulation 106: 118-123, 2002.

238. Kunau WH, Dommes V, and Schulz H. Beta-oxidation of fatty acids in mitochondria, peroxisomes, and bacteria: a century of continued progress. Prog Lipid Res 34: 267-342, 1995.

239. Kurzelewski M, Duda M, Stanley WC, Boemke W, and Beresewicz A. Nitric oxide synthase inhibition and elevated endothelin increase oxygen consumption but do not affect glucose and palmitate oxidation in the isolated rat heart. J Physiol Pharmacol 55: $27-38,2004$

240. Kusuoka H and Marban E. Mechanism of the diastolic dysfunction induced by glycolytic inhibition. Does adenosine triphosphate derived from glycolysis play a favored role in cellular $\mathrm{Ca}^{2+}$ homeostasis in ferret myocardium? J Clin Invest 93: 1216-1223, 1994.

241. Lakatta EG. Cardiovascular aging: perspectives from humans to rodents. Am J Geriatr Cardiol 7: 32-45, 1998.

242. Lakatta EG. Age-associated cardiovascular changes in health: impact on cardiovascular disease in older persons. Heart Fail Rev 7: 29-49, 2002.

243. Lammerant J, Huynh-Thu T, and Kolanowski J. Inhibitory effects of the $\mathrm{D}(-)$ isomer of 3-hydroxybutyrate on cardiac non- esterified fatty acid uptake and oxygen demand induced by norepinephrine in the intact dog. J Mol Cell Cardiol 17: 421-433, 1985.

244. Laplante A, Vincent G, Poirier M, and Des Rosiers C. Effects and metabolism of fumarate in the perfused rat heart. $\mathrm{A}^{13} \mathrm{C}$ mass isotopomer study. Am J Physiol Endocrinol Metab 272: E74-E82, 1997.

245. Lassers BW, Wahlqvist ML, Kaijser L, and Carlson LA. Effect of nicotinic acid on myocardial metabolism in man at rest and during exercise. J Appl Physiol 33: 72-80, 1972.

246. Laughlin MR, Taylor J, Chesnick AS, and Balaban RS. Nonglucose substrates increase glycogen synthesis in vivo in dog heart. Am J Physiol Heart Circ Physiol 267: H219-H223, 1994.

247. Lavie CJ and Milani RV. Obesity and cardiovascular disease: the hippocrates paradox? J Am Coll Cardiol 42: 677-679, 2003.

248. Lavie CJ, Osman AF, Milani RV, and Mehra MR. Body composition and prognosis in chronic systolic heart failure: the obesity paradox. Am J Cardiol 91: 891-894, 2003.

249. Lawson JW and Uyeda K. Effects of insulin and work on fructose 2,6-bisphosphate content and phosphofructokinase activity in perfused rat hearts. J Biol Chem 262: 3165-3173, 1987.

250. Lehman JJ, Barger PM, Kovacs A, Saffitz JE, Medeiros DM, and Kelly DP. Peroxisome proliferator-activated receptor gamma coactivator-1 promotes cardiac mitochondrial biogenesis. $J$ Clin Invest 106: 847-856, 2000.

251. Lehman JJ and Kelly DP. Gene regulatory mechanisms governing energy metabolism during cardiac hypertrophic growth. Heart Fail Rev 7: 175-185, 2002.

252. Lei B, Lionetti V, Young ME, Chandler MP, D' Agostino C, Kang E, Altarejos M, Matsuo K, Hintze TH, Stanley WC, and Recchia FA. Paradoxical downregulation of the glucose oxidation pathway despite enhanced flux in severe heart failure. $J$ Mol Cell Cardiol 36: 567-576, 2004.

253. Lesnefsky EJ, Moghaddas S, Tandler B, Kerner J, and Hoppel CL. Mitochondrial dysfunction in cardiac disease: ischemia-reperfusion, aging, and heart failure. J Mol Cell Cardiol 33: 1065-1089, 2001.

254. Lewandowski ED. Metabolic mechanisms associated with antianginal therapy. Circ Res 86: 487-489, 2000.

255. Li J, Hu X, Selvakumar P, Russell RR, III, Cushman SW, Holman GD, and Young LH. Role of the nitric oxide pathway in AMPK-mediated glucose uptake and GLUT4 translocation in heart muscle. Am J Physiol Endocrinol Metab 287: E834-E841, 2004.

256. Liao R, Jain M, Cui L, D'Agostino J, Aiello F, Luptak I, Ngoy S, Mortensen RM, and Tian R. Cardiac-specific overexpression of GLUT1 prevents the development of heart failure attributable to pressure overload in mice. Circulation 106: 2125-2131, 2002.

257. Liao R, Nascimben L, Friedrich J, Gwathmey JK, and Ingwall JS. Decreased energy reserve in an animal model of dilated cardiomyopathy. Relationship to contractile performance. Circ Res 78: 893-902, 1996.

258. Liedtke AJ, Hacker T, Renstrom B, and Nellis SH. Anaplerotic effects of propionate on oxidations of acetate and long-chain fatty acids. Am J Physiol Heart Circ Physiol 270: H2197-H2203, 1996.

259. Lionetti V, Linke A, Chandler MP, Young ME, Penn MS, Gupte S, d'Agostino C, Hintze TH, Stanley WC, and Recchia FA. Carnitine palmitoyl transferase-I inhibition prevents ventricular remodeling and delays decompensation in pacing-induced heart failure. Cardiovasc Res 66: 274-281, 2005.

260. Listenberger LL, Ory DS, and Schaffer JE. Palmitate-induced apoptosis can occur through a ceramide-independent pathway. J Biol Chem 276: 14890-14895, 2001.

261. Little JR, Goto M, and Spitzer JJ. Effect of ketones on metabolism of FFA by dog myocardium and skeletal muscle in vivo. $A m \mathrm{~J}$ Physiol 219: 1458-1463, 1970.

262. Liu J, Wang C, Murakami Y, Gong G, Ishibashi Y, Prody C, Ochiai K, Bache RJ, Godinot $\mathbf{C}$, and Zhang J. Mitochondrial ATPase and high-energy phosphates in failing hearts. Am J Physiol Heart Circ Physiol 281: H1319-H1326, 2001.

263. Liu YH, Yang XP, Nass O, Sabbah HN, Peterson E, and Carretero OA. Chronic heart failure induced by coronary artery ligation in Lewis inbred rats. Am J Physiol Heart Circ Physiol 272: H722-H727, 1997. 
264. Lommi J, Koskinen P, Naveri H, Harkonen M, and Kupari M. Heart failure ketosis. J Intern Med 242: 231-238, 1997.

265. Lommi J, Kupari M, Koskinen P, Naveri H, Leinonen H, Pulkki K, and Harkonen M. Blood ketone bodies in congestive heart failure. J Am Coll Cardiol 28: 665-672, 1996.

266. Lommi J, Kupari M, and Yki-Jarvinen H. Free fatty acid kinetics and oxidation in congestive heart failure. Am J Cardiol 81: 45-50, 1998.

267. Longnus SL, Wambolt RB, Parsons HL, Brownsey RW, and Allard MF. 5-Aminoimidazole-4-carboxamide 1-beta-D-ribofuranoside (AICAR) stimulates myocardial glycogenolysis by allosteric mechanisms. Am J Physiol Regul Integr Comp Physiol 284: R936R944, 2003.

268. Lopaschuk GD, Barr R, Thomas PD, and Dyck JR. Beneficial effects of trimetazidine in ex vivo working ischemic hearts are due to a stimulation of glucose oxidation secondary to inhibition of long-chain 3-ketoacyl coenzyme a thiolase. Circ Res 93: e33-e37, 2003.

269. Lopaschuk GD and Barr RL. Measurements of fatty acid and carbohydrate metabolism in the isolated working rat heart. Mol Cell Biochem 172: 137-147, 1997.

270. Lopaschuk GD, Belke DD, Gamble J, Itoi T, and Schonekess BO. Regulation of fatty acid oxidation in the mammalian heart in health and disease. Biochim Biophys Acta 1213: 263-276, 1994.

271. Lopaschuk GD, Collins-Nakai R, Olley PM, Montague TJ, McNeil G, Gayle M, Penkoske P, and Finegan BA. Plasma fatty acid levels in infants and adults after myocardial ischemia. Am Heart $J$ 128: 61-67, 1994.

272. Lopaschuk GD, Collins-Nakai RL, and Itoi T. Developmental changes in energy substrate use by the heart. Cardiovasc Res 26 : 1172-1180, 1992.

273. Lopaschuk GD and Spafford MA. Energy substrate utilization by isolated working hearts from newborn rabbits. Am J Physiol Heart Circ Physiol 258: H1274-H1280, 1990.

274. Lopaschuk GD, Spafford MA, and Marsh DR. Glycolysis is predominant source of myocardial ATP production immediately after birth. Am J Physiol Heart Circ Physiol 261: H1698-H1705, 1991.

275. Lopaschuk GD, Witters LA, Itoi T, Barr R, and Barr A. AcetylCoA carboxylase involvement in the rapid maturation of fatty acid oxidation in the newborn rabbit heart. J Biol Chem 269: 2587125878, 1994

276. Lucas DT and Szweda LI. Declines in mitochondrial respiration during cardiac reperfusion: age-dependent inactivation of alphaketoglutarate dehydrogenase. Proc Natl Acad Sci USA 96: 66896693, 1999.

277. Luiken JJ, Coort SL, Koonen DP, Van Der Horst DJ, Bonen A, Zorzano A, and Glatz JF. Regulation of cardiac long-chain fatty acid and glucose uptake by translocation of substrate transporters. Pflügers Arch 448: 1-15, 2004.

278. Luiken JJ, Coort SL, Willems J, Coumans WA, Bonen A, van der Vusse GJ, and Glatz JF. Contraction-induced fatty acid translocase/CD36 translocation in rat cardiac myocytes is mediated through AMP-activated protein kinase signaling. Diabetes 52: 16271634, 2003.

279. Luiken JJ, Willems J, van der Vusse GJ, and Glatz JF. Electrostimulation enhances FAT/CD36-mediated long-chain fatty acid uptake by isolated rat cardiac myocytes. Am J Physiol Endocrinol Metab 281: E704-E712, 2001.

280. Lygate CA, Hulbert K, Monfared M, Cole MA, Clarke K, and Neubauer S. The PPARgamma-activator rosiglitazone does not alter remodeling but increases mortality in rats post-myocardial infarction. Cardiovasc Res 58: 632-637, 2003.

281. Lysiak W, Toth PP, Suelter CH, and Bieber LL. Quantitation of the efflux of acylcarnitines from rat heart, brain, and liver mitochondria. J Biol Chem 261: 13698-13703, 1986.

282. Makinde AO, Gamble J, and Lopaschuk GD. Upregulation of $5^{\prime}$-AMP-activated protein kinase is responsible for the increase in myocardial fatty acid oxidation rates following birth in the newborn rabbit. Circ Res 80: 482-489, 1997.

283. Mallet RT. Pyruvate: metabolic protector of cardiac performance. Proc Soc Exp Biol Med 223: 136-148, 2000
284. Malloy CR, Sherry AD, and Jeffrey FM. Evaluation of carbon flux and substrate selection through alternate pathways involving the citric acid cycle of the heart by ${ }^{13} \mathrm{C}$ NMR spectroscopy. $J$ Biol Chem 263: 6964-6971, 1988.

285. Marin-Garcia J and Goldenthal MJ. Fatty acid metabolism in cardiac failure: biochemical, genetic and cellular analysis. Cardiovasc Res 54: 516-527, 2002.

286. Marin-Garcia J, Goldenthal MJ, and Moe GW. Abnormal cardiac and skeletal muscle mitochondrial function in pacing-induced cardiac failure. Cardiovasc Res 52: 103-110, 2001.

287. Marin-Garcia J, Goldenthal MJ, and Moe GW. Mitochondrial pathology in cardiac failure. Cardiovasc Res 49: 17-26, 2001.

288. Marsin AS, Bertrand L, Rider MH, Deprez J, Beauloye C, Vincent MF, Van den BG, Carling D, and Hue L. Phosphorylation and activation of heart PFK-2 by AMPK has a role in the stimulation of glycolysis during ischaemia. Curr Biol 10: 1247$1255,2000$.

289. Martin MA, Gomez MA, Guillen F, Bornstein B, Campos Y, Rubio JC, de la Calzada CS, and Arenas J. Myocardial carnitine and carnitine palmitoyltransferase deficiencies in patients with severe heart failure. Biochim Biophys Acta 1502: 330-336, 2000.

290. Martini WZ, Stanley WC, Huang H, Rosiers CD, Hoppel CL, and Brunengraber $\mathbf{H}$. Quantitative assessment of anaplerosis from propionate in pig heart in vivo. Am J Physiol Endocrinol Metab 284: E351-E356, 2003.

291. Massie BM, Schaefer S, Garcia J, McKirnan MD, Schwartz GG, Wisneski JA, Weiner MW, and White FC. Myocardial highenergy phosphate and substrate metabolism in swine with moderate left ventricular hypertrophy. Circulation 91: 1814-1823, 1995.

292. Massie BM, Schwartz GG, Garcia J, Wisneski JA, Weiner MW, and Owens T. Myocardial metabolism during increased work states in the porcine left ventricle in vivo. Circ Res 74: 64-73, 1994.

293. Mazer CD, Stanley WC, Hickey RF, Neese RA, Cason BA, Demas KA, Wisneski JA, and Gertz EW. Myocardial metabolism during hypoxia: maintained lactate oxidation during increased glycolysis. Metabolism 39: 913-918, 1990.

294. McCormack JG and Denton RM. Role of $\mathrm{Ca}^{2+}$ ions in the regulation of intramitochondrial metabolism in rat heart. Evidence from studies with isolated mitochondria that adrenaline activates the pyruvate dehydrogenase and 2-oxoglutarate dehydrogenase complexes by increasing the intramitochondrial concentration of $\mathrm{Ca}^{2+}$. Biochem J 218: 235-247, 1984.

295. McCormack JG and Denton RM. Influence of calcium ions on mammalian intramitochondrial dehydrogenases. Methods Enzymol 174: 95-118, 1989.

296. McCormack JG, Halestrap AP, and Denton RM. Role of calcium ions in regulation of mammalian intramitochondrial metabolism. Physiol Rev 70: 391-425, 1990.

297. McCormack JG, Stanley WC, and Wolff AA. Ranolazine: a novel metabolic modulator for the treatment of angina. Gen Pharmacol 30: 639-645, 1998.

298. McCutcheon LJ, Cory CR, Nowack L, Shen H, Mirsalami M, Lahucky R, Kovac L, O'Grady M, Horne R, and O'Brien PJ. Respiratory chain defect of myocardial mitochondria in idiopathic dilated cardiomyopathy of Doberman pinscher dogs. Can J Physiol Pharmacol 70: 1529-1533, 1992.

299. McDonald KM, Yoshiyama M, Francis GS, Ugurbil K, Cohn JN, and Zhang J. Myocardial bioenergetic abnormalities in a canine model of left ventricular dysfunction. J Am Coll Cardiol 23: 786$793,1994$.

300. McGarry JD and Brown NF. The mitochondrial carnitine palmitoyltransferase system. From concept to molecular analysis. Eur J Biochem 244: 1-14, 1997.

301. McGarry JD and Dobbins RL. Fatty acids, lipotoxicity and insulin secretion. Diabetologia 42: 128-138, 1999.

302. McGarry JD, Mills SE, Long CS, and Foster DW. Observations on the affinity for carnitine, and malonyl-CoA sensitivity, of carnitine palmitoyltransferase I in animal and human tissues. Demonstration of the presence of malonyl-CoA in non-hepatic tissues of the rat. Biochem $J$ 214: 21-28, 1983.

303. McMillin JB, Taffet GE, Taegtmeyer H, Hudson EK, and Tate CA. Mitochondrial metabolism and substrate competition in the aging Fischer rat heart. Cardiovasc Res 27: 2222-2228, 1993. 
304. McMillin JB, Wang D, Witters LA, and Buja LM. Kinetic properties of carnitine palmitoyltransferase I in cultured neonatal rat cardiac myocytes. Arch Biochem Biophys 312: 375-384, 1994.

305. McNulty PH, Jacob R, Deckelbaum LI, and Young LH. Effect of hyperinsulinemia on myocardial amino acid uptake in patients with coronary artery disease. Metabolism 49: 1365-1369, 2000.

306. Merkel M, Eckel RH, and Goldberg IJ. Lipoprotein lipase: genetics, lipid uptake, and regulation. J Lipid Res 43: 1997-2006, 2002.

307. Mirotsou M, Watanabe CM, Schultz PG, Pratt RE, and Dzau VJ. Elucidating the molecular mechanism of cardiac remodeling using a comparative genomic approach. Physiol Gen 15: 115-126, 2003.

308. Miyamoto T, Takeishi Y, Tazawa S, Inoue M, Aoyama T, Takahashi H, Arimoto T, Shishido T, Tomoike H, and Kubota I. Fatty acid metabolism assessed by ${ }^{125}$ I-iodophenyl 9-methylpentadecanoic acid (9MPA) and expression of fatty acid utilization enzymes in volume-overloaded hearts. Eur J Clin Invest 34: 176181, 2004.

309. Mjos OD. Effect of free fatty acids on myocardial function and oxygen consumption in intact dogs. J Clin Invest 50: 1386-1389, 1971.

310. Mjos OD and Kjekshus J. Increased local metabolic rate by free fatty acids in the intact dog heart. Scand J Clin Lab Invest 28: 389-393, 1971.

311. Mjos OD, Kjekshus JK, and Lekven J. Importance of free fatty acids as a determinant of myocardial oxygen consumption and myocardial ischemic injury during norepinephrine infusion in dogs. $J$ Clin Invest 53: 1290-1299, 1974.

312. Moe GW, Marin-Garcia J, Konig A, Goldenthal M, Lu X, and Feng $\mathbf{Q}$. In vivo TNF-alpha inhibition ameliorates cardiac mitochondrial dysfunction, oxidative stress, and apoptosis in experimental heart failure. Am J Physiol Heart Circ Physiol 287: H1813H1820, 2004.

313. Mohr S, Hallak H, de Boitte A, Lapetina EG, and Brune B. Nitric oxide-induced $S$-glutathionylation and inactivation of glyceraldehyde-3-phosphate dehydrogenase. J Biol Chem 274: 9427-9430, 1999.

314. Montgomery C, Hamilton N, and Ianuzzo CD. Energy status of the rapidly paced canine myocardium in congestive heart failure. J Appl Physiol 73: 2363-2367, 1992.

315. Mootha VK, Arai AE, and Balaban RS. Maximum oxidative phosphorylation capacity of the mammalian heart. Am J Physiol Heart Circ Physiol 272: H769-H775, 1997.

316. Mourmans J, Wendel U, Bentlage HA, Trijbels JM, Smeitink JA, de Coo IF, Gabreels FJ, Sengers RC, and Ruitenbeek W. Clinical heterogeneity in respiratory chain complex III deficiency in childhood. J Neurol Sci 149: 111-117, 1997.

317. Muders F and Elsner D. Animal models of chronic heart failure. Pharmacol Res 41: 605-612, 2000.

318. Mudge GH Jr, Mills RM Jr, Taegtmeyer H, Gorlin R, and Lesch M. Alterations of myocardial amino acid metabolism in chronic ischemic heart disease. J Clin Invest 58: 1185-1192, 1976.

319. Muoio DM, Seefeld K, Witters LA, and Coleman RA. AMPactivated kinase reciprocally regulates triacylglycerol synthesis and fatty acid oxidation in liver and muscle: evidence that $s n$ glycerol-3-phosphate acyltransferase is a novel target. Biochem $J$ 338: 783-791, 1999.

320. Neglia D, Michelassi C, Trivieri MG, Sambuceti G, Giorgetti A, Pratali L, Gallopin M, Salvadori P, Sorace O, Carpeggiani C, Poddighe R, L'Abbate A, and Parodi O. Prognostic role of myocardial blood flow impairment in idiopathic left ventricular dysfunction. Circulation 105: 186-193, 2002.

321. Neglia D, Parodi O, Gallopin M, Sambuceti G, Giorgetti A, Pratali L, Salvadori P, Michelassi C, Lunardi M, and Pelosi G. Myocardial blood flow response to pacing tachycardia and to dipyridamole infusion in patients with dilated cardiomyopathy without overt heart failure. A quantitative assessment by positron emission tomography. Circulation 92: 796-804, 1995.

322. Neubauer S, Beer M, Landschutz W, Sandstede J, Seyfarth T, Lipke C, Kostler H, Pabst TW, Meininger M, von Kienlin M, Horn M, Harre K, and Hahn D. Absolute quantification of high energy phosphate metabolites in normal, hypertrophied and failing human myocardium. MAGMA 11: 73-74, 2000.

323. Neubauer S, Horn M, Cramer M, Harre K, Newell JB, Peters W, Pabst T, Ertl G, Hahn D, Ingwall JS, and Kochsiek K. Myocardial phosphocreatine-to-ATP ratio is a predictor of mortality in patients with dilated cardiomyopathy. Circulation 96: 2190 2196, 1997.

324. Neubauer S, Krahe T, Schindler R, Horn M, Hillenbrand H, Entzeroth C, Mader H, Kromer EP, Riegger GA, and Lackner K. ${ }^{31} \mathrm{P}$ magnetic resonance spectroscopy in dilated cardiomyopathy and coronary artery disease. Altered cardiac high-energy phosphate metabolism in heart failure. Circulation 86: 1810-1818, 1992.

325. Newsholme EA and Randle PJ. Regulation of glucose upake by muscle. Effects of fatty acids, ketone bodies and pyruvate, and of alloxan diabetes, starvation, hypophysectomy, and adrenalectomy, on the concentrations of hexose phosphates, nucleotides, and inorganic phosphate in perfused rat heart. Biochem $J$ 93: 641-651, 1964.

326. Nikolaidis LA, Doverspike A, Hentosz T, Zourelias L, Shen YT, Elahi D, and Shannon RP. Glucagon-like peptide-1 (GLP-1) limits myocardial stunning following brief coronary occlusion and reperfusion in conscious canines. J Pharmacol Exp Ther 312: 303-308, 2005.

327. Nikolaidis LA, Elahi D, Hentosz T, Doverspike A, Huerbin R, Zourelias L, Stolarski C, Shen YT, and Shannon RP. Recombinant glucagon-like peptide-1 increases myocardial glucose uptake and improves left ventricular performance in conscious dogs with pacing-induced dilated cardiomyopathy. Circulation 110: 955-961, 2004.

328. Nikolaidis LA, Hentosz T, Doverspike A, Huerbin R, Stolarski C, Shen YT, and Shannon RP. Catecholamine stimulation is associated with impaired myocardial $\mathrm{O}_{2}$ utilization in heart failure. Cardiovasc Res 53: 392-404, 2002.

329. Nikolaidis LA, Sturzu A, Stolarski C, Elahi D, Shen YT, and Shannon RP. The development of myocardial insulin resistance in conscious dogs with advanced dilated cardiomyopathy. Cardiovasc Res 61: 297-306, 2004.

330. Oliveira SM, Ehtisham J, Redwood CS, Ostman-Smith I, Blair EM, and Watkins H. Mutation analysis of AMP-activated protein kinase subunits in inherited cardiomyopathies: implications for kinase function and disease pathogenesis. $J$ Mol Cell Cardiol 35: 1251-1255, 2003.

331. Opie LH. The Heart: Physiology and Metabolism. New York: Raven, 1991.

332. Osorio JC, Stanley WC, Linke A, Castellari M, Diep QN, Panchal AR, Hintze TH, Lopaschuk GD, and Recchia FA. Impaired myocardial fatty acid oxidation and reduced protein expression of retinoid $\mathrm{X}$ receptor-alpha in pacing-induced heart failure. Circulation 106: 606-612, 2002.

333. Ostrander DB, Sparagna GC, Amoscato AA, McMillin JB, and Dowhan W. Decreased cardiolipin synthesis corresponds with cytochrome $c$ release in palmitate-induced cardiomyocyte apoptosis. J Biol Chem 276: 38061-38067, 2001.

334. Ozcan C, Bienengraeber M, Hodgson DM, Mann DL, and Terzic A. Mitochondrial tolerance to stress impaired in failing heart. $J$ Mol Cell Cardiol 35: 1161-1166, 2003.

335. Panchal AR, Comte B, Huang H, Dudar B, Roth B, Chandler M, des RC, Brunengraber H, and Stanley WC. Acute hibernation decreases myocardial pyruvate carboxylation and citrate release. Am J Physiol Heart Circ Physiol 281: H1613-H1620, 2001.

336. Panchal AR, Comte B, Huang H, Kerwin T, Darvish A, des Rosiers C, Brunengraber $\mathbf{H}$, and Stanley WC. Partitioning of pyruvate between oxidation and anaplerosis in swine hearts. Am J Physiol Heart Circ Physiol 279: H2390-H2398, 2000.

337. Panchal AR, Stanley WC, Kerner J, and Sabbah HN. Betareceptor blockade decreases carnitine palmitoyl transferase I activity in dogs with heart failure. J Card Fail 4: 121-126, 1998.

338. Paolisso G, Gambardella A, Galzerano D, D'Amore A, Rubino $P$, Verza M, Teasuro P, Varricchio $M$, and D'Onofrio F. Totalbody and myocardial substrate oxidation in congestive heart failure. Metabolism 43: 174-179, 1994. 
339. Paulson DJ, and Crass MF III. Endogenous triacylglycerol metabolism in diabetic heart. Am J Physiol Heart Circ Physiol 242: H1084-H1094, 1982.

340. Pepine CJ and Wolff AA. A controlled trial with a novel antiischemic agent, ranolazine, in chronic stable angina pectoris that is responsive to conventional antianginal agents. Ranolazine Study Group. Am J Cardiol 84: 46-50, 1999.

341. Peyton RB, Jones RN, Attarian D, Sink JD, Van Trigt P, Currie WD, and Wechsler AS. Depressed high-energy phosphate content in hypertrophied ventricles of animal and man: the biologic basis for increased sensitivity to ischemic injury. Ann Surg 196: 278-284, 1982.

342. Pfeffer JM, Pfeffer MA, Fletcher PJ, and Braunwald E. Ventricular performance in rats with myocardial infarction and failure. Am J Med 76: 99-103, 1984.

343. Pfeffer JM, Pfeffer MA, Fletcher PJ, and Braunwald E. Progressive ventricular remodeling in rat with myocardial infarction. Am J Physiol Heart Circ Physiol 260: H1406-H1414, 1991.

344. Pierce GN and Philipson KD. Binding of glycolytic enzymes to cardiac sarcolemmal and sarcoplasmic reticular membranes. $\mathrm{J} \mathrm{Biol}$ Chem 260: 6862-6870, 1985.

345. Poirier M, Vincent G, Reszko AE, Bouchard B, Kelleher JK, Brunengraber $\mathbf{H}$, and des Rosiers $\mathbf{C}$. Probing the link between citrate and malonyl-CoA in perfused rat hearts. Am J Physiol Heart Circ Physiol 283: H1379-H1386, 2002.

346. Polekhina G, Gupta A, Michell BJ, van Denderen B, Murthy S, Feil SC, Jennings IG, Campbell DJ, Witters LA, Parker MW, Kemp BE, and Stapleton D. AMPK beta subunit targets metabolic stress sensing to glycogen. Curr Biol 13: 867-871, 2003.

347. Power JM and Tonkin AM. Large animal models of heart failure. Aust N Z J Med 29: 395-402, 1999.

348. Pressman BC and Lardy HA. Effects of surface active agents on the latent ATPase of mitochondria. Biochim Biophys Acta 21: 458-466, 1956.

349. Quigley AF, Kapsa RM, Esmore D, Hale G, and Byrne E. Mitochondrial respiratory chain activity in idiopathic dilated cardiomyopathy. J Card Fail 6: 47-55, 2000.

350. Randle PJ. Fuel selection in animals. Biochem Soc Trans 14: 799-806, 1986.

351. Randle PJ, Denton RM, and England PJ. Citrate as a metabolic regulator in muscle and adipose tissue. Biochem Soc Symp 27: 87-103, 1968.

352. Randle PJ, England PJ, and Denton RM. Control of the tricarboxylate cycle and its interactions with glycolysis during acetate utilization in rat heart. Biochem $J$ 117: 677-695, 1970.

353. Randle PJ, Garland PB, Hales CN, and Newsholme EA. The glucose fatty-acid cycle. Its role in insulin sensitivity and the metabolic disturbances of diabetes mellitus. Lancet 1: 785-789, 1963.

354. Randle PJ, Newsholme EA, and Garland PB. Regulation of glucose uptake by muscle. 8 . Effects of fatty acids, ketone bodies and pyruvate, and of alloxan-diabetes and starvation, on the uptake and metabolic fate of glucose in rat heart and diaphragm muscles. Biochem J 93: 652-665, 1964.

355. Randle PJ and Priesman DA. Short term and longer term regulation of pyruvate dehydrogenase kinase. In: Alpha-keto Acid Dehydrogenase Complexes. Basel: Birkhauser Verlag, 1996, p. 151161.

356. Razeghi P, Young ME, Alcorn JL, Moravec CS, Frazier OH, and Taegtmeyer H. Metabolic gene expression in fetal and failing human heart. Circulation 104: 2923-2931, 2001.

357. Razeghi P, Young ME, Ying J, Depre C, Uray IP, Kolesar J, Shipley GL, Moravec CS, Davies PJ, Frazier OH, and Taegtmeyer H. Downregulation of metabolic gene expression in failing human heart before and after mechanical unloading. Cardiology 97: 203-209, 2002.

358. Recchia FA. Role of nitric oxide in the regulation of substrate metabolism in heart failure. Heart Fail Rev 7: 141-148, 2002.

359. Recchia FA, McConnell PI, Bernstein RD, Vogel TR, Xu X, and Hintze TH. Reduced nitric oxide production and altered myocardial metabolism during the decompensation of pacing-induced heart failure in the conscious dog. Circ Res 83: 969-979, 1998.
360. Recchia FA, McConnell PI, Loke KE, Xu X, Ochoa M, and Hintze TH. Nitric oxide controls cardiac substrate utilization in the conscious dog. Cardiovasc Res 44: 325-332, 1999.

361. Recchia FA, Osorio JC, Chandler MP, Xu X, Panchal AR, Lopaschuk GD, Hintze TH, and Stanley WC. Reduced synthesis of NO causes marked alterations in myocardial substrate metabolism in conscious dogs. Am J Physiol Endocrinol Metab 282: E197-E206, 2002.

362. Remondino A, Rosenblatt-Velin N, Montessuit C, Tardy I, Papageorgiou I, Dorsaz PA, Jorge-Costa M, and Lerch R. Altered expression of proteins of metabolic regulation during remodeling of the left ventricle after myocardial infarction. $J \mathrm{Mol} \mathrm{Cell}$ Cardiol 32: 2025-2034, 2000.

363. Renstrom B, Rommelfanger S, Stone CK, DeGrado TR, Carlson KJ, Scarbrough E, Nickles RJ, Liedtke AJ, and Holden JE. Comparison of fatty acid tracers FTHA and BMIPP during myocardial ischemia and hypoxia. J Nucl Med 39: 1684-1689, 1998.

364. Reszko AE, Kasumov T, Comte B, Pierce BA, David F, Bederman IR, Deutsch J, des Rosiers $\mathrm{C}$, and Brunengraber $\mathbf{H}$. Assay of the concentration and ${ }^{13} \mathrm{C}$-isotopic enrichment of malonylcoenzyme A by gas chromatography-mass spectrometry. Anal Biochem 298: 69-75, 2001.

365. Reszko AE, Kasumov T, David F, Jobbins KA, Thomas KR, Hoppel CL, Brunengraber H, and des Rosiers C. Peroxisomal fatty acid oxidation is a substantial source of the acetyl moiety of malonyl-CoA in rat heart. J Biol Chem 279: 19574-19579, 2004.

366. Reszko AE, Kasumov T, David F, Thomas KR, Jobbins KA, Cheng JF, Lopaschuk GD, Dyck JR, Diaz M, des Rosiers C, Stanley WC, and Brunengraber $\mathbf{H}$. Regulation of malonyl-CoA concentration and turnover in the normal heart. J Biol Chem 279: 34298-34301, 2004.

367. Reszko AE, Kasumov T, Pierce BA, David F, Hoppel CL, Stanley WC, des Rosiers C, and Brunengraber H. Assessing the reversibility of the anaplerotic reactions of the propionyl-CoA pathway in heart and liver. J Biol Chem 278: 34959-34965, 2003.

368. Rider MH, Van Damme J, Vertommen D, Michel A, Vandekerckhove J, and Hue L. Evidence for new phosphorylation sites for protein kinase $\mathrm{C}$ and cyclic AMP-dependent protein kinase in bovine heart 6-phosphofructo-2-kinase/fructose-2,6-bisphosphatase. FEBS Lett 310: 139-142, 1992.

369. Roe CR, Sweetman L, Roe DS, David F, and Brunengraber H. Treatment of cardiomyopathy and rhabdomyolysis in long-chain fat oxidation disorders using an anaplerotic odd-chain triglyceride. $J$ Clin Invest 110: 259-269, 2002.

370. Rolfe DF, Hulbert AJ, and Brand MD. Characteristics of mitochondrial proton leak and control of oxidative phosphorylation in the major oxygen-consuming tissues of the rat. Biochim Biophys Acta 1188: 405-416, 1994.

371. Rolfe DF, Newman JM, Buckingham JA, Clark MG, and Brand MD. Contribution of mitochondrial proton leak to respiration rate in working skeletal muscle and liver and to SMR. Am J Physiol Cell Physiol 276: C692-C699, 1999.

372. Rolph TP and Jones CT. Regulation of glycolytic flux in the heart of the fetal guinea pig. J Dev Physiol 5: 31-49, 1983.

373. Rosano GM, Vitale C, Sposato B, Mercuro G, and Fini M. Trimetazidine improves left ventricular function in diabetic patients with coronary artery disease: a double-blind placebo-controlled study. Cardiovasc Diabetol 2: 16, 2003.

374. Rosenblatt-Velin N, Montessuit C, Papageorgiou I, Terrand J, and Lerch R. Postinfarction heart failure in rats is associated with upregulation of GLUT-1 and downregulation of genes of fatty acid metabolism. Cardiovasc Res 52: 407-416, 2001.

375. Ruderman NB, Saha AK, Vavvas D, and Witters LA. MalonylCoA, fuel sensing, and insulin resistance. Am J Physiol Endocrinol Metab 276: E1-E18, 1999.

376. Rupp H, Schulze W, and Vetter R. Dietary medium-chain triglycerides can prevent changes in myosin and SR due to CPT-1 inhibition by etomoxir. Am J Physiol Regul Integr Comp Physiol 269: R630-R640, 1995.

377. Rupp H and Vetter R. Sarcoplasmic reticulum function and carnitine palmitoyltransferase-1 inhibition during progression of heart failure. Br J Pharmacol 131: 1748-1756, 2000. 
378. Rupp H, Zarain-Herzberg A, and Maisch B. The use of partial fatty acid oxidation inhibitors for metabolic therapy of angina pectoris and heart failure. Herz 27: 621-636, 2002.

379. Russell RR, III, Bergeron R, Shulman GI, and Young LH. Translocation of myocardial GLUT-4 and increased glucose uptake through activation of AMPK by AICAR. Am J Physiol Heart Circ Physiol 277: H643-H649, 1999.

380. Russell RR III, Li J, Coven DL, Pypaert M, Zechner C, Palmeri M, Giordano FJ, Mu J, Birnbaum MJ, and Young LH. AMPactivated protein kinase mediates ischemic glucose uptake and prevents postischemic cardiac dysfunction, apoptosis, and injury. $J$ Clin Invest 114: 495-503, 2004.

381. Sabbah HH and Stanley WC. Partial fatty acid oxidation inhibitors: a potentially new class of drugs for heart failure. Eur J Heart Fail 4: 3-6, 2002.

382. Sabbah HN, Chandler MP, Mishima T, Suzuki G, Chaudhry P, Nass O, Biesiadecki BJ, Blackburn B, Wolff A, and Stanley WC. Ranolazine, a partial fatty acid oxidation (pFOX) inhibitor, improves left ventricular function in dogs with chronic heart failure. J Card Fail 8: 416-422, 2002.

383. Sabbah HN, Sharov V, Riddle JM, Kono T, Lesch M, and Goldstein S. Mitochondrial abnormalities in myocardium of dogs with chronic heart failure. J Mol Cell Cardiol 24: 1333-1347, 1992.

384. Sabbah HN, Shimoyama H, Kono T, Gupta RC, Sharov VG, Scicli G, Levine TB, and Goldstein S. Effects of long-term monotherapy with enalapril, metoprolol, and digoxin on the progression of left ventricular dysfunction and dilation in dogs with reduced ejection fraction. Circulation 89: 2852-2859, 1994.

385. Sabbah HN, Stanley WC, Sharov VG, Mishima T, Tanimura M, Benedict CR, Hegde S, and Goldstein S. Effects of dopamine beta-hydroxylase inhibition with nepicastat on the progression of left ventricular dysfunction and remodeling in dogs with chronic heart failure. Circulation 102: 1990-1995, 2000

386. Sabbah HN, Stein PD, Kono T, Gheorghiade M, Levine TB, Jafri S, Hawkins ET, and Goldstein S. A canine model of chronic heart failure produced by multiple sequential coronary microembolizations. Am J Physiol Heart Circ Physiol 260: H1379H1384, 1991.

387. Sacher HL, Sacher ML, Landau SW, Kersten R, Dooley F, Sacher A, Sacher M, Dietrick K, and Ichkhan K. The clinical and hemodynamic effects of coenzyme Q10 in congestive cardiomyopathy. Am J Ther 4: 66-72, 1997.

388. Sack MN and Kelly DP. The energy substrate switch during development of heart failure: gene regulatory mechanisms (review). Int J Mol Med 1: 17-24, 1998.

389. Sack MN, Rader TA, Park S, Bastin J, McCune SA, and Kelly DP. Fatty acid oxidation enzyme gene expression is downregulated in the failing heart. Circulation 94: 2837-2842, 1996.

390. Saddik M, Gamble J, Witters LA, and Lopaschuk GD. AcetylCoA carboxylase regulation of fatty acid oxidation in the heart. J Biol Chem 268: 25836-25845, 1993.

391. Saddik M and Lopaschuk GD. Myocardial triglyceride turnover and contribution to energy substrate utilization in isolated working rat hearts. J Biol Chem 266: 8162-8170, 1991.

392. Saddik M and Lopaschuk GD. Myocardial triglyceride turnover during reperfusion of isolated rat hearts subjected to a transient period of global ischemia. J Biol Chem 267: 3825-3831, 1992.

393. Saddik M and Lopaschuk GD. Triacylglycerol turnover in isolated working hearts of acutely diabetic rats. Can J Physiol Pharmacol 72: 1110-1119, 1994.

394. Saha AK, Schwarsin AJ, Roduit R, Masse F, Kaushik V, Tornheim K, Prentki M, and Ruderman NB. Activation of malonylCoA decarboxylase in rat skeletal muscle by contraction and the AMP-activated protein kinase activator 5-aminoimidazole-4-carboxamide-1-beta-D-ribofuranoside. J Biol Chem 275: 24279-24283, 2000.

395. Saha AK, Vavvas D, Kurowski TG, Apazidis A, Witters LA, Shafrir E, and Ruderman NB. Malonyl-CoA regulation in skeletal muscle: its link to cell citrate and the glucose-fatty acid cycle. Am J Physiol Endocrinol Metab 272: E641-E648, 1997.

396. Sambandam N, Lopaschuk GD, Brownsey RW, and Allard MF. Energy metabolism in the hypertrophied heart. Heart Fail Rev 7: 161-173, 2002.
397. Sanbe A, Tanonaka K, Hanaoka Y, Katoh T, and Takeo S. Regional energy metabolism of failing hearts following myocardial infarction. J Mol Cell Cardiol 25: 995-1013, 1993.

398. Sanbe A, Tanonaka K, Kobayasi R, and Takeo S. Effects of long-term therapy with ACE inhibitors, captopril, enalapril and trandolapril, on myocardial energy metabolism in rats with heart failure following myocardial infarction. $\mathrm{J} \mathrm{Mol} \mathrm{Cell} \mathrm{Cardiol} \mathrm{27:}$ 2209-2222, 1995.

399. Sanbe A, Tanonaka K, Niwano Y, and Takeo S. Improvement of cardiac function and myocardial energy metabolism of rats with chronic heart failure by long-term coenzyme Q10 treatment. J Pharmacol Exp Ther 269: 51-56, 1994.

400. Scarpulla RC. Nuclear activators and coactivators in mammalian mitochondrial biogenesis. Biochim Biophys Acta 1576: 1-14, 2002.

401. Schaffer JE. Fatty acid transport: the roads taken. Am J Physiol Endocrinol Metab 282: E239-E246, 2002.

402. Schaffer JE. Lipotoxicity: when tissues overeat. Curr Opin Lipidol 14: 281-287, 2003.

403. Schaper J, Froede R, Hein S, Buck A, Hashizume H, Speiser B, Friedl A, and Bleese N. Impairment of the myocardial ultrastructure and changes of the cytoskeleton in dilated cardiomyopathy. Circulation 83: 504-514, 1991.

404. Scheubel RJ, Tostlebe M, Simm A, Rohrbach S, Prondzinsky R, Gellerich FN, Silber RE, and Holtz J. Dysfunction of mitochondrial respiratory chain complex I in human failing myocardium is not due to disturbed mitochondrial gene expression. $J$ Am Coll Cardiol 40: 2174-2181, 2002.

405. Schmidt-Schweda $\mathbf{S}$ and Holubarsch $\mathbf{C}$. First clinical trial with etomoxir in patients with chronic congestive heart failure. Clin Sci 99: 27-35, 2000.

406. Schofield RS and Hill JA. The use of ranolazine in cardiovascular disease. Expert Opin Invest Drugs 11: 117-123, 2002.

407. Schonekess BO, Allard MF, and Lopaschuk GD. Propionyl L-carnitine improvement of hypertrophied heart function is accompanied by an increase in carbohydrate oxidation. Circ Res 77: 726-734, 1995.

408. Schrauwen P, Saris WH, and Hesselink MK. An alternative function for human uncoupling protein 3: protection of mitochondria against accumulation of nonesterified fatty acids inside the mitochondrial matrix. FASEB $J$ 15: 2497-2502, 2001.

409. Schulz H. Regulation of fatty acid oxidation in heart. $J$ Nutr 124: 165-171, 1994.

410. Schwartz GG, Greyson C, Wisneski JA, and Garcia J. Inhibition of fatty acid metabolism alters myocardial high-energy phosphates in vivo. Am J Physiol Heart Circ Physiol 267: H224-H231, 1994.

411. Schwartz K, Boheler KR, de la BD, Lompre AM, and Mercadier JJ. Switches in cardiac muscle gene expression as a result of pressure and volume overload. Am J Physiol Regul Integr Comp Physiol 262: R364-R369, 1992.

412. Schwartz RG, Barrett EJ, Francis CK, Jacob R, and Zaret BL. Regulation of myocardial amino acid balance in the conscious dog. J Clin Invest 75: 1204-1211, 1985.

413. Sentex E, Helies-Toussaint C, Rousseau D, Lucien A, Ferrary E, and Grynberg A. Influence of trimetazidine on the synthesis of complex lipids in the heart and other target organs. Fundam Clin Pharmacol 15: 255-264, 2001.

414. Sentex E, Sergiel JP, Lucien A, and Grynberg A. Trimetazidine increases phospholipid turnover in ventricular myocyte. Mol Cell Biochem 175: 153-162, 1997.

415. Sentex E, Sergiel JP, Lucien A, and Grynberg A. Is the cytoprotective effect of trimetazidine associated with lipid metabolism? Am J Cardiol 82: 18K-24K, 1998.

416. Sharma N, Okere IC, McElfresh TA, King KL, Sterk JP, Huang H, Brunengraber DZ, Chandler MP, and Stanley WC. Regulation of glucose oxidation and pyruvate dehydrogenase activity during high cardiac energy expenditure: critical role for fatty acid oxidation. J Physiol 562: 593-603, 2004.

417. Sharov VG, Goussev A, Lesch M, Goldstein S, and Sabbah HN. Abnormal mitochondrial function in myocardium of dogs with chronic heart failure. J Mol Cell Cardiol 30: 1757-1762, 1998. 
418. Sharov VG, Sabbah HN, Shimoyama H, Goussev AV, Lesch M, and Goldstein S. Evidence of cardiocyte apoptosis in myocardium of dogs with chronic heart failure. Am J Pathol 148: 141-149, 1996.

419. Sharov VG, Todor AV, Silverman N, Goldstein S, and Sabbah HN. Abnormal mitochondrial respiration in failed human myocardium. J Mol Cell Cardiol 32: 2361-2367, 2000.

420. Shen W, Asai K, Uechi M, Mathier MA, Shannon RP, Vatner SF, and Ingwall JS. Progressive loss of myocardial ATP due to a loss of total purines during the development of heart failure in dogs: a compensatory role for the parallel loss of creatine. Circulation 100: 2113-2118, 1999.

421. Simonsen $\mathbf{S}$ and Kjekshus JK. The effect of free fatty acids on myocardial oxygen consumption during atrial pacing and catecholamine infusion in man. Circulation 58: 484-491, 1978.

422. Slama M, Ahn J, Varagic J, Susic D, and Frohlich ED. Longterm left ventricular echocardiographic follow-up of SHR and WKY rats: effects of hypertension and age. Am J Physiol Heart Circ Physiol 286: H181-H185, 2004.

423. Smith CJ, Sun D, Hoegler C, Roth BS, Zhang X, Zhao G, Xu XB, Kobari Y, Pritchard $\mathrm{K}$ Jr, Sessa WC, and Hintze TH. Reduced gene expression of vascular endothelial NO synthase and cyclooxygenase-1 in heart failure. Circ Res 78: 58-64, 1996.

424. Solomon SD, St John SM, Lamas GA, Plappert T, Rouleau JL, Skali H, Moye L, Braunwald E, and Pfeffer MA. Ventricular remodeling does not accompany the development of heart failure in diabetic patients after myocardial infarction. Circulation 106: 1251-1255, 2002.

425. Sparagna GC, Hickson-Bick DL, Buja LM, and McMillin JB. A metabolic role for mitochondria in palmitate-induced cardiac myocyte apoptosis. Am J Physiol Heart Circ Physiol 279: H2124H2132, 2000.

426. Stanley WC. Myocardial lactate metabolism during exercise. Med Sci Sports Exercise 23: 920-924, 1991.

427. Stanley WC. Partial fatty acid oxidation inhibitors for stable angina. Expert Opin Invest Drugs 11: 615-629, 2002.

428. Stanley WC and Chandler MP. Energy metabolism in the normal and failing heart: potential for therapeutic interventions. Heart Fail Rev 7: 115-130, 2002.

429. Stanley WC, Hall JL, Stone CK, and Hacker TA. Acute myocardial ischemia causes a transmural gradient in glucose extraction but not glucose uptake. Am J Physiol Heart Circ Physiol 262: H91-H96, 1992.

430. Stanley WC, Hernandez LA, Spires D, Bringas J, Wallace S, and McCormack JG. Pyruvate dehydrogenase activity and malonyl CoA levels in normal and ischemic swine myocardium: effects of dichloroacetate. J Mol Cell Cardiol 28: 905-914, 1996.

431. Stanley WC and Hoppel CL. Mitochondrial dysfunction in heart failure: potential for therapeutic interventions? Cardiovasc Res 45: 805-806, 2000.

432. Stanley WC, Kivilo KM, Panchal AR, Hallowell PH, Bomont C, Kasumov T, and Brunengraber H. Post-ischemic treatment with dipyruvyl-acetyl-glycerol decreases myocardial infarct size in the pig. Cardiovasc Drugs Ther 17: 209-216, 2003.

433. Stanley WC, Lopaschuk GD, Hall JL, and McCormack JG. Regulation of myocardial carbohydrate metabolism under normal and ischaemic conditions. Potential for pharmacological interventions. Cardiovasc Res 33: 243-257, 1997.

434. Stanley WC, Lopaschuk GD, and McCormack JG. Regulation of energy substrate metabolism in the diabetic heart. Cardiovasc Res 34: 25-33, 1997.

435. Stanley WC and Marzilli M. Metabolic therapy in the treatment of ischaemic heart disease: the pharmacology of trimetazidine. Fundam Clin Pharmacol 17: 133-145, 2003.

436. Stanley WC, Meadows SR, Kivilo KM, Roth BA, and Lopaschuk GD. beta-Hydroxybutyrate inhibits myocardial fatty acid oxidation in vivo independent of changes in malonyl-CoA content. Am J Physiol Heart Circ Physiol 285: H1626-H1631, 2003.

437. Stavinoha MA, RaySpellicy JW, Essop MF, Graveleau C, Abel ED, Hart-Sailors ML, Mersmann HJ, Bray MS, and Young ME. Evidence for mitochondrial thioesterase 1 as a peroxisome proliferator-activated receptor- $\alpha$-regulated gene in cardiac and skeletal muscle. Am J Physiol Endocrinol Metab 287: E888-E895, 2004.
438. Stone CK, Holden JE, Stanley W, and Perlman SB. Effect of nicotinic acid on exogenous myocardial glucose utilization. $J$ Nucl Med 36: 996-1002, 1995.

439. Stuart JA, Brindle KM, Harper JA, and Brand MD. Mitochondrial proton leak and the uncoupling proteins. J Bioenerg Biomembr 31: 517-525, 1999.

440. Suga H. Ventricular energetics. Physiol Rev 70: 247-277, 1990.

441. Sultan AM. Effects of diabetes and insulin on ketone bodies metabolism in heart. Mol Cell Biochem 110: 17-23, 1992.

442. Sundqvist KE, Hiltunen JK, and Hassinen IE. Pyruvate carboxylation in the rat heart. Role of biotin-dependent enzymes. Biochem J 257: 913-916, 1989.

443. Swanton EM and Saggerson ED. Effects of adrenaline on triacylglycerol synthesis and turnover in ventricular myocytes from adult rats. Biochem J 328: 913-922, 1997.

444. Swedberg K, Bristow MR, Cohn JN, Dargie H, Straub M, Wiltse C, and Wright TJ. Effects of sustained-release moxonidine, an imidazoline agonist, on plasma norepinephrine in patients with chronic heart failure. Circulation 105: 1797-1803, 2002.

445. Szwed H, Sadowski Z, Elikowski W, Koronkiewicz A, Mamcarz A, Orszulak W, Skibinska E, Szymczak K, Swiatek J, and Winter M. Combination treatment in stable effort angina using trimetazidine and metoprolol: results of a randomized, doubleblind, multicentre study (TRIMPOL II). TRIMetazidine in POLand. Eur Heart $J$ 22: 2267-2274, 2001.

446. Tabbi-Anneni I, Helies-Toussaint C, Morin D, Bescond-Jacquet A, Lucien A, and Grynberg A. Prevention of heart failure in rats by trimetazidine treatment: a consequence of accelerated phospholipid turnover? J Pharmacol Exp Ther 304: 1003-1009, 2003.

447. Tada H, Thompson CI, Recchia FA, Loke KE, Ochoa M, Smith CJ, Shesely EG, Kaley G, and Hintze TH. Myocardial glucose uptake is regulated by nitric oxide via endothelial nitric oxide synthase in Langendorff mouse heart. Circ Res 86: 270-274, 2000.

448. Taegtmeyer H. Energy metabolism of the heart: from basic concepts to clinical applications. Curr Prob Cardiol 19: 59-113, 1994.

449. Taegtmeyer H, McNulty $\mathbf{P}$, and Young ME. Adaptation and maladaptation of the heart in diabetes. Part I: general concepts. Circulation 105: 1727-1733, 2002.

450. Takeishi Y, Minamihaba O, Yamauchi S, Arimoto T, Hirono O, Takahashi H, Akiyama H, Miyamoto T, Nitobe J, Nozaki N, Tachibana H, Okuyama M, Fukui A, Kubota I, Okada A, and Takahashi K. Dynamic ${ }^{123}$ I-BMIPP single-photon emission computed tomography in patients with congestive heart failure: effect of angiotensin II type-1 receptor blockade. Clin Cardiol 27: 204210,2004

451. Tan FL, Moravec CS, Li J, Apperson-Hansen C, McCarthy PM, Young JB, and Bond $\mathbf{M}$. The gene expression fingerprint of human heart failure. Proc Natl Acad Sci USA 99: 11387-11392, 2002.

452. Tang WH and Francis GS. Novel pharmacological treatments for heart failure. Expert Opin Invest Drugs 12: 1791-1801, 2003.

453. Taylor M, Wallhaus TR, DeGrado TR, Russell DC, Stanko P, Nickles RJ, and Stone CK. An evaluation of myocardial fatty acid and glucose uptake using PET with $\left[{ }^{18} \mathrm{~F}\right]$ fluoro-6-thia-heptadecanoic acid and. J Nucl Med 42: 55-62, 2001.

454. Thampy KG. Formation of malonyl coenzyme A in rat heart. Identification and purification of an isozyme of A carboxylase from rat heart. J Biol Chem 264: 17631-17634, 1989.

455. Thiemermann C. Ligands of the peroxisome proliferator-activated receptor-gamma and heart failure. Br J Pharmacol 142: 1049-1051, 2004.

456. Thomassen A, Nielsen TT, Bagger JP, Pedersen AK, and Henningsen $P$. Antiischemic and metabolic effects of glutamate during pacing in patients with stable angina pectoris secondary to either coronary artery disease or syndrome X. Am J Cardiol 68: 291-295, 1991.

457. Thomassen AR. Myocardial uptake and effects of glutamate during non-ischaemic and ischaemic conditions. A clinical study with special reference to possible interrelationships between glutamate and myocardial utilization of carbohydrate substrates. Dan Med Bull 39: 471-488, 1992.

458. Thomassen AR, Mortensen PT, Nielsen TT, Falstie-Jensen N, Thygesen K, and Henningsen P. Altered plasma concentrations 
of glutamate, alanine and citrate in the early phase of acute myocardial infarction in man. Eur Heart J 7: 773-778, 1986.

459. Thomassen AR, Nielsen TT, Bagger JP, and Henningsen P. Myocardial exchanges of glutamate, alanine and citrate in controls and patients with coronary artery disease. Clin Sci 64: 33-40, 1983.

460. Thrasher JR, Cooper MD, and Dunaway GA. Developmental changes in heart and muscle phosphofructokinase isozymes. J Biol Chem 256: 7844-7848, 1981.

461. Thumelin S, Esser V, Charvy D, Kolodziej M, Zammit VA, McGarry D, Girard J, and Pegorier JP. Expression of liver carnitine palmitoyltransferase I and II genes during development in the rat. Biochem J 300: 583-587, 1994.

462. Tian R, Musi N, D'Agostino J, Hirshman MF, and Goodyear LJ. Increased adenosine monophosphate-activated protein kinase activity in rat hearts with pressure-overload hypertrophy. Circulation 104: 1664-1669, 2001.

463. Tian R, Nascimben L, Kaddurah-Daouk R, and Ingwall JS. Depletion of energy reserve via the creatine kinase reaction during the evolution of heart failure in cardiomyopathic hamsters. $J \mathrm{Mol}$ Cell Cardiol 28: 755-765, 1996.

464. Treasure CB, Vita JA, Cox DA, Fish RD, Gordon JB, Mudge GH, Colucci WS, Sutton MG, Selwyn AP, and Alexander RW. Endothelium-dependent dilation of the coronary microvasculature is impaired in dilated cardiomyopathy. Circulation 81: 772-779, 1990.

465. Tsuura Y, Ishida H, Shinomura T, Nishimura M, and Seino Y. Endogenous nitric oxide inhibits glucose-induced insulin secretion by suppression of phosphofructokinase activity in pancreatic islets. Biochem Biophys Res Commun 252: 34-38, 1998.

466. Turcani M and Rupp H. Modification of left ventricular hypertrophy by chronic etomixir treatment. Br J Pharmacol 126: 501-507, 1999.

467. Ungar I, Gilbert M, Siegel A, Blain JM, and Bing RJ. Studies on myocardial metabolism. IV. Myocardial metabolism in diabetes. Am J Med 18: 385-396, 1955.

468. Unger RH. Lipotoxic diseases. Annu Rev Med 53: 319-336, 2002.

469. Unger RH. Minireview: weapons of lean body mass destruction: the role of ectopic lipids in the metabolic syndrome. Endocrinology 144: 5159-5165, 2003.

470. Unverferth DV, Lee SW, and Wallick ET. Human myocardial adenosine triphosphatase activities in health and heart failure. $\mathrm{Am}$ Heart $J$ 115: 139-146, 1988.

471. Uren NG, Camici PG, Melin JA, Bol A, de Bruyne B, Radvan J, Olivotto I, Rosen SD, Impallomeni M, and Wijns W. Effect of aging on myocardial perfusion reserve. J Nucl Med 36: 2032-2036, 1995.

472. Van Bilsen M, van der Vusse GJ, Gilde AJ, Lindhout M, and Van Der Lee KA. Peroxisome proliferator-activated receptors: lipid binding proteins controlling gene expression. Mol Cell Biochem 239: 131-138, 2002.

473. Van der Vusse GJ, van Bilsen M, and Glatz JF. Cardiac fatty acid uptake and transport in health and disease. Cardiovasc Res 45 : 279-293, 2000.

474. Vanoverschelde JL, Wijns W, Kolanowski J, Bol A, Decoster PM, Michel C, Cogneau M, Heyndrickx GR, Essamri B, and Melin JA. Competition between palmitate and ketone bodies as fuels for the heart: study with positron emission tomography. Am J Physiol Heart Circ Physiol 264: H701-H707, 1993.

475. Vedia L, McDonald B, Reep B, Brune B, Di Silvio M, Billiar TR, and Lapetina EG. Nitric oxide-induced $S$-nitrosylation of glyceraldehyde-3-phosphate dehydrogenase inhibits enzymatic activity and increases endogenous ADP-ribosylation. J Biol Chem 267: 24929-24932, 1992.

476. Vega RB, Huss JM, and Kelly DP. The coactivator PGC-1 cooperates with peroxisome proliferator-activated receptor alpha in transcriptional control of nuclear genes encoding mitochondrial fatty acid oxidation enzymes. Mol Cell Biol 20: 1868-1876, 2000.

477. Ventura-Clapier RF, Garnier A, and Veksler V. Energy metabolism in heart failure. J Physiol 555: 1-13, 2004.

478. Vidal-Puig AJ, Grujic D, Zhang CY, Hagen T, Boss O, Ido Y, Szczepanik A, Wade J, Mootha V, Cortright R, Muoio DM, and Lowell BB. Energy metabolism in uncoupling protein 3 gene knockout mice. J Biol Chem 275: 16258-16266, 2000.
479. Vincent G, Bouchard B, Khairallah M, and des Rosiers C. Differential modulation of citrate synthesis and release by fatty acids in perfused working rat hearts. Am J Physiol Heart Circ Physiol 286: H257-H266, 2004.

480. Wallhaus TR, Taylor M, DeGrado TR, Russell DC, Stanko P, Nickles RJ, and Stone CK. Myocardial free fatty acid and glucose use after carvedilol treatment in patients with congestive heart failure. Circulation 103: 2441-2446, 2001.

481. Wang CH, Weisel RD, Liu PP, Fedak PW, and Verma S. Glitazones and heart failure: critical appraisal for the clinician. Circulation 107: 1350-1354, 2003.

482. Warshaw JB. Cellular energy metabolism during fetal development. I. Oxidative phosphorylation in the fetal heart. J Cell Biol 41: 651-657, 1969.

483. Warshaw JB. Cellular energy metabolism during fetal development. IV. Fatty acid activation, acyl transfer and fatty acid oxidation during development of the chick and rat. Dev Biol 28: 537-544, 1972.

484. Watson PS, Scalia GM, Galbraith A, Burstow DJ, Bett N, and Aroney CN. Lack of effect of coenzyme Q on left ventricular function in patients with congestive heart failure. $\mathrm{J} \mathrm{Am} \mathrm{Coll} \mathrm{Car-}$ diol 33: 1549-1552, 1999 .

485. Weis BC, Cowan AT, Brown N, Foster DW, and McGarry JD. Use of a selective inhibitor of liver carnitine palmitoyltransferase I (CPT I) allows quantification of its contribution to total CPT I activity in rat heart. Evidence that the dominant cardiac CPT I isoform is identical to the skeletal muscle enzyme. $J$ Biol Chem 269: 26443-26448, 1994.

486. Weiss J and Hiltbrand B. Functional compartmentation of glycolytic versus oxidative metabolism in isolated rabbit heart. $J$ Clin Invest 75: 436-447, 1985.

487. Weiss JN and Lamp ST. Glycolysis preferentially inhibits ATPsensitive $\mathrm{K}^{+}$channels in isolated guinea pig cardiac myocytes. Science 238: 67-69, 1987.

488. Weiss JN and Lamp ST. Cardiac ATP-sensitive $\mathrm{K}^{+}$channels. Evidence for preferential regulation by glycolysis. J Gen Physiol 94: 911-935, 1989.

489. Werner JC and Sicard RE. Lactate metabolism of isolated, perfused fetal, and newborn pig hearts. Pediatr Res 22: 552-556, 1987.

490. Whitehouse S, Cooper RH, and Randle PJ. Mechanism of activation of pyruvate dehydrogenase by dichloroacetate and other halogenated carboxylic acids. Biochem $J$ 141: 761-774, 1974.

491. Wieland O, Siess E, Schulze-Wethmar FH, von Funcke HG, and Winton B. Active and inactive forms of pyruvate dehydrogenase in rat heart and kidney: effect of diabetes, fasting, and refeeding on pyruvate dehydrogenase interconversion. Arch Biochem Biophys 143: 593-601, 1971.

492. Wisneski JA, Gertz EW, Neese RA, Gruenke LD, and Craig JC. Dual carbon-labeled isotope experiments using $\mathrm{D}-\left[6-{ }^{14} \mathrm{C}\right] \mathrm{glu}-$ cose and $\mathrm{L}-\left[1,2,3{ }^{-13} \mathrm{C} 3\right]$ lactate: a new approach for investigating human myocardial metabolism during ischemia. J Am Coll Cardiol 5: 1138-1146, 1985.

493. Wisneski JA, Gertz EW, Neese RA, Gruenke LD, Morris DL, and Craig JC. Metabolic fate of extracted glucose in normal human myocardium. J Clin Invest 76: 1819-1827, 1985.

494. Wisneski JA, Gertz EW, Neese RA, and Mayr M. Myocardial metabolism of free fatty acids. Studies with ${ }^{14} \mathrm{C}$-labeled substrates in humans. J Clin Invest 79: 359-366, 1987.

495. Wisneski JA, Stanley WC, Neese RA, and Gertz EW. Effects of acute hyperglycemia on myocardial glycolytic activity in humans. $J$ Clin Invest 85: 1648-1656, 1990.

496. Wu P, Peters JM, and Harris RA. Adaptive increase in pyruvate dehydrogenase kinase 4 during starvation is mediated by peroxisome proliferator-activated receptor alpha. Biochem Biophys Res Commun 287: 391-396, 2001.

497. Xia Y, Buja LM, and McMillin JB. Change in expression of heart carnitine palmitoyltransferase I isoforms with electrical stimulation of cultured rat neonatal cardiac myocytes. J Biol Chem 271: 12082-12087, 1996.

498. Xie YW, Shen W, Zhao G, Xu X, Wolin MS, and Hintze TH. Role of endothelium-derived nitric oxide in the modulation of canine myocardial mitochondrial respiration in vitro. Implications for the development of heart failure. Circ Res 79: 381-387, 1996. 
499. Xing Y, Musi N, Fujii N, Zou L, Luptak I, Hirshman MF, Goodyear LJ, and Tian R. Glucose metabolism and energy homeostasis in mouse hearts overexpressing dominant negative alpha2 subunit of AMP-activated protein kinase. J Biol Chem 278: 28372-28377, 2003.

500. Xu KY, Zweier JL, and Becker LC. Functional coupling between glycolysis and sarcoplasmic reticulum $\mathrm{Ca}^{2+}$ transport. Circ Res 77: 88-97, 1995.

501. Yagyu H, Chen G, Yokoyama M, Hirata K, Augustus A, Kako Y, Seo T, Hu Y, Lutz EP, Merkel M, Bensadoun A, Homma S, and Goldberg IJ. Lipoprotein lipase (LpL) on the surface of cardiomyocytes increases lipid uptake and produces a cardiomyopathy. J Clin Invest 111: 419-426, 2003.

502. Yamauchi S, Takeishi Y, Minamihaba O, Arimoto T, Hirono O, Takahashi H, Miyamoto T, Nitobe J, Nozaki N, Tachibana H, Watanabe T, Fukui A, and Kubota I. Angiotensin-converting enzyme inhibition improves cardiac fatty acid metabolism in patients with congestive heart failure. Nucl Med Commun 24: 901906, 2003.

503. Yazaki Y, Isobe M, Takahashi W, Kitabayashi H, Nishiyama O, Sekiguchi M, and Takemura T. Assessment of myocardial fatty acid metabolic abnormalities in patients with idiopathic dilated cardiomyopathy using ${ }^{123}$ I BMIPP SPECT: correlation with clinicopathological findings and clinical course. Heart 81: 153-159, 1999.

504. Ye Y, Gong G, Ochiai K, Liu J, and Zhang J. High-energy phosphate metabolism and creatine kinase in failing hearts: a new porcine model. Circulation 103: 1570-1576, 2001.

505. Yokoyama M, Yagyu H, Hu Y, Seo T, Hirata K, Homma S, and Goldberg IJ. Apolipoprotein B production reduces lipotoxic cardiomyopathy: studies in heart specific lipoprotein lipase transgenic mouse. J Biol Chem 279: 4204-4211, 2004.

506. Young LH, Coven DL, and Russell RR III. Cellular and molecular regulation of cardiac glucose transport. J Nucl Cardiol 7: 267276, 2000.

507. Young LH, Renfu Y, Russell R, Hu X, Caplan M, Ren J, Shulman GI, and Sinusas AJ. Low-flow ischemia leads to translocation of canine heart GLUT-4 and GLUT-1 glucose transporters to the sarcolemma in vivo. Circulation 95: 415-422, 1997.

508. Young ME, Goodwin GW, Ying J, Guthrie P, Wilson CR, Laws FA, and Taegtmeyer H. Regulation of cardiac and skeletal muscle malonyl-CoA decarboxylase by fatty acids. Am J Physiol Endocrinol Metab 280: E471-E479, 2001.

509. Young ME, Laws FA, Goodwin GW, and Taegtmeyer H. Reactivation of peroxisome proliferator-activated receptor alpha is as- sociated with contractile dysfunction in hypertrophied rat heart. J Biol Chem 276: 44390-44395, 2001.

510. Young ME, McNulty P, and Taegtmeyer H. Adaptation and maladaptation of the heart in diabetes. Part II: potential mechanisms. Circulation 105: 1861-1870, 2002.

511. Young ME, Patil S, Ying J, Depre C, Ahuja HS, Shipley GL, Stepkowski SM, Davies PJ, and Taegtmeyer H. Uncoupling protein 3 transcription is regulated by peroxisome proliferatoractivated receptor (alpha) in the adult rodent heart. FASEB $J 15$ : 833-845, 2001.

512. Young ME, Radda GK, and Leighton B. Nitric oxide stimulates glucose transport and metabolism in rat skeletal muscle in vitro. Biochem J 322: 223-228, 1997.

513. Zammit VA, Fraser F, and Orstorphine CG. Regulation of mitochondrial outer-membrane carnitine palmitoyltransferase (CPT I): role of membrane-topology. Adv Enzyme Regul 37: 295-317, 1997.

514. Zarain-Herzberg A and Rupp H. Therapeutic potential of CPT I inhibitors: cardiac gene transcription as a target. Expert Opin Invest Drugs 11: 345-356, 2002.

515. Zarain-Herzberg A, Rupp H, Elimban V, and Dhalla NS. Modification of sarcoplasmic reticulum gene expression in pressure overload cardiac hypertrophy by etomoxir. FASEB J 10: 1303-1309, 1996.

516. Zhang J, Merkle H, Hendrich K, Garwood M, From AH, Ugurbil K, and Bache RJ. Bioenergetic abnormalities associated with severe left ventricular hypertrophy. J Clin Invest 92: 993-1003, 1993.

517. Zhang J and Snyder SH. Nitric oxide stimulates auto-ADP-ribosylation of glyceraldehyde-3-phosphate dehydrogenase. Proc Natl Acad Sci USA 89: 9382-9385, 1992.

518. Zhang J, Toher C, Erhard M, Zhang Y, Ugurbil K, Bache RJ, Lange T, and Homans DC. Relationships between myocardial bioenergetic and left ventricular function in hearts with volumeoverload hypertrophy. Circulation 96: 334-343, 1997.

519. Zhou L, Salem JE, Saidel GM, Stanley WC, and Cabrera ME. Mechanistic model of cardiac energy metabolism predicts localization of glycolysis to cytosolic subdomain during ischemia. Am J Physiol Heart Circ Physiol 288: H2400-H2411, 2005.

520. Zhou YT, Grayburn P, Karim A, Shimabukuro M, Higa M, Baetens D, Orci L, and Unger RH. Lipotoxic heart disease in obese rats: implications for human obesity. Proc Natl Acad Sci USA 97: 1784-1789, 2000. 


\section{Myocardial Substrate Metabolism in the Normal and Failing Heart \\ William C. Stanley, Fabio A. Recchia and Gary D. Lopaschuk}

Physiol Rev 85:1093-1129, 2005. doi:10.1152/physrev.00006.2004

You might find this additional info useful...

This article cites 512 articles, 263 of which can be accessed free at:

http://physrev.physiology.org/content/85/3/1093.full.html\#ref-list-1

This article has been cited by 100 other HighWire hosted articles, the first 5 are:

Metformin Prevents the Development of Chronic Heart Failure in the SHHF Rat Model Antonio Cittadini, Raffaele Napoli, Maria Gaia Monti, Domenica Rea, Salvatore Longobardi, Paolo Antonio Netti, Marion Walser, Mariateresa Samà, Gianluca Aimaretti, Jörgen Isgaard and Luigi Saccà

Diabetes, April , 2012; 61 (4): 944-953.

[Abstract] [Full Text] [PDF]

Dietary Fat and Heart Failure: Moving From Lipotoxicity to Lipoprotection William C. Stanley, Erinne R. Dabkowski, Rogerio F. Ribeiro, Jr and Kelly A. O'Connell Circulation Research, March 2, 2012; 110 (5): 764-776.

[Abstract] [Full Text] [PDF]

Targeting Energetic Metabolism : A New Frontier in the Pathogenesis and Treatment of Pulmonary Hypertension

Rubin M. Tuder, Laura A. Davis and Brian B. Graham

Am. J. Respir. Crit. Care Med., February 1, 2012; 185 (3): 260-266.

[Abstract] [Full Text] [PDF]

Targeting myocardial substrate metabolism in heart failure: potential for new therapies Hossein Ardehali, Hani N. Sabbah, Michael A. Burke, Satyam Sarma, Peter P. Liu, John G.F. Cleland, Aldo Maggioni, Gregg C. Fonarow, E. Dale Abel, Umberto Campia and Mihai Gheorghiade

Eur J Heart Fail, February , 2012; 14 (2): 120-129.

[Abstract] [Full Text] [PDF]

Doxorubicin Increases Oxidative Metabolism in HL-1 Cardiomyocytes as Shown by 13 C Metabolic Flux Analysis

Alexander Strigun, Judith Wahrheit, Jens Niklas, Elmar Heinzle and Fozia Noor

Toxicol. Sci., February , 2012; 125 (2): 595-606.

[Abstract] [Full Text] [PDF]

Updated information and services including high resolution figures, can be found at:

http://physrev.physiology.org/content/85/3/1093.full.html

Additional material and information about Physiological Reviews can be found at:

http://www.the-aps.org/publications/prv

This information is current as of April 17, 2012.

Physiological Reviews provides state of the art coverage of timely issues in the physiological and biomedical sciences. It is published quarterly in January, April, July, and October by the American Physiological Society, 9650 Rockville Pike, Bethesda MD 20814-3991. Copyright (C 2005 by the American Physiological Society. ISSN: 0031-9333, ESSN: 1522-1210. Visit our website at http://www.the-aps.org/. 